TITLE:

\title{
Nine Species of the Genus Aoroides (Crustacea : Amphipoda : Aoridae) from Osaka Bay, Central Japan
}

\author{
$\operatorname{AUTHOR}(\mathrm{S}):$
}

Ariyama, Hiroyuki

\section{CITATION:}

Ariyama, Hiroyuki. Nine Species of the Genus Aoroides (Crustacea : Amphipoda : Aoridae) from Osaka Bay, Central Japan. PUBLICATIONS OF THE SETO MARINE BIOLOGICAL LABORATORY 2004, 40(1-2): 1-66

\section{ISSUE DATE:}

2004-07-31

URL:

http://hdl.handle.net/2433/176318

RIGHT: 
Publ. Seto Mar. Biol. Lab., 40 (1/2): 1-66, 2004

\title{
Nine Species of the Genus Aoroides (Crustacea: Amphipoda: Aoridae) from Osaka Bay, Central Japan
}

\author{
Hiroyuki ARIYAma \\ Osaka Prefectural Fisheries Experimental Station
}

\begin{abstract}
Nine species of the genus Aoroides were collected from coastal areas in Osaka Bay, central Japan. Among them, seven species were revealed to be new to science. Species collected are Aoroides columnaris sp. nov., A. curvipes sp. nov., A. ellipticus sp. nov., A. myojinensis sp. nov., A. punctatus sp. nov., A. rubellus sp. nov., A. semicurvatus sp. nov., A. longimerus Ren and Zheng, 1996, and A. secundus Gurjanova, 1938. All of them are described with notes on coloration in life and shape change of male gnathopods with growth. A key to species of Aoroides from Osaka Bay is provided. Each species is distinguishable from one another by the setal pattern of male gnathopod 1, the number of spines on the rami of uropod 3 and the body coloration, and further the habitat of each species differs in both depth and preferred substratum. Dispersal of Aoroides is discussed.
\end{abstract}

Key words: Amphipoda, Aoridae, Aoroides, Osaka Bay, Japan, new species, dispersal

\section{Introduction}

The genus Aoroides Walker, 1898 is distributed in the coastal regions of the North Pacific, and south to Hawaii and Indonesia. Barnard and Karaman (1991) enumerated seven species in this genus until 1986. After then Aoroides vitiosus Myers, 1995 and A. longimerus Ren and Zheng, 1996 were described from Papua New Guinea and China, respectively. In Japan, three species, Aoroides columbiae Walker, 1898 (Nagata, 1960, 1965; Hirayama, 1984), A. secunda Gurjanova, 1938 (Nagata, 1965 ) and A. sp. 1 (Ishimaru, 1990), were recorded so far. However, idetification of Aoroides species has been confused in Japan, because Nagata provided only one figure and his descriptions were not so clear.

I have been ivestigating the amphipod fauna of Osaka Bay, eastern part of the Seto Inland Sea, since 1981. During this survey, nine Aoroides species were collected, and seven of them have turned out to be new species. The present paper deals with the descriptions of them and provides a key to these Aoroides species.

\section{Materials and Methods}

The samples treated here were collected mainly from Osaka Bay, and materials from other localities were also examined for reference (Fig. 1). The collections were carried out by the author, unless otherwise stated. Most of the samples were dissected and figures of the appendages were drawn under a phase-contrast microscope. The body length was measured from the apex of the rostrum along the dorsal margin to the distal end of the telson. The dissected specimens including the type series are deposited in the Osaka Museum of Natural History (OMNH).

\section{Diagnosis of Aoroides Walker, 1898}

Male

Antennae: antenna 1 slender, accessory flagellum vestigial or absent; antenna 2 shorter than antenna 1, flagellum short, with 2-4 articles.

Mouth parts: upper lip roundish, ventral margin with thin setae; mandibular palp weak, slender, article 3 longest, rod-shaped, with 2-7 setae (mandibular palp lacking in Aoroides vitiosus); mandibular molar traversed with parallel channels; lower lip, upper margin of outer lobe with several 


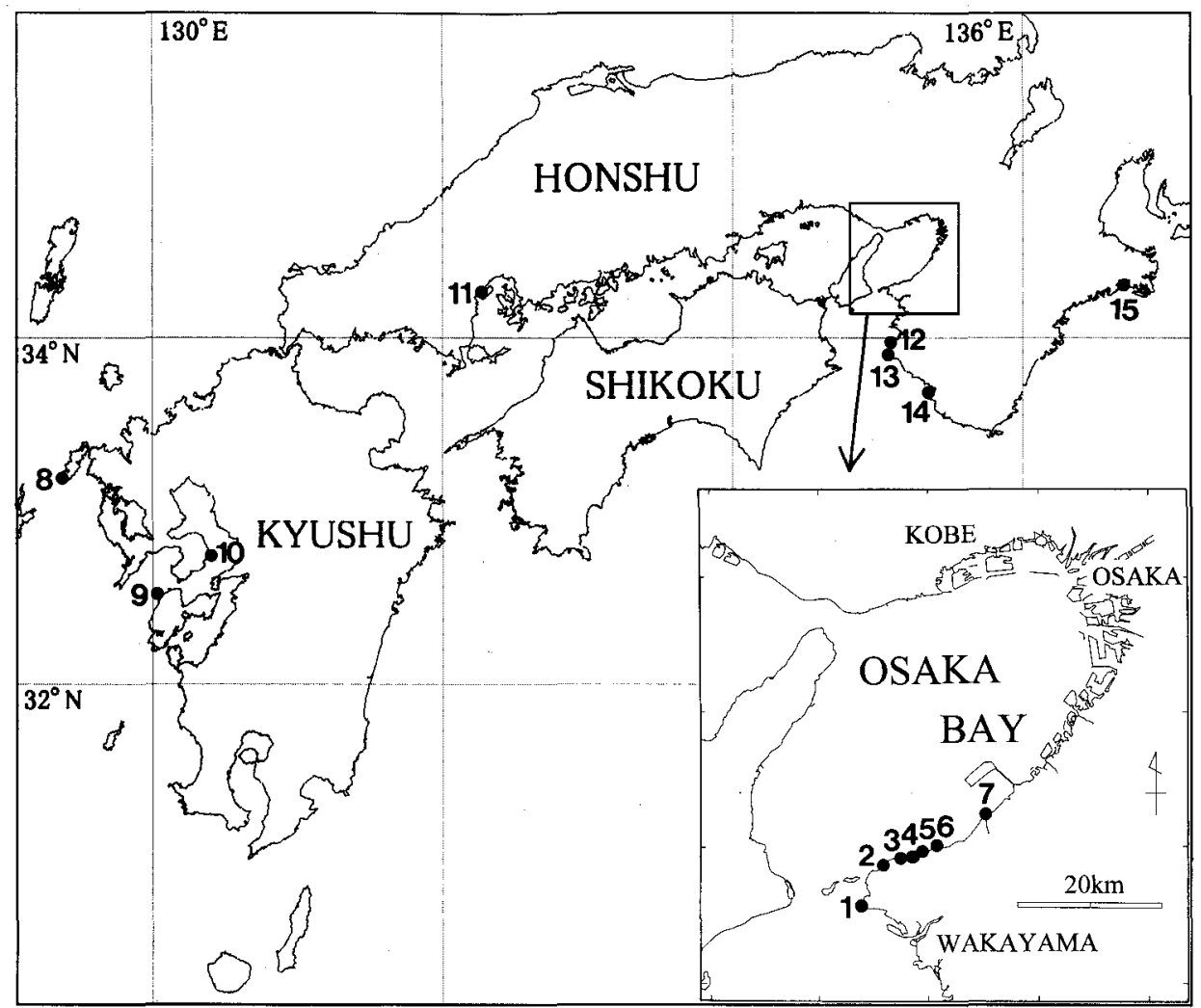

Fig. 1. Map showing the collecting localities. Osaka Prefecture: 2, Myojin-zaki coast in Misaki; 3, Tanigawa, Toyokuni-zaki coast and Osaka Prefectural Fisheries Experimental Station in Misaki; 4, off Fuke in Misaki; 5, Nagasaki coast in Misaki; 6, off Tan'nowa in Misaki; 7, outside of the mouth of the Onosato River in Han'nan. Other prefectures: 1, Tagura-zaki coast in Wakayama Pref.; 8, Shijiki Bay in Nagasaki Pref.; 9, outside of Tomoezaki in Tomioka, Kumamoto Pref.; 10, off the mouth of the Mizunashi River in Nagasaki Pref.; 11 , Ohno in Hiroshima Pref.; 12, Kii-yura in Wakayama Pref.; 13, Oura in Hidaka, Wakayama Pref.; 14, Engetsu Island in Shirahama, Wakayama Pref.; 15, Gokasho Bay in Mie Pref.

setae, surfaces of outer and inner lobes covered with thin setae; maxilla 1, outer plate with 10 apical spines, palp 2-articulated, with several spines distally; maxilla 2, outer plate broader than inner, both plates with row of marginal setae; maxilliped, inner plate with distal spines, outer plate with 7-12 marginal spines, palp with 4 articles, article 3 with a distal projection.

Gnathopod 1 greatly enlarged, merochelate (sensu Barnard and Karaman, 1991); coxal plate elongate, usually with a spine anteriorly; article 2 long, excavate anterodistally; article 3 short; article 4 produced into a long distal tooth, ventral margin setose; article 5 long and broad, longer than article 6; article 6 longish, with setae on posterior margin; article 7, posterior margin setose; shape of each article changing with growth.

Gnathopod 2 small, subchelate; article 2 long; article 3 short; article 4 narrow, setose distally; article 5 relatively broad, longer than or as long as article 6; articles 5-6, posterior margins setose; palm of article 6 oblique or almost transverse, usually defined by a spine; article 7 , inner margin 
serrate.

Pereopods: pereopods 3-4 similar to each other, articles 2 elongate, articles 3 short, articles 4 shorter than or as long as articles 5, articles 6 slender; pereopods 5-7 similar to each other, progressively longer, coxal plates 5-6 with posterior half shallower than anterior one, coxal plate 7 small, roundish, articles 2 usually broad, articles 5 with distal spines, articles 6 with a row of marginal spines, articles 7 short, curved. Coxal gills long, present on pereopods 2-6.

Epimeral plates 1-3 with a notch on ventroposterior corner, lateral ridge lacking.

Pleopods, peduncles with plumose setae and 2 coupling spines, outer ramus shorter than inner; pleopod 3 shortest.

Uropods biramous; uropod 1, peduncle shorter than or same length as rami, distal end of peduncle with a long inter-ramal process (20-50\% length of inner ramus), both rami subequal in length, dorsal surface of peduncle spinous, dorsal surface and tips of rami with spines; uropod 2 shorter than uropod 1 , peduncle shorter than rami, both rami subequal in length, dorsal surface and tips of rami spinous; uropod 3 shortest, peduncle relatively elongate, with a few spines on dorsodistal end, rami subequal in length, inner ramus with a single or several terminal setae, outer ramus with tiny second article and several setae on tip.

Telson entire, fleshy, with a pair of hooked cusps and a few setae on dorsodistal margin.

Female

Almost the same as male except for gnathopods and oostegites.

Gnathopod 1 smaller than that of male, subchelate; coxal plate lozenge-shaped or rectangular, without spines; article 2 elongate; article 4 setose distally; articles 5-6 longish, posterior margins setose, article 5 shorter than or equal to article 6 , middle part of article 6 posterior margin with a long spine, palm angular or oblique; article 7 long, inner margin serrate.

Gnathopod 2 relatively smaller than gnathopod 1, subchelate; coxal plate broader than those of male gnathopod 2 and female gnathopod 1; article 2 elongate; article 4 setose distally; articles 5-6 longish, posterior margins setose, article 5 shorter than or equal to article 6 , palm oblique or transverse, defined by a spine; article 7 medium length, inner margin serrate.

Oostegites broad, present on pereopods 2-5.

Type species: Aoroides columbiae Walker, 1898 (monotypy).

\section{Descriptions of Aoroides species}

Aoroides columnaris sp. nov.

(Plate I, Figs. 1-2; Text-figs. 2-5; Table 1)

(Japanese name: bouashi-burabura-sokoebi, new)

? Aoroides columbiae: Nagata, 1960, p. 175, pl. 16, fig. 94; Nagata, 1965, p. 309 (in part); (not Walker, 1898, p. 285, pl. 16, figs. 7-10).

Material examined.

Holotype: male (OMNH-Ar-4164), 4.1mm, attaching to a basket trap set on the bottom (ca. $10 \mathrm{~m}$ depth) off Tanigawa in Misaki, Osaka Pref. ( $\left.34^{\circ} 19^{\prime} \mathrm{N}, 135^{\circ} 07^{\prime} \mathrm{E}\right), 14$ May 1984. Allotype: ovigerous female (OMNH-Ar-4165), $4.2 \mathrm{~mm}$, the same data as the holotype. Paratypes: 1 male (OMNH-Ar4166), $3.7 \mathrm{~mm}$ and 1 ovigerous female (OMNH-Ar-4167), $3.4 \mathrm{~mm}$, the same data as the holotype; 1 male (OMNH-Ar-4168), 3.8mm and 1 ovigerous female (OMNH-Ar-4169), 3.5mm, among a red alga Gelidium elegans at Kii-yura, Wakayama Pref., 6 Mar. 1988; 1 male (OMNH-Ar-4170), 2.6mm and 1 ovigerous female (OMNH-Ar-4171), $2.7 \mathrm{~mm}$, among a red alga Gelidium elegans (6m depth) at Oura in Hidaka, Wakayama Pref., 9 Aug. 1998. 
Male [based on holotype, $4.1 \mathrm{~mm}$, and paratype 1,3.7mm (mandible, lower lip, maxillae 1-2 and maxilliped)]

Body (Fig. 2) relatively slender; eyes small.

Antennae: antenna 1 (Figs. 3A, A1), ratio of peduncular articles 1-3 1:1.4:0.5, ventral surface of article 1 with several setae, primary flagellum with 13 medium and 1 short articles; antenna 2 (Fig. 3B) slender, about $65 \%$ length of antenna 1 , setose, inner surface of peduncle without spines, flagellum with 3 articles, each articles with 2 curved spines (Fig. 3B1).

Mouth parts: mandible (Fig. 3D), palp with 2 setae on the tip; maxilla 1 (Fig. 3F), palp article 2 with 5 apical spines; maxilliped (Fig. $3 \mathrm{H}$ ), outer plate with 7 marginal spines.

Gnathopod 1 (Fig. 3I): coxal plate produced anteriorly, depressed triangular in shape, with a spine anteriorly; article 2, anterior margin bare, lateral margin with several short setae, posterior margin with a few tiny setae; article 3 inflated anterodistally on inner face; article 4 cylindrical, very elongate, tip abruptly narrowed reaching distal end of article 5 , ventral margin with several short setae; article 5 cylindrical, with a few setae only; article 6 also cylindrical, setose on antero- and posterodistal corners; article 7 long, with a few setae on posterior margin.

Gnathopod 2 (Fig. 3J): coxal plate square-shaped; article 2 with a few short setae on anterior and posterior margins; palm oblique, defined by a spine (Fig. 3J1); article 7 medium in length, inner margin with 3 notches.

Pereopods: pereopods 3-4 (Figs. 4A-B), articles 2 with a few short setae on anterior and posterior margins, articles 5 without spines; pereopod 5 (Fig. 4C), article 2 relatively broad; pereopod 6 (Fig. 4D), article 5 with a spine on lateral surface, article 6 with a row of spines on anterior margin; pereopod 7 (Fig. 4E), coxal plate oval, article 2 relatively broad.

Pleopods (Figs. 4G-I), pleopod 2 longer than pleopod 1.

Uropods: uropod 1 (Fig. 5A), peduncle same length as outer ramus, shorter than inner ramus, inter-ramal process $28 \%$ length of inner ramus; uropod 2 (Fig. 5B), inter-ramal process $10 \%$ length of inner ramus; uropod 3 (Figs. 5C-D), peduncle subequal to rami in length, with 3 spines on dorsodistal end, inner ramus with 1-2 spines in the middle, outer ramus with a small terminal spine.

Telson (Fig. 5D) rectangular in lateral view.

Female (allotype, $4.2 \mathrm{~mm}$ )

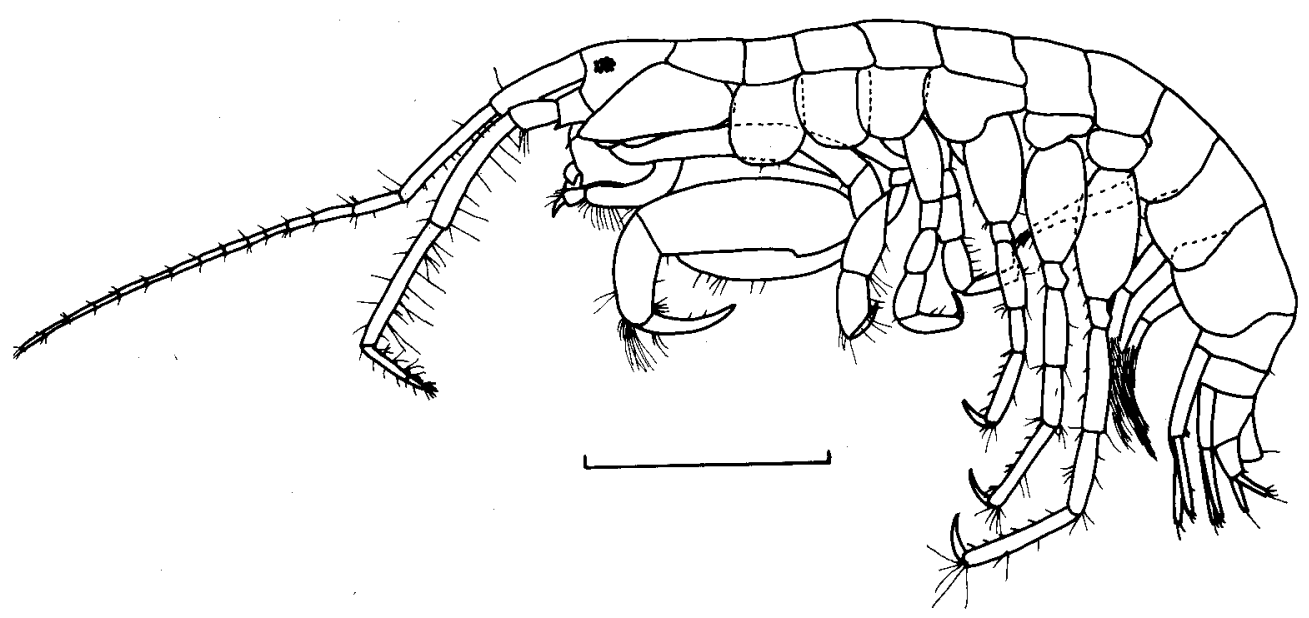

Fig. 2. Aoroides columnaris sp. nov. Male (holotype), $4.1 \mathrm{~mm}$. Scale: $1 \mathrm{~mm}$. 


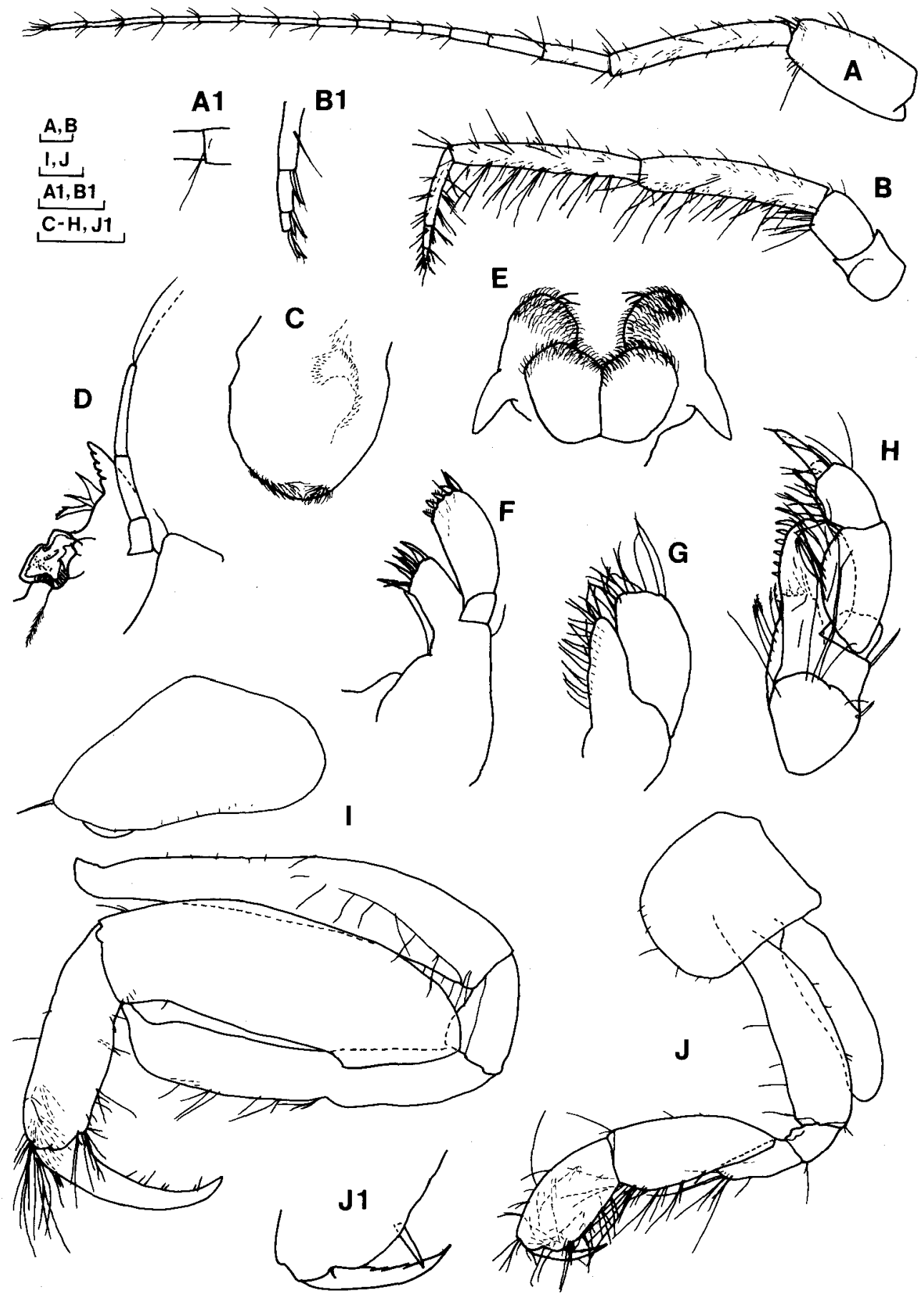

Fig. 3. Aoroides columnaris sp. nov. Male (holotype), 4.1mm: A, antenna 1; A1, accessory flagellum; B, antenna 2; B1, flagellum of antenna 2; C, upper lip; I, gnathopod 1; J, gnathopod 2; J1, palm and article 7 of gnathopod 2. Male (paratype 1), 3.7mm: D, mandible; E, lower lip; F, maxilla 1; G, maxilla 2; H, maxilliped. Scale: $0.1 \mathrm{~mm}$. 


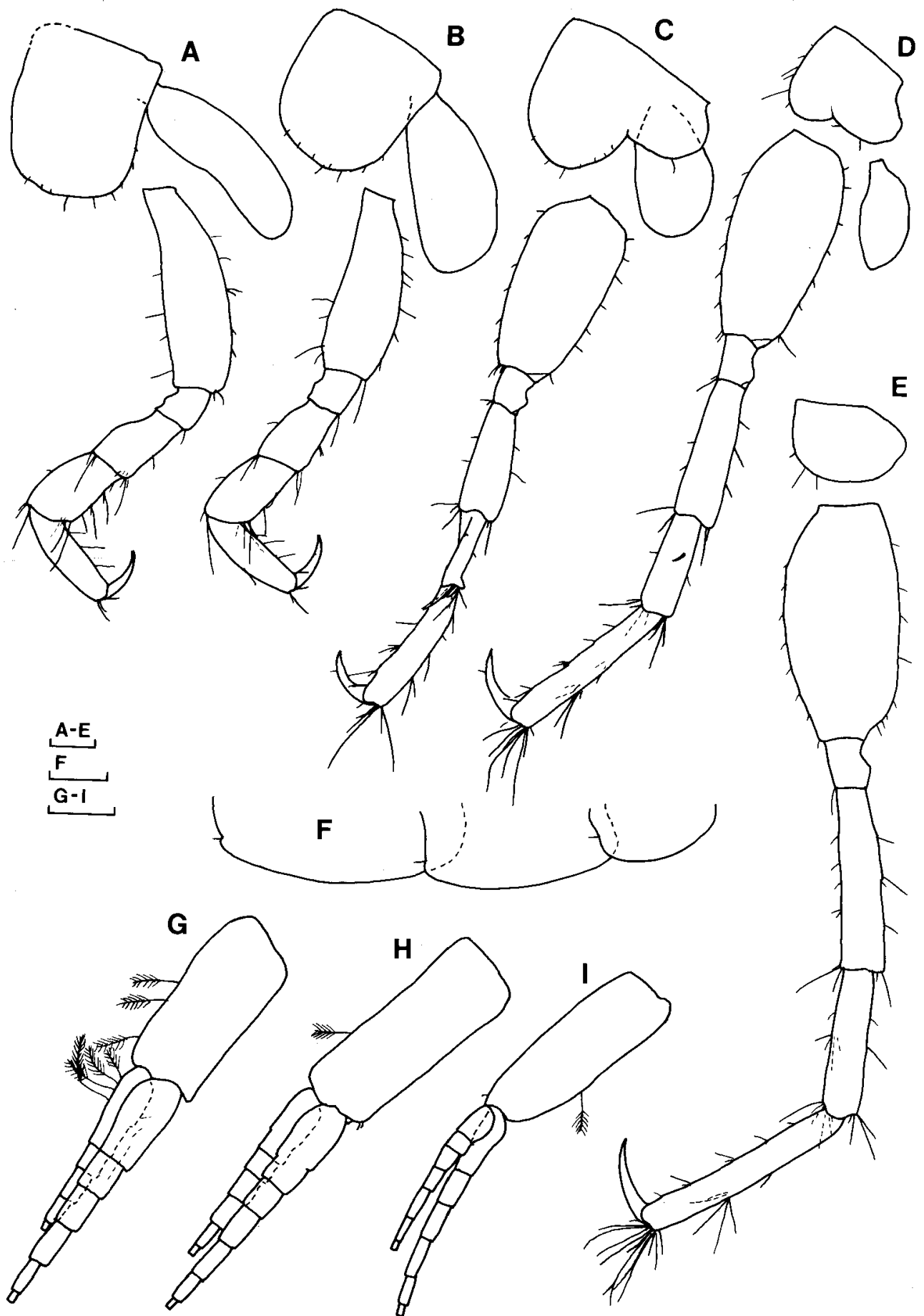

Fig. 4. Aoroides columnaris sp. nov. Male (holotype), 4.1mm: A-E, pereopods 3-7; F, epimeral plates 1-3; G-I, pleopods 1-3. Scale: $0.1 \mathrm{~mm}$. 


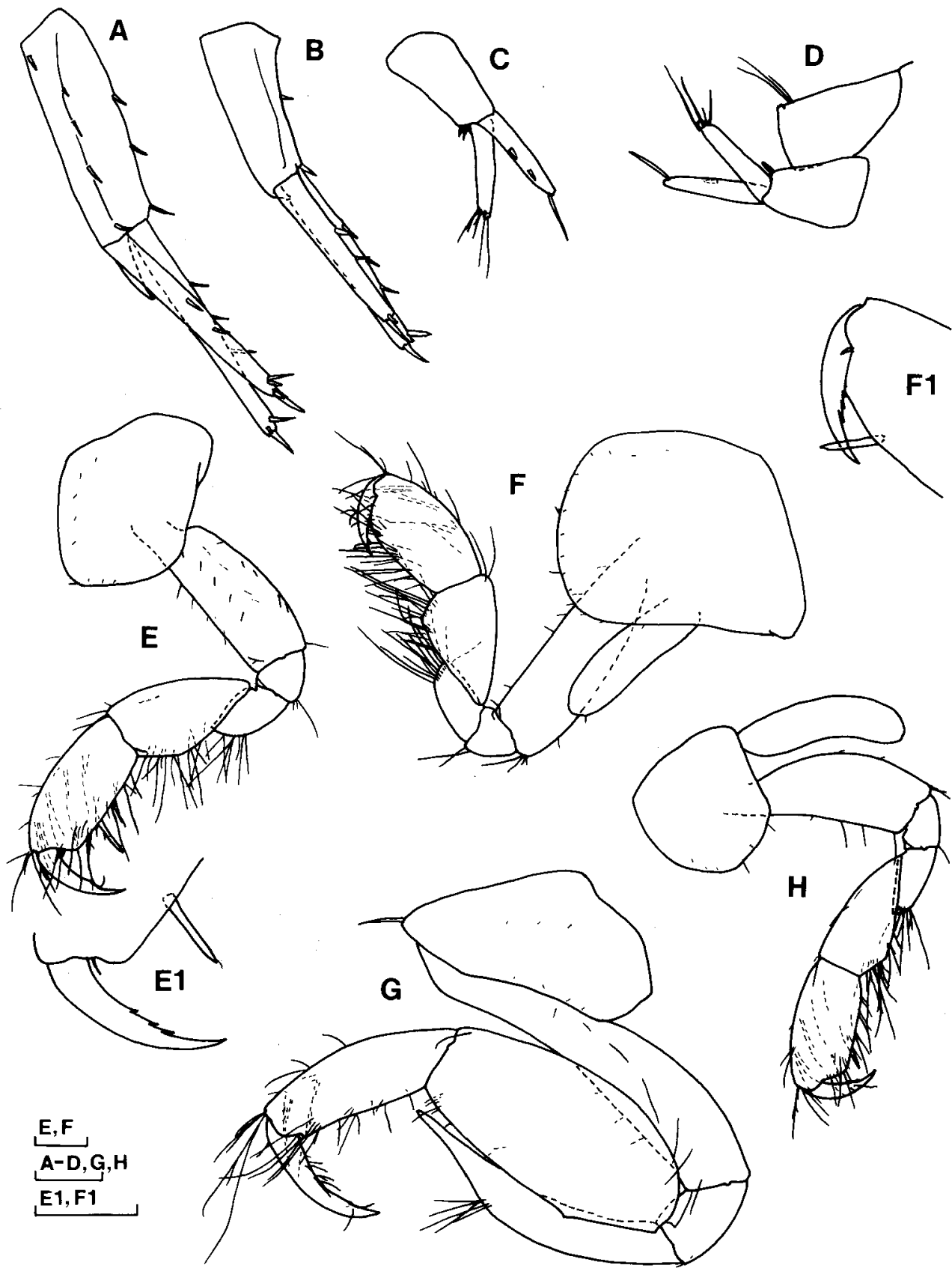

Fig. 5. Aoroides columnaris sp. nov. Male (holotype), $4.1 \mathrm{~mm}$ : A-C, uropods 1-3; D, telson and uropod 3 (lateral view). Female (allotype), $4.2 \mathrm{~mm}$ : E, gnathopod 1; E1, palm and article 7 of gnathopod 1; F, gnathopod 2 (oostegite omitted); F1, palm and article 7 of gnathopod 2. Male (paratype 5), 2.6mm: G-H, gnathopods $1-2$. Scale: $0.1 \mathrm{~mm}$. 
Table 1. Numbers of spines on uropod 3 rami in Aoroides columnaris sp. nov.

\begin{tabular}{ccccccc}
\hline \multirow{2}{*}{ Sex } & \multirow{2}{*}{ Body length } & \multicolumn{2}{c}{ Outer ramus } & & \multicolumn{2}{c}{ Inner ramus } \\
\cline { 3 - 4 } \cline { 5 - 6 } & $(\mathrm{mm})$ & Left & Right & & Left & Right \\
\hline \multirow{2}{*}{ Male } & 4.1 & $0+1^{*}$ & $0+1$ & & $2+0$ & $1+0$ \\
& 3.8 & $0+1$ & $0+1$ & & $0+0$ & $0+0$ \\
& 3.7 & $0+1$ & $0+1$ & & $1+0$ & $1+0$ \\
& 2.6 & $0+1$ & $0+1$ & & $0+0$ & $0+0$ \\
\hline \multirow{2}{*}{ Female } & 4.2 & $0+4$ & $0+4$ & & $1+2$ & $2+2$ \\
& 3.5 & $1+1$ & $0+2$ & & $1+2$ & $1+2$ \\
& 3.4 & $0+1$ & $0+1$ & & $1+1$ & $1+1$ \\
& 2.7 & lost & $0+1$ & & lost & $0+1$ \\
\hline
\end{tabular}

* " $\mathrm{X}+\mathrm{Y}$ " indicates $\mathrm{X}$ marginal spines and $\mathrm{Y}$ terminal spines.

Gnathopod 1 (Figs. 5E, E1): coxal plate roundish lozenge-shaped; article 2 relatively broad; article 6 trapezoidal, palm angular; inner margin of article 7 with 3 notches.

Gnathopod 2 (Figs. 5F, F1), characters similar to the holotype; but coxal plate broader, article 5 short, pyriform, palm oblique, inner margin of article 7 with many notches.

\section{Variation}

Gnathopods of small male (paratype 5, 2.6mm): gnathopod 1 (Fig. 5G), coxal plate and articles 23 almost similar to the holotype, article 4 elongate, gradually narrowed distally, ventral margin with a bundle of setae, article 5 slenderly barrel-shaped, article 6 cylindrical, antero- and posterodistal corners with several long setae, article 7 with several setae on posterior margin; gnathopod 2 (Fig. 5H) almost the same as the holotype.

Numbers of spines on uropod 3 rami (Table 1): in males, outer ramus without marginal spines but with a terminal spine, inner ramus with 0-2 marginal spines; in females, outer ramus with 1-4 terminal spines, inner ramus with 0-2 marginal and 1-2 terminal spines.

\section{Coloration in life}

Light type [specimens from Osaka Prefecture (Plate I, Fig. 1)]: posterior part of head brown; anterior and posterior margins of pereonite 1, posterior margins of pereonites 2-7 and pleonites 1-3 with brown dots; other parts white.

Dark type [specimens from Wakayama Prefecture (Plate I, Fig. 2)]: posterior part of head, pereonites 1-7 and pleonites 1-3 brown; coxa 1 in males and coxae 1-7 in females with brown pigments; other parts white.

Etymology

From the Latin columnaris (= cylindrical), referring to the shapes of articles 4-6 in the male gnathopod 1.

\section{Remarks}

This new species is characterized by its poorly setose male gnathopod 1 , which has depressed triangular coxa, article 2 with sparse setae, cylindrical articles 4-6, and brush-like setae on the anteroand posterodistal corners of article 6 . There is no other species having such a gnathopod 1 in the genus, but Aoroides columbiae sensu Nagata, 1960 from the Seto Inland Sea and A. nahili Barnard, 1970 from Hawaii (Barnard, 1970) and Moluccas (Ledoyer, 1979) have a similar gnathopod 1 to the small male of $A$. columnaris sp. nov. Nagata (1960) identified his specimens as $A$. columbiae, comparing with $A$. columbiae sensu Barnard, 1954 (junior synonym of $A$. spinosus Conlan and 
Bousfield, 1982) and A. californica Alderman, 1936 [synonymized with A. columbiae by Barnard (1954) and Conlan and Bousfield (1982)]. Because male gnathopod 1 of A. columbiae sensu Barnard has a setose article 2 and coxa 1 of A. californica is very extended, Nagat's A. columbiae is clearly different from these species. Although he provided only one figure of male gnathopod 1 , the similarity of the male gnathopod 1 suggests a possibility to be A. columnaris. However, he wrote that each character of male gnathopod 1 was much variable. It is probably because he had examined more than one species. On the other hand, A. nahili can be distinguished from A. columnaris by the short article 4 of maxillipedal palp and the presence of marginal spine on the uropod 3 outer ramus.

Aoroides columnaris also has a short inter-ramal process of the uropod 2 peduncle (10\% length of inner ramus). All Aoroides species in the northeastern Pacific, A. columbiae, A. exilis Conlan and Bousfield, 1982, A. inermis Conlan and Bousfield, 1982, A. intermedius Conlan and Bousfield, 1982 and $A$. spinosus, have a well-developed inter-ramal process (Conlan and Bousfield, 1982). The remaining four species, A. longimerus, $A$. nahili, $A$. secundus and $A$. vitiosus, as well as six new species to be described later, have only a rudimentary process. However, $A$. columnaris is different from $A$. longimerus and $A$. secundus in having a poorly setose male gnathopod 1, and from A. vitiosus in having an ordinary mandibular palp.

Habitat

This species occurs in the subtidal zone (depth: $3-10 \mathrm{~m}$ ) and attaches to basket traps, algae and oysters.

\section{Distribution}

From Tanigawa in Misaki, Osaka Prefecture to Oura in Hidaka, Wakayama Prefecture; Kushimoto in Wakayama Prefecture; Kii-nagashima and Kami Island in Mie Prefecture.

\section{Aoroides curvipes sp. nov.}

(Plate I, Fig. 3; Text-figs. 6-10; Table 2)

(Japanese name: burabura-sokoebi)

Aoroides columbiae: Hirayama, 1984, p. 86, fig. 97 (map); Hirayama, 1995, p. 177, fig. 21-137; (not Walker, 1898, p. 285, pl. 16, figs. 7-10).

? Aoroides columbiae: Nagata, 1965, p. 309 (in part).

Material examined.

Holotype: male (OMNH-Ar-4172), 3.9mm, sandy mud bottom (9m depth) off Tan'nowa in Misaki, Osaka Pref. $\left(34^{\circ} 20^{\prime} \mathrm{N}, 135^{\circ} 11^{\prime} \mathrm{E}\right), 11$ May 1992. Allotype: ovigerous female (OMNH-Ar4173), $3.5 \mathrm{~mm}$, the same data as the holotype. Paratypes: 2 males, $4.0 \mathrm{~mm}$ (OMNH-Ar-4174) and 4.3mm (OMNH-Ar-4175), in a rearing tank of Osaka Prefectural Fisheries Experimental Station (OPFES), of which bottom covered with sand, 11 Apr. 1987; 2 males, 3.1mm (OMNH-Ar-4176) and $3.1 \mathrm{~mm}$ (OMNH-Ar-4177), the same data as the holotype; 1 male (OMNH-Ar-4178), 2.8mm and 1 ovigerous female (OMNH-Ar-4179), 4.0mm, sandy mud bottom ( $3 \mathrm{~m}$ depth) off Tanigawa in Misaki, Osaka Pref., 4 Jun. 1997; 1 male (OMNH-Ar-4180), 3.2mm, from the surface of an ascidian Halocynthia hispida (5m depth), off Tanigawa in Misaki, Osaka Pref., 29 May 1996; 1 male (OMNHAr-4181), 2.4mm, sandy mud bottom (4m depth), off Tan'nowa in Misaki, Osaka Pref., 9 Jun. 1997; 1 ovigerous female (OMNH-Ar-4182), $4.1 \mathrm{~mm}$, from the surface of an ascidian Halocynthia hispida ( $5 \mathrm{~m}$ depth), off Tanigawa in Misaki, Osaka Pref., 18 Mar. 1994; 1 male (OMNH-Ar-4183), 4.4mm, sandy mud bottom in Gokasho Bay, Mie Pref., 8 Mar. 1996, collected by H. Yokoyama; 1 male (OMNH-Ar4184), $3.1 \mathrm{~mm}$ and 1 female (OMNH-Ar-4185), 3.2mm, attaching to an experimental block, Engetsu Island in Shirahama, Wakayama Pref., 3 Jul. 1998, collected by H. Kitada; 1 male (OMNH-Ar-4186), $2.8 \mathrm{~mm}$ and 1 female (OMNH-Ar-4187), 2.2mm, sandy mud bottom (3m depth) in front of "National 
Research Institute of Fisheries and Environment of Inland Sea" in Ohno, Hiroshima Pref., 27 Nov. 1998.

Materials from Kyushu (undissected): 4 males, 2.2-2.5mm, and 4 females, 2.4-3.5mm, sandy mud bottom in Shijiki Bay, Nagasaki Pref., 17 Jun. 1984, collected by H. Sudo; 2 males, 4.0mm, 5.0mm, and 5 females, 3.6-4.5mm, off the mouth of the Mizunashi River, Nagasaki Pref., 28 Mar. 1994, collected by M. Azuma; 1 male, $2.8 \mathrm{~mm}$, and 2 females, $2.1 \mathrm{~mm}, 4.3 \mathrm{~mm}$, off the mouth of the Mizunashi River, Nagasaki Pref., 8 Nov. 1995, collected by M. Azuma.

Male [based on holotype, $3.9 \mathrm{~mm}$, paratype $1,4.0 \mathrm{~mm}$ (body), and paratype 2, 4.3mm (antennae and pereopod 7)]

Body (Fig. 6), eyes medium size.

Antennae: antenna 1 (Figs. 7A, A1), ratio of peduncular articles 1-3 1:1.4:0.5, inner surface of article 1 without spines, primary flagellum with 17 medium and 1 short articles; antenna 2 (Fig. 7B) slender, about 55\% length of antenna 1 , weakly setose, inner surface of peduncle without spines, flagellum with 3 articles, both flagellar articles 2-3 with 2 curved spines (Fig. 7B1).

Mouth parts: upper lip (Fig. 7C) relatively galeate; mandible (Fig. 7D), palp with 6 setae; maxilla 1 (Fig. 7F), palp article 2 with 7 apical spines; maxilliped (Fig. 7H), outer plate with 9 marginal spines, palp articles relatively slender.

Gnathopod 1 (Fig. 7I): coxal plate elongate, slender, with a spine anteriorly; article 2 broadened distally, curved medially, middle part flexed in the prepared specimen, anterior, posterior and lateral margins with several short setae; article 3 relatively long, inflated anterodistally on inner surface; article 4 lanceolate, posterior part of ventral surface and middle part of dorsal surface concaved, ventral margin with several short setae; article 5 broad, narrowed distally, ventral margin with several setae, inner ventral surface with a hollow for receiving article 4; article 6 elongate, curved posteriorly, anterior margin with a few setae, posterior margin with many setae; article 7 long, posterior margin setose.

Gnathopod 2 (Fig. 7J) weakly merochelate, i.e. article 6 curved posteriorly and attached to article 5 at a right angle; coxal plate square-shaped; article 2 broadened distally, anterior and posterior margins with several setae; article 4 rectangular; article 5 , anterior margin with a few setae, posterior margin setose; article 6 narrow, strongly curved posteriorly, palm almost transeverse (Fig. 7J1), posterior margin setose, without spines; article 7 long, inner margin with 5 notches.

Pereopods: pereopods 3-4 (Figs. 8A-B), articles 2 with several short setae on anterior and posterior margins, articles 5 without spines; pereopod 5 (Fig. 8C), article 2 relatively broad, with

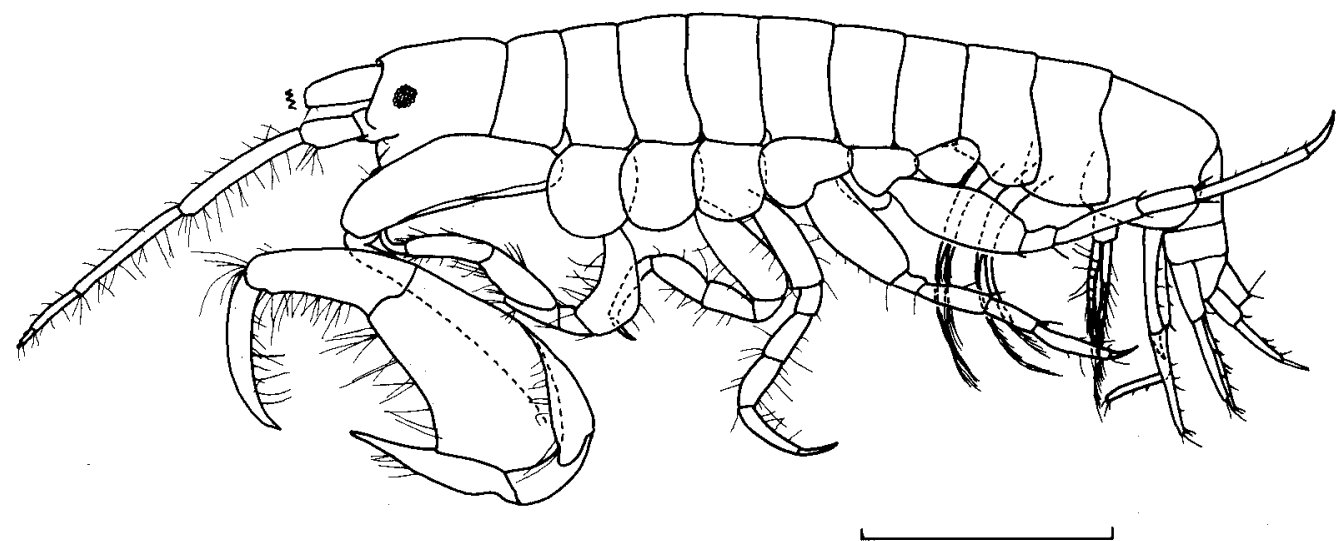

Fig.6. Aoroides curvipes sp. nov. Male (paratype 1), $4.0 \mathrm{~mm}$. Scale: $1 \mathrm{~mm}$. 


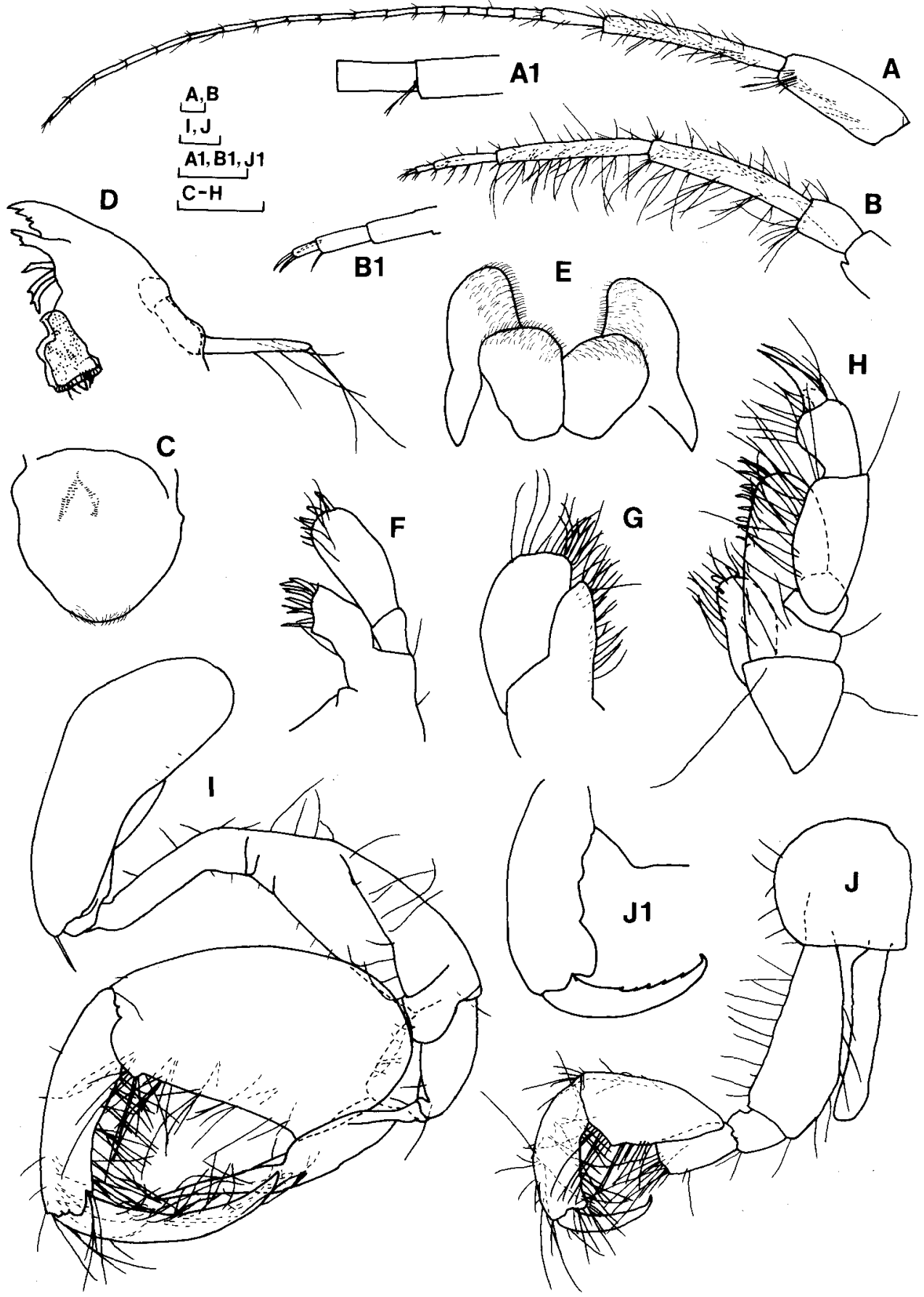

Fig. 7. Aoroides curvipes sp. nov. Male (paratype 2), 4.3mm: A, antenna 1; A1, accessory flagellum; B, antenna 2; B1, flagellum of antenna 2. Male (holotype), $3.9 \mathrm{~mm}$ : C, upper lip; D, mandible; $\mathrm{E}$, lower lip; F, maxilla $1 ; \mathrm{G}$, maxilla $2 ; \mathrm{H}$, maxilliped; I, gnathopod 1 ; J, gnathopod 2; J1, articles 67 of gnathopod 2. Scale: $0.1 \mathrm{~mm}$. 


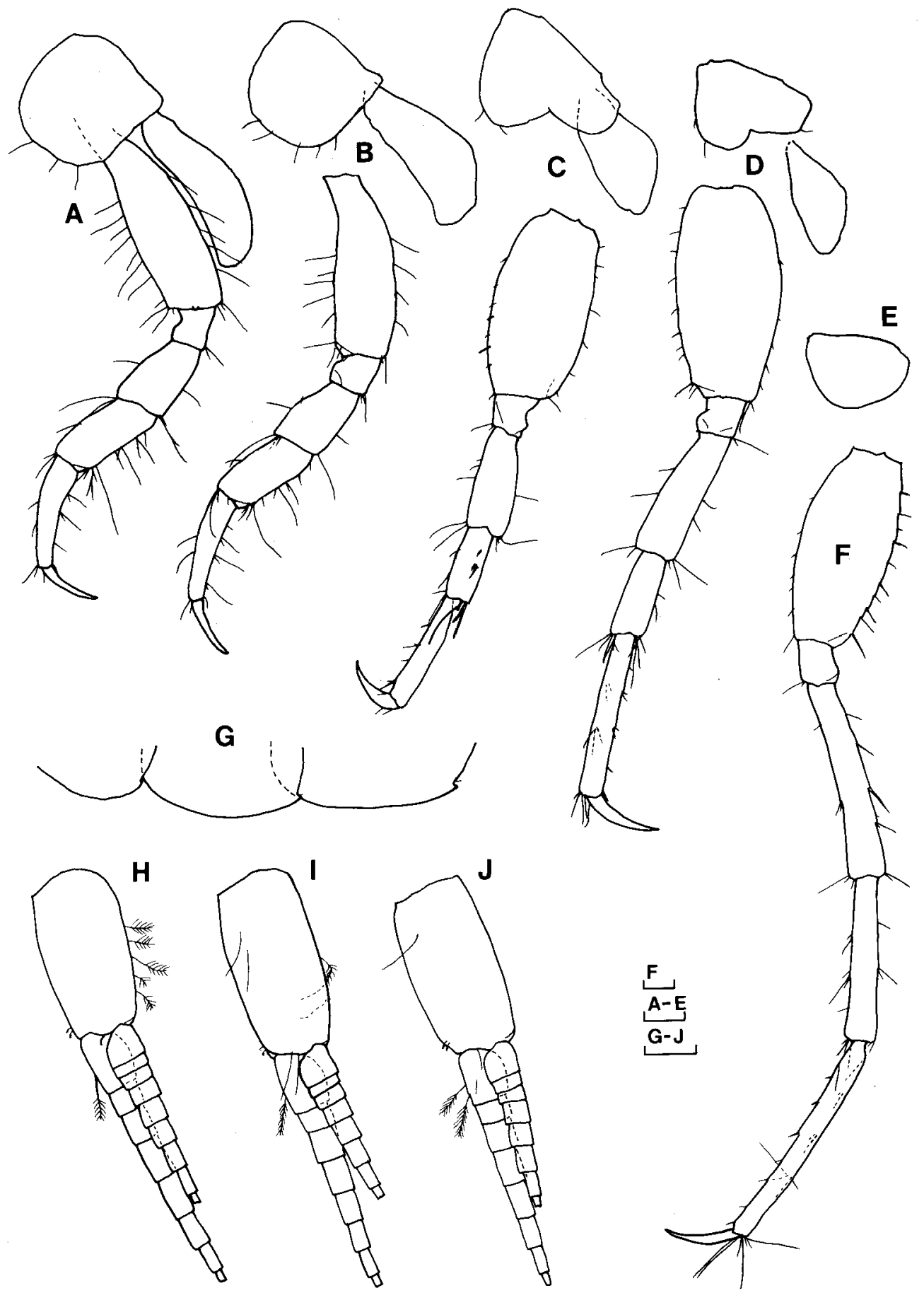

Fig. 8. Aoroides curvipes sp. nov. Male (holotype), 3.9mm: A-D, pereopods 3-6; E, coxa 7; G, epimeral plates 1-3; H-J, pleopods 1-3. Male (paratype 2), $4.3 \mathrm{~mm}$ : F, pereopod 7. Scale: $0.1 \mathrm{~mm}$. 


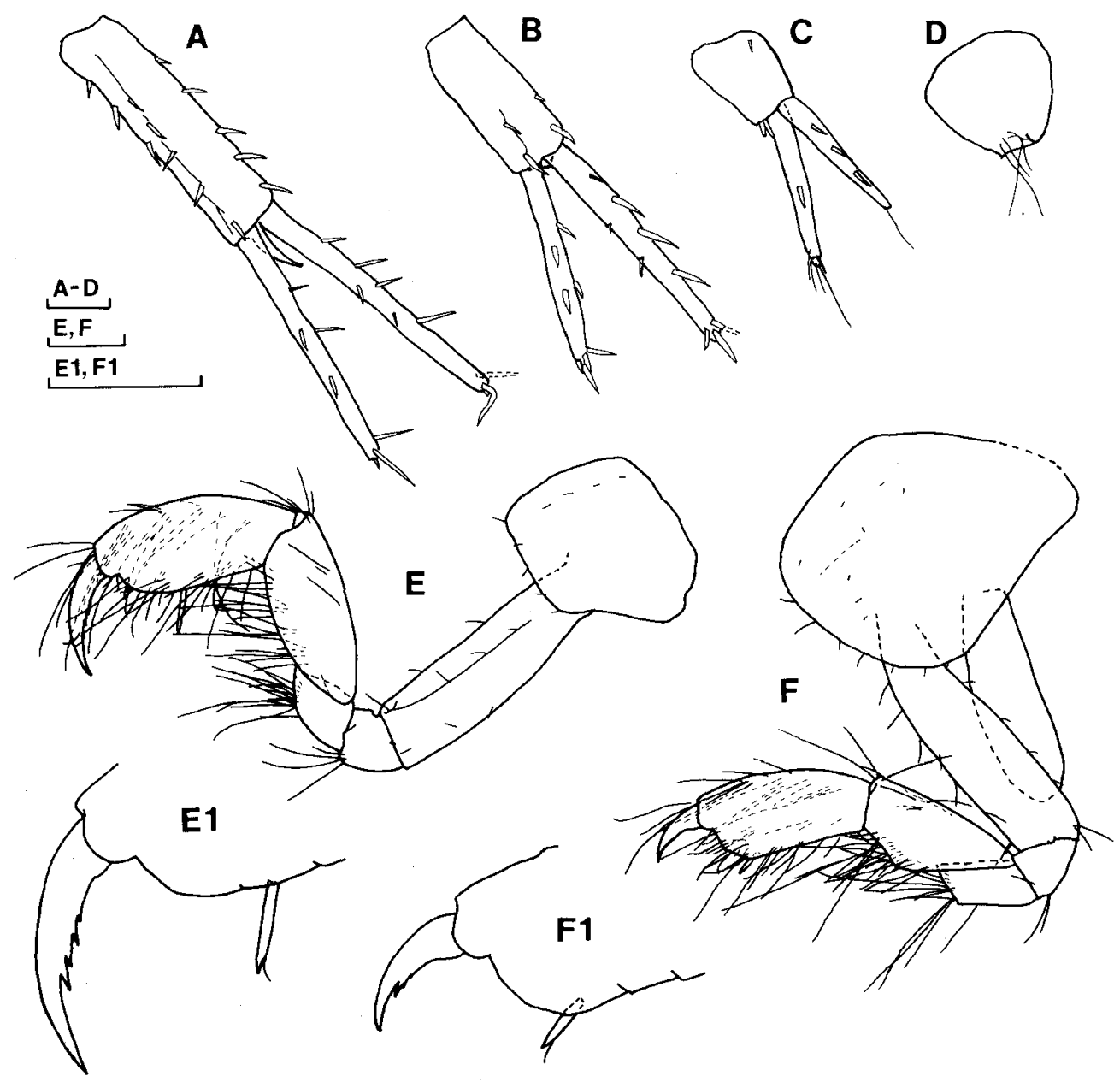

Fig. 9. Aoroides curvipes sp. nov. Male (holotype), 3.9mm: A-C, uropods 1-3; D, telson (dorsal view). Female (allotype), 3.5mm: E, gnathopod 1; E1, palm and article 7 of gnathopod 1; F, gnathopod 2 (oostegite omitted); F1, palm and article 7 of gnathopod 2. Scale: $0.1 \mathrm{~mm}$.

several short spines on anterior and posterior margins, article 5 with 1, 2 lateral and 4 distal spines; pereopod 6 (Fig. 8D), article 2 with several marginal short spines; pereopod 7 (Figs. 8E-F) slendar, coxal plate galeate, article 2 relatively broad, with marginal spines, article 5 with 2 spines on distal end.

Pleopods (Figs. 8H-J), pleopod 1 as long as pleopod 2.

Uropods: uropod 1 (Fig. 9A), peduncle same length as outer ramus, shorter than inner ramus, inter-ramal process $22 \%$ length of inner ramus, dorsal and lateral surfaces of peduncle with 10,3 spines, respectively; uropod 2 (Fig. 9B), inter-ramal process $5 \%$ length of inner ramus; uropod 3 (Fig. $9 \mathrm{C}$ ), peduncle short, about $60 \%$ length of outer ramus, proximal part and distal end with 1,2 spines, respectively, inner ramus with 3 spines, outer ramus with one marginal and one terminal spines.

Telson (Fig. 9D) roundish triangular in dorsal view. 


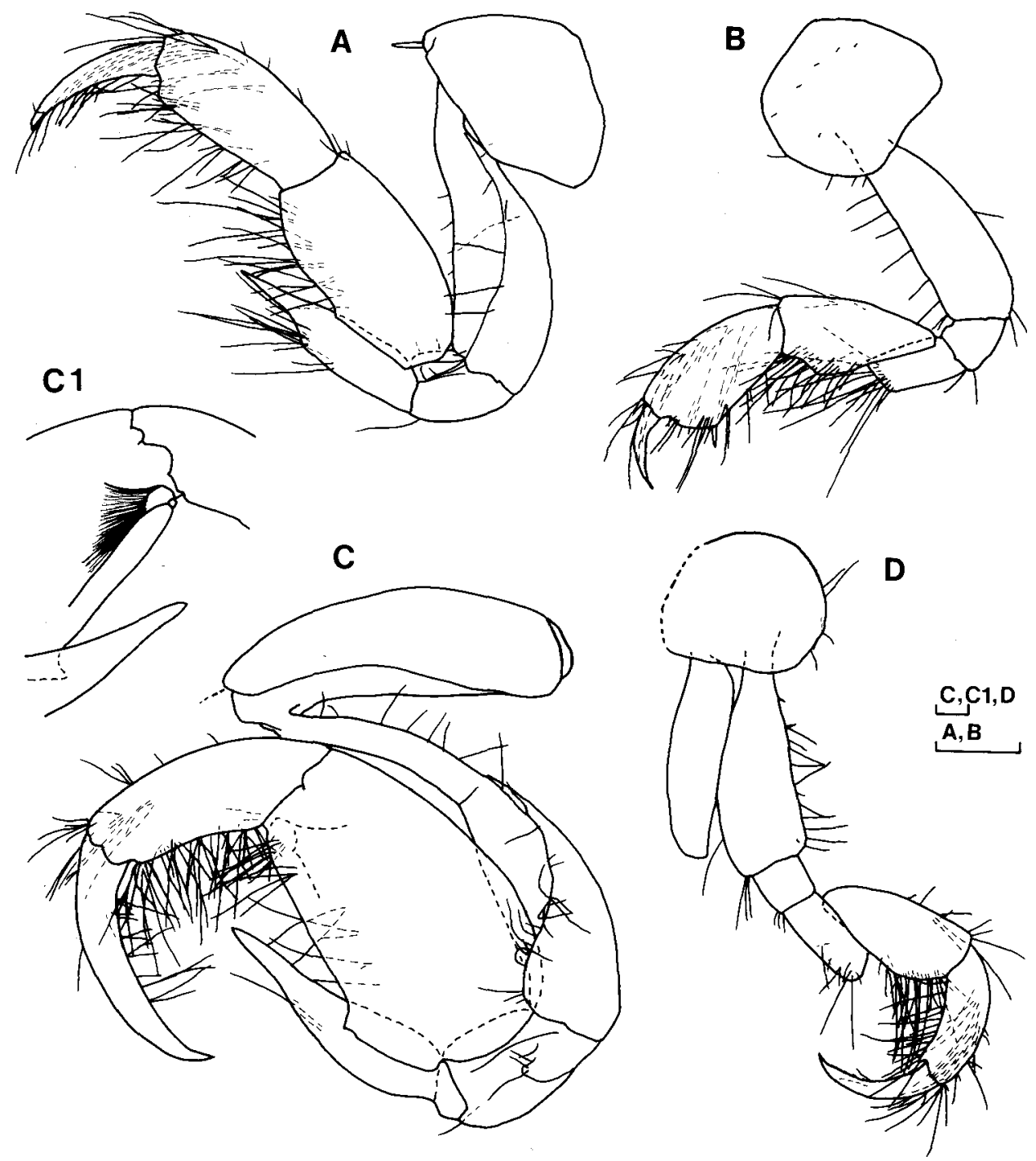

Fig. 10. Aoroides curvipes sp. nov. Male (paratype 8), 2.4mm: A-B, gnathopods 1-2. Male (paratype 2), $4.3 \mathrm{~mm}$ : C, gnathopod 1; C1, distal part of gnathopod 1 article 5 (inner surface); D, right gnathopod 2. Scale: $0.1 \mathrm{~mm}$.

Female (allotype, $4.2 \mathrm{~mm}$ )

Gnathopod 1 (Figs. 9E, E1): coxal plate roundish trapezoidal; article 2 slender; article 5 elongate; article 6 trapezoidal, middle part broadened, palm oblique; inner margin of article 7 with 4 notches.

Gnathopod 2 (Figs. 9F, F1) ordinarily subchelate; coxal plate very broad; articles 2-5 similar to the holotype; article 6 straight and broad, palm oblique, posterodistal corner with a spine; article 7 short, inner margin with 3 notches.

\section{Variation}

Gnathopods of small male (paratype 8, 2.4mm): gnathopod 1 (Fig. 10A), coxal plate broad, article 5 narrower than the holotype, inner surface without hollow, article 6 straight, broader than the 
Table 2. Numbers of spines on uropod 3 rami in Aoroides curvipes sp. nov.

\begin{tabular}{|c|c|c|c|c|c|}
\hline \multirow[t]{2}{*}{ Sex } & \multirow{2}{*}{$\begin{array}{l}\text { Body length } \\
(\mathrm{mm})\end{array}$} & \multicolumn{2}{|c|}{ Outer ramus } & \multicolumn{2}{|c|}{ Inner ramus } \\
\hline & & Left & Right & Left & Right \\
\hline \multirow[t]{11}{*}{ Male } & 4.4 & $2+2^{* 1}$ & $2+2$ & $3+0$ & $3+0$ \\
\hline & 4.3 & $2+2$ & $2+2$ & $3+0$ & $3+0$ \\
\hline & 4.0 & $1+1$ & $2+1$ & $3+0$ & $3+0$ \\
\hline & 3.9 & $1+1$ & $1+1$ & $3+0$ & $3+0$ \\
\hline & 3.2 & $1+0$ & $1+0$ & $2+0$ & $2+0$ \\
\hline & 3.1 & $1+0$ & $2+0$ & $2+0$ & $3+0$ \\
\hline & 3.1 & $1+0$ & $1+0$ & $2+0$ & $2+0$ \\
\hline & 3.1 & $1+0$ & $2+0$ & $3+0$ & $3+0$ \\
\hline & 2.8 & $1+0$ & $1+0$ & $2+0$ & $2+0$ \\
\hline & 2.8 & $r^{* 2}$ & $1+1$ & r & r \\
\hline & 2.4 & $1+1$ & $1+1$ & $2+0$ & $2+0$ \\
\hline \multirow[t]{5}{*}{ Female } & 4.1 & $1+1$ & $2+1$ & $3+0$ & $2+0$ \\
\hline & 4.0 & $1+1$ & $2+1$ & $3+0$ & $3+0$ \\
\hline & 3.5 & $1+1$ & $2+1$ & $3+0$ & $2+0$ \\
\hline & 3.2 & $1+3$ & $2+1$ & $2+0$ & $2+0$ \\
\hline & 2.2 & $1+1$ & $1+1$ & $1+0$ & $1+0$ \\
\hline
\end{tabular}

holotype; gnathopod 2 (Fig. 10B) similar to the allotype except narrower coxal plate.

Gnathopods of large male (paratype 2,4.3mm): gnathopod 1 (Fig. 10C) subequal to the holotype except a distinct hollow of article 5 inner surface (Fig. 10C1); gnathopod 2 (Fig. 10D), coxa, articles 23 and article 7 almost the same as the holotype, article 4 trapezoidal, ventrodistal corner weakly projected, article 5 with ventral margin roundish, article 6 without spines and with small projection on ventrodistal corner.

Numbers of spines on uropod 3 rami (Table 2): outer ramus with 1-2 marginal spines and 0-3 terminal spines; inner ramus with 1-3 marginal spines.

\section{Coloration in life (Plate. I, Fig. 3)}

Dorsal part of head, whole pereonites 1-5, lower part of pereonite 7, dorsal and lower parts of pleonite 1 and lower part of pleonites 2-3 brown; coxae 1-5 and 7 also brown; antennae slightly reddish; other parts white; in specimens attaching to the surfaces of ascidians and blocks, pigments on pereonite 1 distinct.

Etymology

From the Latin curvipes (= curved foot), referring to the shape of article 6 in the male gnathopod 2.

\section{Remarks}

This new species has a unique-shaped male gnathopod 2 with posteriorly curved article 6 . In the known species of Aoroides, only A. vitiosus has a similar gnathopod 2. However, A. curvipes sp. nov. can be clearly distinguished from $A$. vitiosus by the presence of mandibular palp and the presence of spines on the both rami of uropod 3 . Although A. curvipes resembles $A$. columnaris in having a poorly setose male gnathopod 1 , the shape of article 5 is quite different in both species.

Nagata (1960) recorded Aoroides columbiae from the Seto Inland Sea and his specimens seem to be $A$. columnaris as stated above. He recorded A. columbiae again in Nagata (1965), but there is no morphological information in the paper except for "gnathopod 1 in male not densely setose" in the 
key. He stated that he had collected $A$. columbiae from many localities in the Seto Inland Sea. However, I found A. curvipes from sandy mud bottom at Ohno in Hiroshima Prefecture, which was one of Nagata's collecting sites. Therefore I think Nagata (1965)'s materials of A. columbiae probably included specimens of $A$. columnaris and A. curvipes.

Hirayama (1984) reported Aoroides columbiae from west Kyushu. His materials were collected from the sediment bottom of the Ariake Sea, Tomioka Bay, off the west coast of Tomioka Bay and Shijiki Bay (Hirayama, 1983). In my collection of Aoroides specimens from Shijiki Bay and off the mouth of the Mizunashi River (a part of the Ariake Sea), most of them were proven to be A. curvipes. Hirayama (1995) wrote that $A$. columbiae inhabited on sandy mud bottom, and in his figure the species has a poorly setose gnathopod 1 and the article 5 of gnathopod 1 is relatively broad. Based on the reasons above, Hirayama (1984)'s A. columbiae is suggested to be also A. curvipes.

In addition, Aoroides columbiae is clearly different from $A$. curvipes in the setose male gnathopod 1, the well-developed inter-ramal process of uropod 2 (Conlan and Bousfield, 1982), and the shape of male gnathopod 2 .

Habitat

Aoroides curvipes usually occurs in the subtidal zone (3-9m depth). This species lives on sandy mud bottom, but sometimes attaches to the surfaces of ascidians and rocks with algae.

Distribution

From off Kansai International Airport in Izumisano to off Tanigawa in Misaki, Osaka Prefecture; Ohno in Hiroshima Prefecture; Shirahama in Wakayama Prefecture; Gokasho Bay and Matsuzaka in Mie Prefecture; Shijiki Bay in Nagasaki Prefecture; the Ariake Sea.

Aoroides ellipticus sp. nov.

(Plate I, Fig. 4; Text-figs. 11-15; Table 3)

(Japanese name: maruashi-burabura-sokoebi, new)

Material examined.

Holotype: male (OMNH-Ar-4188), 2.2mm, sandy mud bottom (6m depth) off Tanigawa in Misaki, Osaka Pref. ( $\left.34^{\circ} 19^{\prime} \mathrm{N}, 135^{\circ} 07^{\prime} \mathrm{E}\right), 18$ Aug. 1995. Allotype: female (OMNH-Ar-4189), 3.5mm, sandy mud bottom ( $3 \mathrm{~m}$ depth) off Tanigawa in Misaki, Osaka Pref., 4 Jun. 1997. Paratypes: 2 males, $2.8 \mathrm{~mm}$ (OMNH-Ar-4190) and 1.9mm (OMNH-Ar-4191), sandy mud bottom (8m depth) off Fuke in Misaki, Osaka Pref., 9 Jun. 1997; 2 males, 2.5mm (OMNH-Ar-4192) and 2.5mm (OMNH-Ar-4193), sandy mud bottom ( $9 \mathrm{~m}$ depth) off Tan'nowa in Misaki, Osaka Pref., 11 May 1992; 1 male (OMNH-Ar4194), 2.2mm and 2 females, 3.3mm (OMNH-Ar-4195) and 3.1mm (OMNH-Ar-4196), the same data as the holotype; 1 male (OMNH-Ar-4197), $2.7 \mathrm{~mm}$, the same data as the allotype; 1 male (OMNH-Ar4198), 3.9mm, sandy mud bottom in Gokasho Bay, Mie Pref., 8 Mar. 1996, collected by H. Yokoyama.

Materials from Kyushu (undissected): 2 males, $2.6 \mathrm{~mm}, 2.8 \mathrm{~mm}$, and 3 females, $2.8-3.5 \mathrm{~mm}$, off the mouth of the Mizunashi River, Nagasaki Pref., 28 Mar. 1994, collected by M. Azuma.

Male [based on holotype, $2.2 \mathrm{~mm}$, paratype $1,2.8 \mathrm{~mm}$ (body), and paratype 3,2.5mm (mandible)]

Body (Fig. 11) relatively cylindrical; eyes large.

Antennae: antenna 1 (Figs. 12A, A1), ratio of peduncular articles 1-3 1:1.5:0.6, inner surface of article 1 with 3 spines, primary flagellum with 10 medium and 1 short articles; antenna 2 (Fig. 12B) relatively slender, about $60 \%$ length of antenna 1 , weakly setose, inner surface of peduncle without spines, flagellum with 3 articles, tip of flagellar article 3 with 2 curved spines (Fig. 12B1).

Mouth parts: upper lip (Fig. 12C) subrounded; mandible (Fig. 12D), palp with 3 setae; maxilla 1 (Fig. 12F), palp article 2 with 6 apical spines; maxilliped (Fig. 12H), outer plate with 6 marginal 


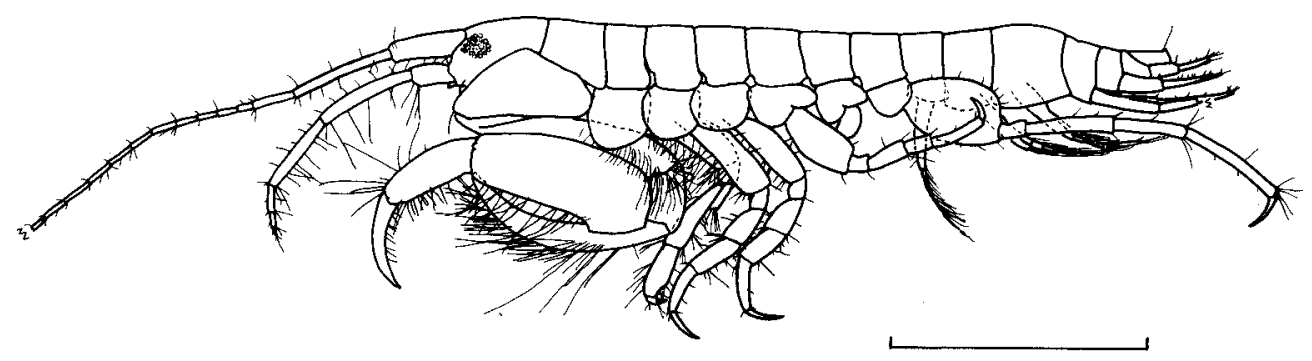

Fig.11. Aoroides ellipticus sp. nov. Male (paratype 1), $2.8 \mathrm{~mm}$. Scale: $1 \mathrm{~mm}$.

spines, palp articles relatively slender.

Gnathopod 1 (Fig. 12I): coxal plate long, depressed triangular in shape, with a long spine anteriorly; article 2 broadened distally, anterior and lateral margins with dense plumose setae, posterior margin bare; article 3, inner surface with several plumose setae; article 4 falcate, gradually narrowed distally, ventral margin with many long plumose setae; article 5 , inner surface with a few plumose setae, ventral margin with many plumose setae; article 6 elongate, posterior margin and distal part of inner surface setose; article 7 long, posterior and inner surfaces with setae.

Gnathopod 2 (Fig. 13A): coxal plate square-shaped; article 2 curved anteriorly, anterior margin with many plumose setae, posterior margin with a few setae; article 4 trapezoidal, distal end with long setae; article 5 relatively long, posterior margin setose; article 6 broad, palm oblique, defined by a short spine (Fig. 13A1); article 7 elongate, inner margin with 2 notches.

Pereopods: pereopods 3-4 (Figs. 13B-C), articles 2 with several short setae on anterior and posterior margins, article 5 of pereopod 3, posterior margin with a spine; pereopod 5 (Fig. 13D), article 2 relatively slender, article 5 with lateral and distal spines; pereopod 6 (Fig. 13E), article 2 slender, with spines on anterior and posterior margins, article 5 with distal spines, article 6 , anterior margin with a few spines; pereopod 7 (Fig. 13F), coxal plate galeate, article 2 elliptical, with marginal spines, articles 4-6 slender, anterior margin of article 6 with a few tiny spines.

Pleopods (Figs. 14A-C) almost same length.

Uropods: uropod 1 (Fig. 14D), peduncle shorter than both rami, inter-ramal process $35 \%$ length of inner ramus, dorsal and lateral surfaces of peduncle with 6 and 1 spines, respectively; uropod 2 (Fig. 14E), inter-ramal process $4 \%$ length of inner ramus; uropod 3 (Fig. 14F), peduncle short, about $75 \%$ length of outer ramus, proximal part and distal end with 1, 2 spines, respectively, inner ramus with a marginal spine, outer ramus without marginal spines but with a terminal spine.

Telson (Fig. 14F) subrounded in dorsal view.

Female (allotype, $3.5 \mathrm{~mm}$ )

Gnathopod 1 (Figs. 14G, G1): coxal plate roundish trapezoidal; article 2 broad; article 5 relatively broad; article 6 with several setae on ventral and inner surfaces, palm oblique; inner margin of article 7 with 4 notches.

Gnathopod 2 (Figs. 14H, H1): coxal plate subsquare; article 5 relatively short; palm slightly oblique; inner margin of article 7 with 3 notches.

\section{Variation}

Gnathopods of small male (paratype 2,1.9mm): gnathopod 1 (Fig. 15A), each article broader than the holotype, article 4 lanceolate, articles 6 and 7 short; gnathopod 2 (Fig. 15B) subequal to the 


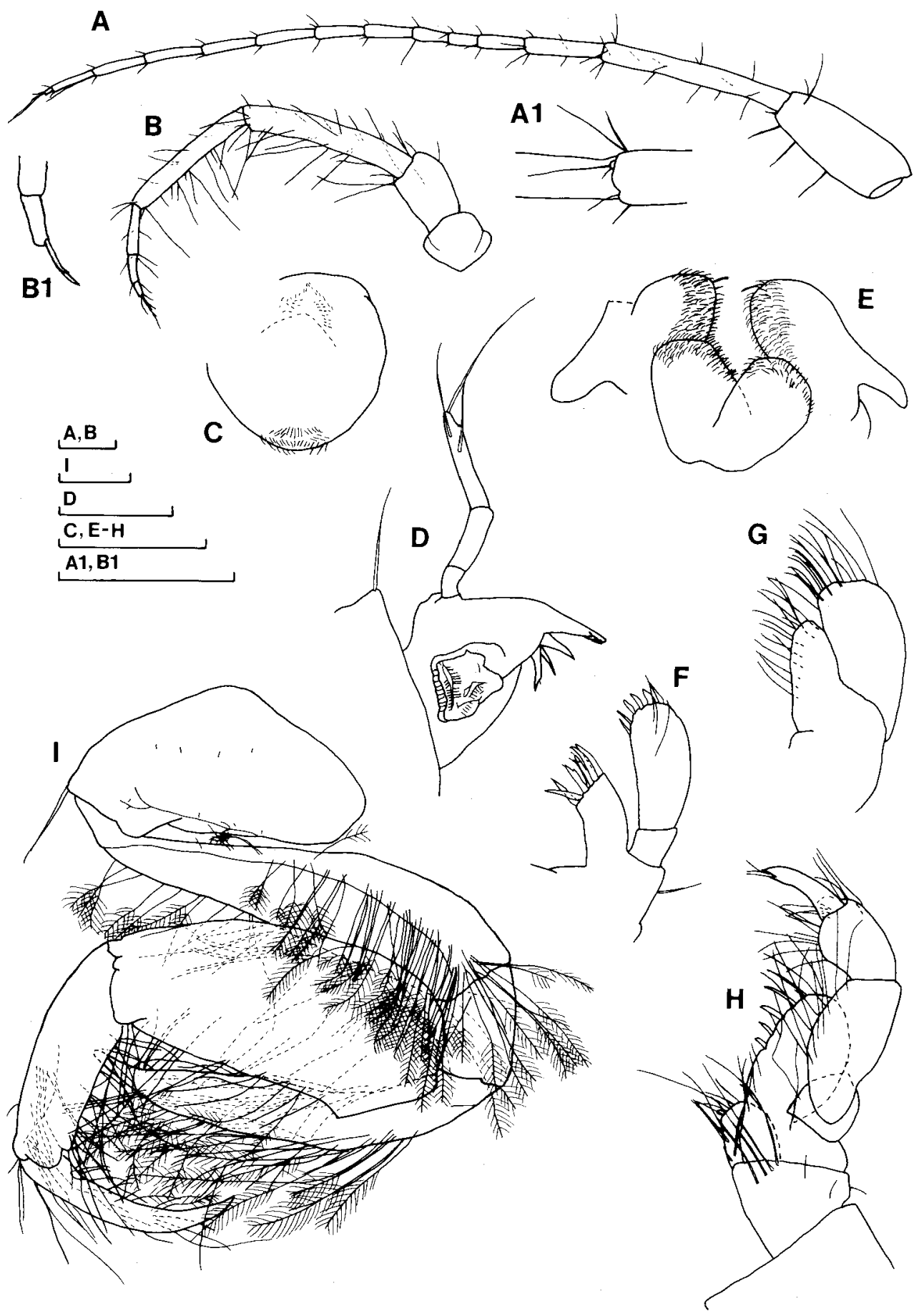

Fig. 12. Aoroides ellipticus sp. nov. Male (holotype), $2.2 \mathrm{~mm}$ : A, antenna 1; A1, accessory flagellum; B, antenna 2; B1, tip of antenna 2; C, upper lip; E, lower lip; F, maxilla 1; G, maxilla 2; H, maxilliped; I, gnathopod 1. Male (paratype 3), $2.5 \mathrm{~mm}$ : D, mandible. Scale: $0.1 \mathrm{~mm}$. 

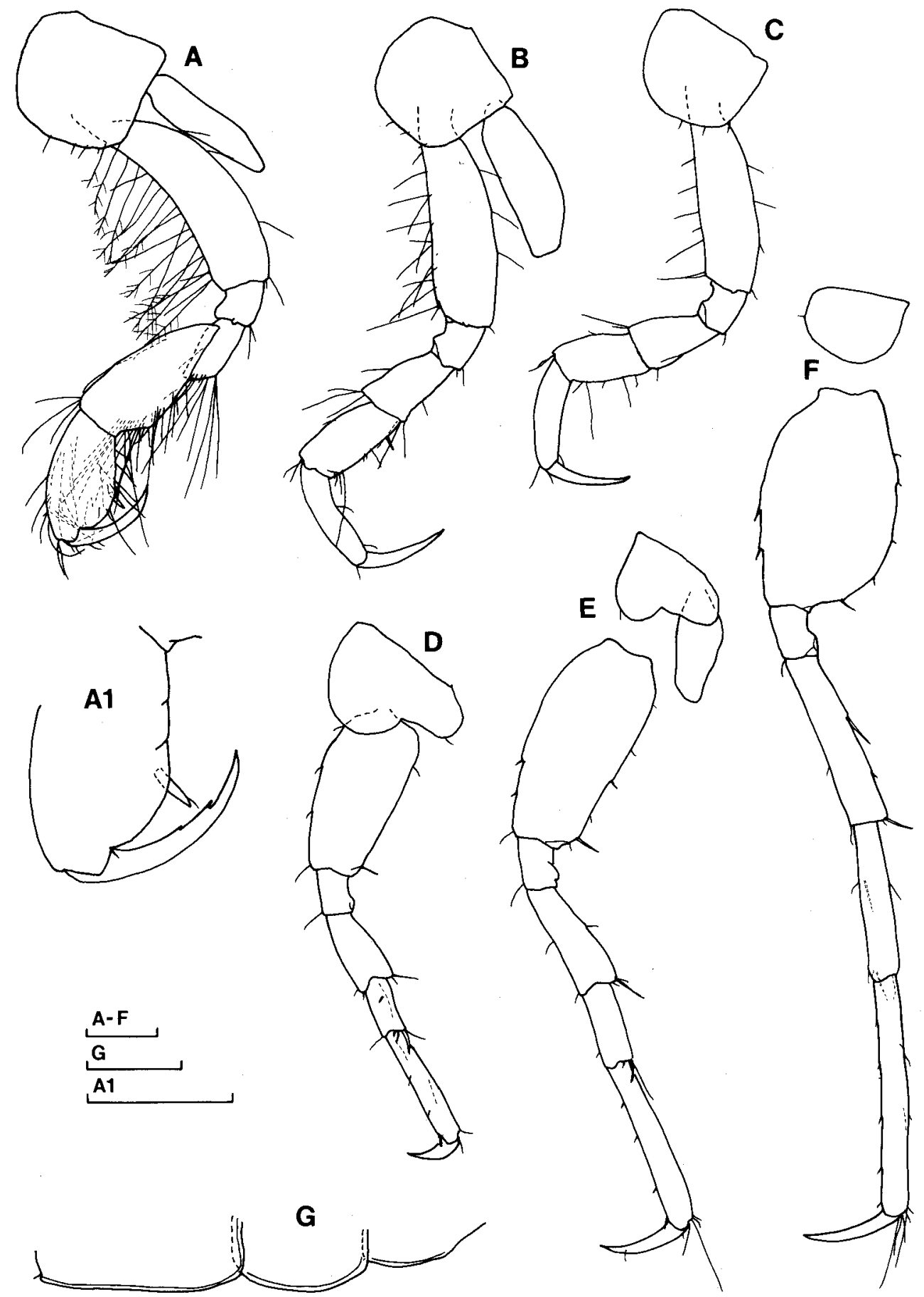

Fig. 13. Aoroides ellipticus sp. nov. Male (holotype), $2.2 \mathrm{~mm}$ : A, gnathopod 2; A1, palm and article 7 of gnathopod 2; B-F, pereopods 3-7 (gills on pereopods 4-5 lost); G, epimeral plates 1-3. Scale: $0.1 \mathrm{~mm}$. 


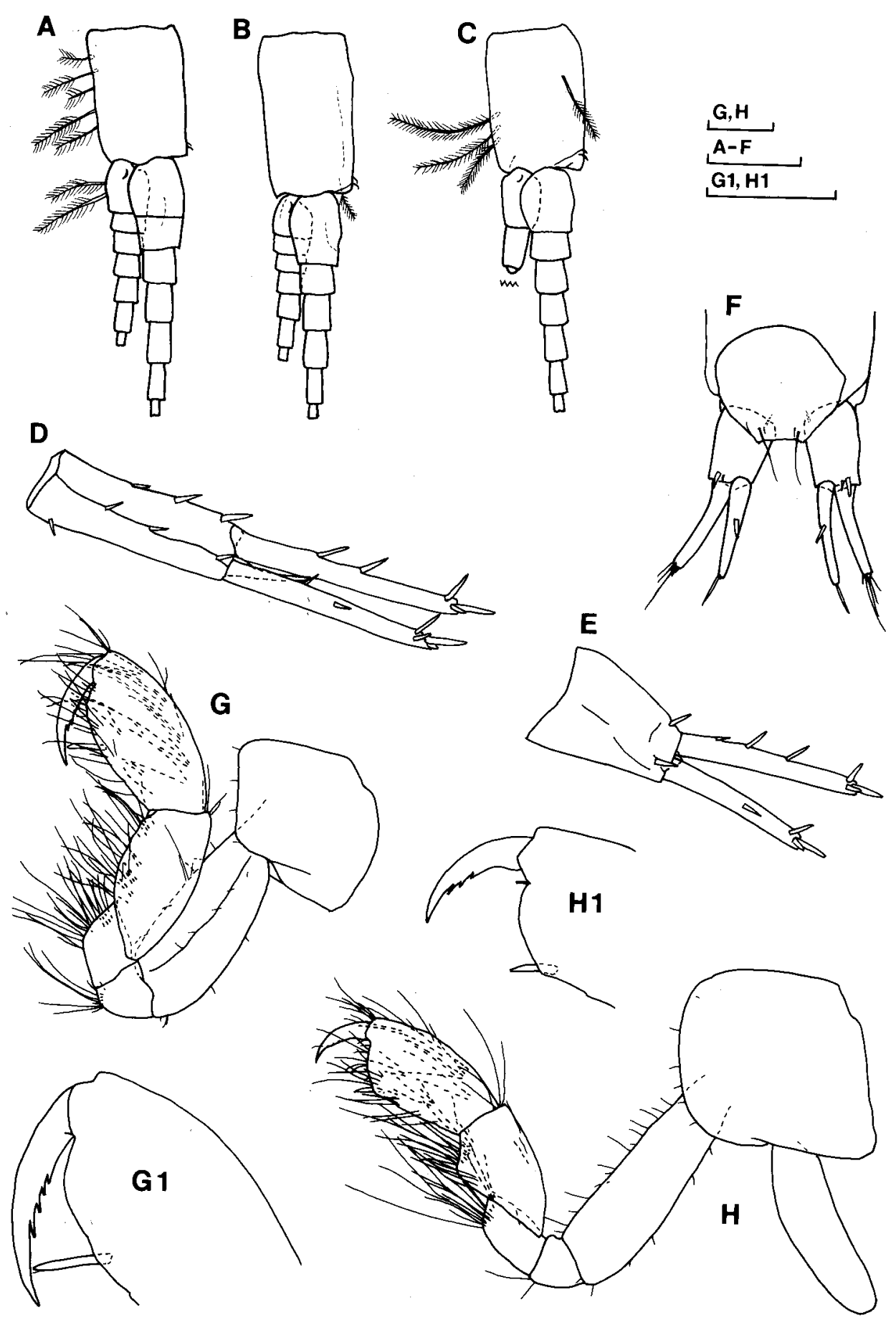

Fig. 14. Aoroides ellipticus sp. nov. Male (holotype), 2.2mm: A-C, pleopods 1-3; D-E, uropods 1-2; F, telson and uropod 3. Female (allotype), $3.5 \mathrm{~mm}$ : $\mathrm{G}$, gnathopod 1; G1, palm and article 7 of gnathopod $1 ; \mathrm{H}$, gnathopod 2 (oostegite omitted); H1, palm and article 7 of gnathopod 2. Scale: $0.1 \mathrm{~mm}$. 


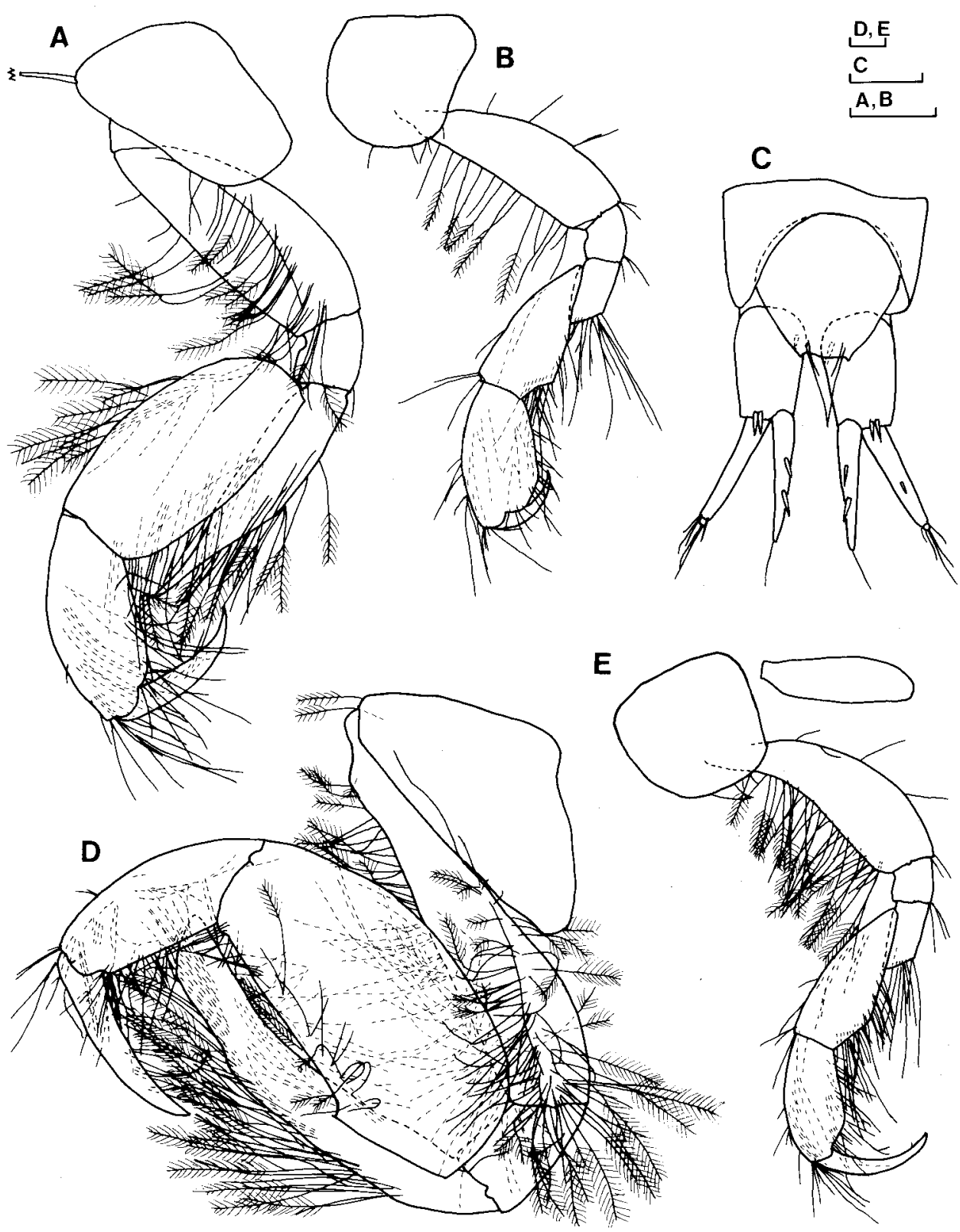

Fig. 15. Aoroides ellipticus sp. nov. Male (paratype 2), 1.9mm: A-B, gnathopods1-2 (gill on gnathopod 2 lost). Male (paratype 9), 3.9mm: C, telson and uropod 3; D-E, gnathopods 1-2. Scale: $0.1 \mathrm{~mm}$. 
Table 3. Numbers of spines on uropod 3 rami in Aoroides ellipticus sp. nov.

\begin{tabular}{ccccccc}
\hline \multirow{2}{*}{ Sex } & Body length & \multicolumn{2}{c}{ Outer ramus } & & \multicolumn{2}{c}{ Inner ramus } \\
\cline { 3 - 4 } \cline { 5 - 6 } & & Left & Right & & Left & Right \\
\hline \multirow{2}{*}{ Male } & 3.9 & $0+1^{*}$ & $1+1$ & & $2+0$ & $2+0$ \\
& 2.8 & $1+1$ & $1+1$ & & $2+0$ & $2+0$ \\
& 2.7 & $0+0$ & $0+0$ & & $1+0$ & $2+0$ \\
& 2.5 & $0+1$ & $0+1$ & & $1+0$ & $1+0$ \\
& 2.5 & $0+0$ & $0+0$ & & $1+0$ & $1+0$ \\
& 2.2 & $0+1$ & $0+1$ & & $1+0$ & $1+0$ \\
& 2.2 & $0+0$ & $0+0$ & & $1+0$ & $2+0$ \\
& 1.9 & $0+0$ & $0+0$ & & $2+0$ & $1+0$ \\
\hline \multirow{2}{*}{ Female } & 3.5 & $1+1$ & $1+1$ & & $2+0$ & $2+1$ \\
& 3.3 & $1+1$ & $1+1$ & & $2+1$ & $2+1$ \\
& 3.1 & $1+1$ & $1+1$ & & $2+0$ & $2+0$ \\
\hline
\end{tabular}

* " $\mathrm{X}+\mathrm{Y}$ " indicates $\mathrm{X}$ marginal spines and $\mathrm{Y}$ terminal spines.

holotype except shorter article 7.

Gnathopods and uropod 3 of large male (paratype 9,3.9mm): gnathopod 1 (Fig. 15D) robuster than the holotype, distal part of article 4 broad, distal end truncate, article 6 relatively broad, article 7 almost straight; gnathopod 2 (Fig. 15E), articles 5-6 narrower than the holotype; uropod 3 (Fig. 15C), right outer and inner rami with 1 and 2 marginal spines, respectively.

Numbers of spines on uropod 3 rami (Table 3): in males, outer ramus usually without marginal spines and often with a terminal spine, inner ramus with 1-2 marginal spines; in large females, outer ramus with a marginal and a terminal spines, inner ramus with 2 marginal and $0-1$ terminal spines.

\section{Coloration in life (Plate I, Fig. 4)}

Dorsal part of head and pereonite 6, pereonites 1-5, dorsal and lower parts of pereonite 7 and pleonites 1-2 brown; coxae 1, 5 and 7 brown; antennae slightly reddish; other parts white. In females, coxae 2-4 also brown.

Etymology

From the Greek ellipticus (= elliptical), referring to the shape of article 2 in the pereopod 7.

Remarks

This new species is characterized by the plumosely setose gnathopod 1 in males and the very short inter-ramal process of uropod 2. These features are shared with Aoroides longimerus and $A$. secundus within the genus. Aoroides ellipticus sp. nov. can be distinguished from the latter two species by (1) fewer setae on anterior margin of article 5 of male gnathopod 1, and (2) elliptical article 2 of pereopod 7.

I examined several specimens of Aoroides ellipticus from the Ariake Sea in Kyushu. However, as the shape and setation of male gnathopod 1 of this species is quite different from A. curvipes, Hirayama (1984)'s A. columbiae probably does not include A. ellipticus.

Habitat

Aoroides ellipticus lives on sandy mud bottom in the subtidal zone (depth: $3-9 \mathrm{~m}$ ). This species often occurs together with $A$. curvipes.

Distribution

From off Hakotsukuri in Han'nan to off Tanigawa in Misaki, Osaka Prefecture; Gokasho Bay in Mie Prefecture; the Ariake Sea. 


\section{Aoroides longimerus Ren and Zheng, 1996}

(Plate I, Fig. 5; Text-figs. 16-19; Table 4)

(Japanese name: kenaga-burabura-sokoebi, new)

Aoroides longimerus Ren and Zheng, 1996, pp. 59-61, 77-78, fig. 2.

\section{Material examined.}

Male(1) (OMNH-Ar-4235), 4.2mm, from the surface of an ascidian Halocynthia hispida $(5 \mathrm{~m}$ depth), off Tanigawa in Misaki, Osaka Pref. ( $\left.34^{\circ} 19^{\prime} \mathrm{N}, 135^{\circ} 07^{\prime} \mathrm{E}\right), 18$ Mar. 1994; male(2) (OMNH-Ar4237), 3.6mm, ovigerous female(1) (OMNH-Ar-4236), 4.6mm, and ovigerous female(2) (OMNH-Ar$4238), 4.5 \mathrm{~mm}$, the same data as male(1); male(3) (OMNH-Ar-4239), 3.7mm, attaching to an experimental board for fouling organisms (1m depth), at Tanigawa in Misaki, Osaka Pref., $10 \mathrm{Jul}$. 1996; male(4) (OMNH-Ar-4240), 2.2mm, among a hydroid Aglaophenia whiteleggei ( $2 \mathrm{~m}$ depth), off Tanigawa in Misaki, Osaka Pref., 28 Aug. 1995; male(5) (OMNH-Ar-4241), 3.1mm, and ovigerous female(3) (OMNH-Ar-4242), 3.7mm, from the surface of bryozoan ( $7 \mathrm{~m}$ depth), off Tanigawa in Misaki, Osaka Pref., 9 Jul. 1988; male(6) (OMNH-Ar-4243), 3.5mm, among a brown alga Sargassum filicinum (3m depth), off Tanigawa in Misaki, Osaka Pref., 10 May 1989; male(7) (OMNH-Ar-4244), $2.3 \mathrm{~mm}$, pebble beach outside of the mouth of the Onosato River in Han nan, Osaka Pref., 28 Apr. 1991.

Male [based on male(1), 4.2mm, male(2), 3.6mm (body, lower lip and maxilla 2), and male(3), $3.7 \mathrm{~mm}$ (antenna 1 and pereopods 4 and 7)]

Body (Fig. 16), eyes medium size.

Antennae: antenna 1 (Figs. 17A, A1, A2), ratio of peduncular articles 1-3 1:1.2:0.4, primary flagellum with 19 medium and 1 short articles, ventral surface of peduncular article 1 with several spines; antenna 2 (Fig. 17B) relatively stout, about 55\% length of antenna 1, setose ventrally, peduncular articles without spines, flagellum with 3 articles, articles 1-3 with 4,2, 2 curved spines, respectively (Fig. 17B1).

Mouth parts: upper lip (Fig. 17C) roundish; mandible (Fig. 17D), palp article 3 with 2 terminal setae; maxilla 1 (Fig. 17F), palp article 2 broad, with 7 apical spines; maxilliped (Figs. 17H, H1), outer plate broad, with 7 marginal spines, palp articles medium width.

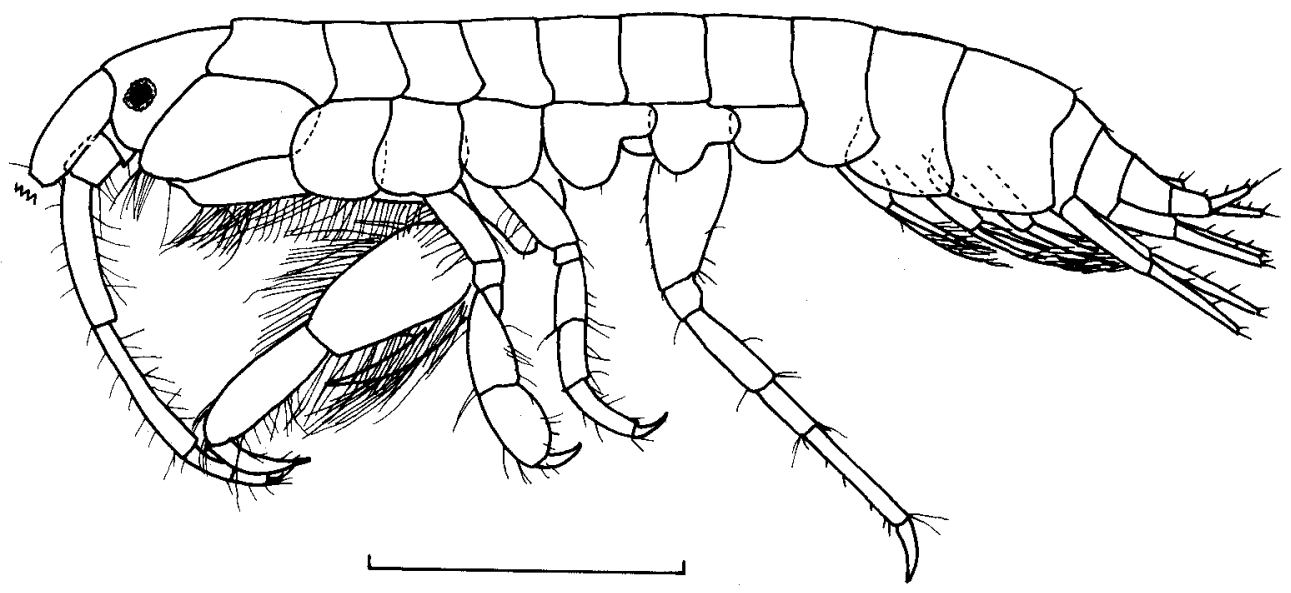

Fig.16. Aoroides longimerus Ren and Zheng. Male(2), 3.6mm. Scale: $1 \mathrm{~mm}$. 


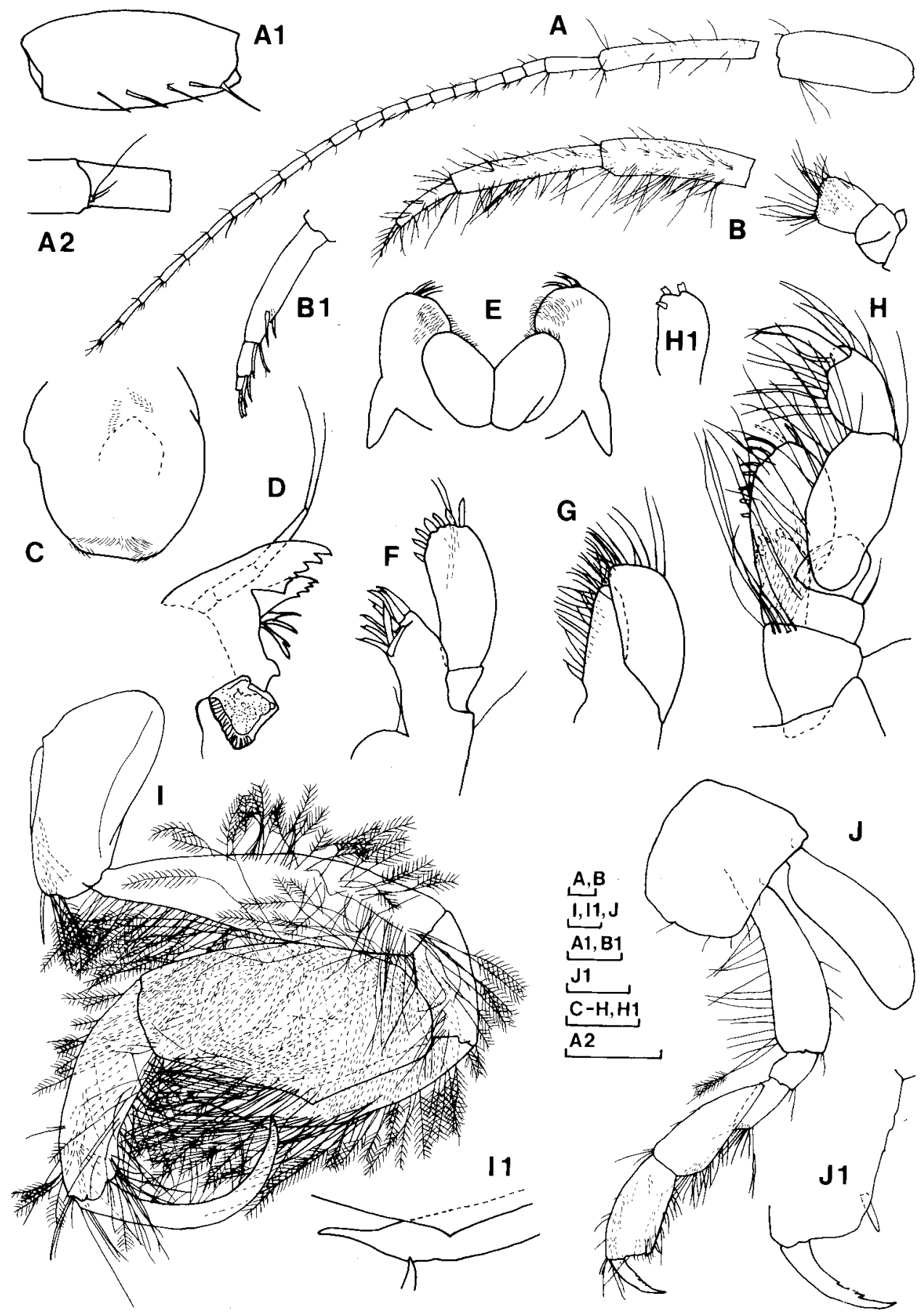

Fig. 17. Aoroides longimerus Ren and Zheng. Male(1), 4.2mm: A, antenna 1; B, antenna 2; B1, flagellum of antenna 2; C, upper lip; D, mandible; F, maxilla $1 ; \mathrm{H}$, maxilliped; $\mathrm{H} 1$, inner plate of maxilliped; I, gnathopod 1; I1, distal part of gnathopod 1 article 4 (setae omitted); J, gnathopod 2; J1, palm and article 7 of gnathopod 2. Male(2), 3.6mm: E, lower lip; G, maxilla 2. Male(3), 3.7mm: A1, peduncular article 1 of antenna 1 (inner view); A2, accessory flagellum. Scale: $0.1 \mathrm{~mm}$. 


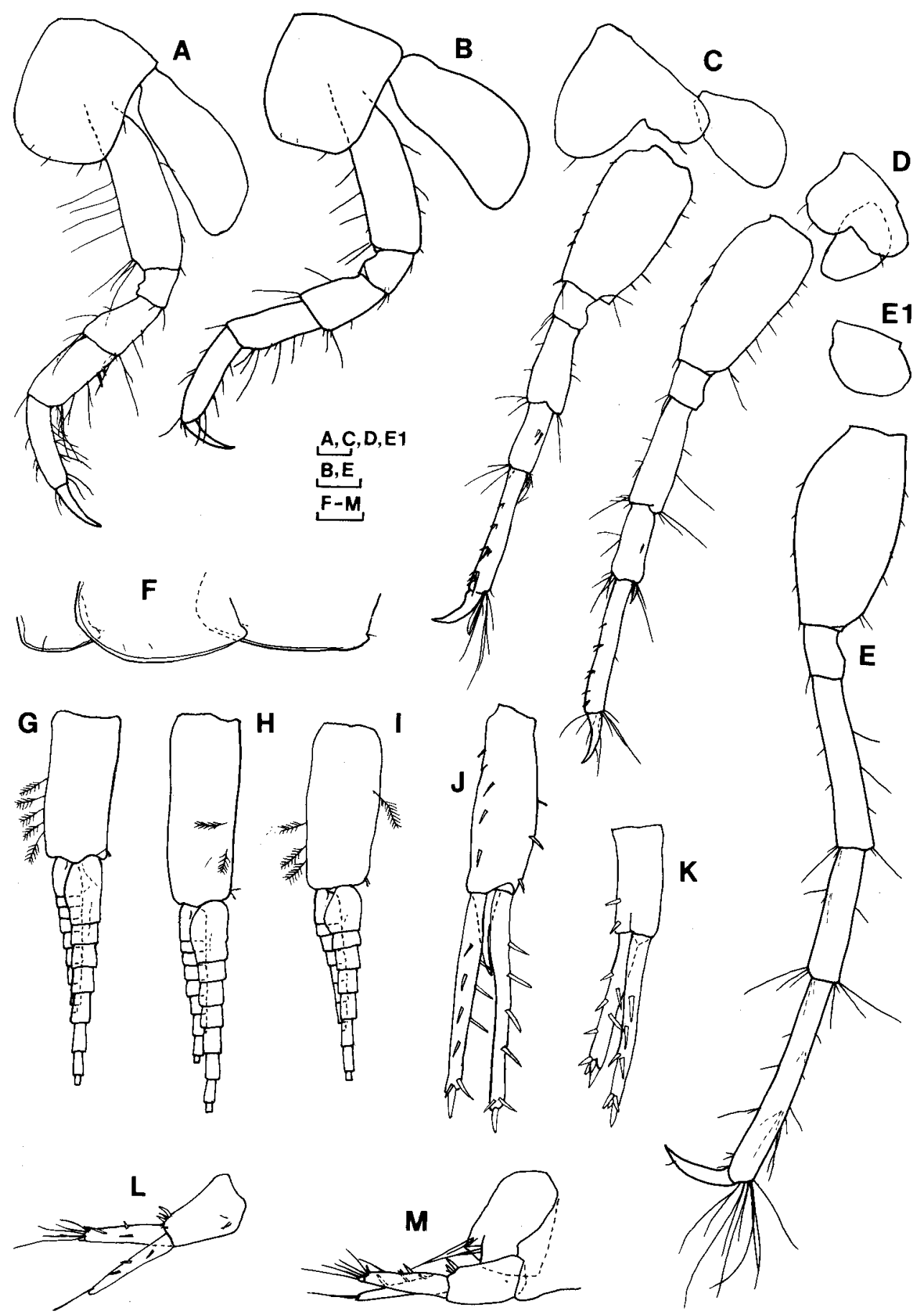

Fig. 18. Aoroides longimerus Ren and Zheng. Male(1), 4.2mm: A, pereopod 3; C-D, pereopods 5-6; E1, coxa 7; F, epimeral plates 1-3; G-I, pleopods 1-3; J-L, uropods 1-3; M, telson and right uropod 3 (lateral view). Male (3), $3.7 \mathrm{~mm}$ : B, pereopod 4; E, pereopod 7. Scale: $0.1 \mathrm{~mm}$. 


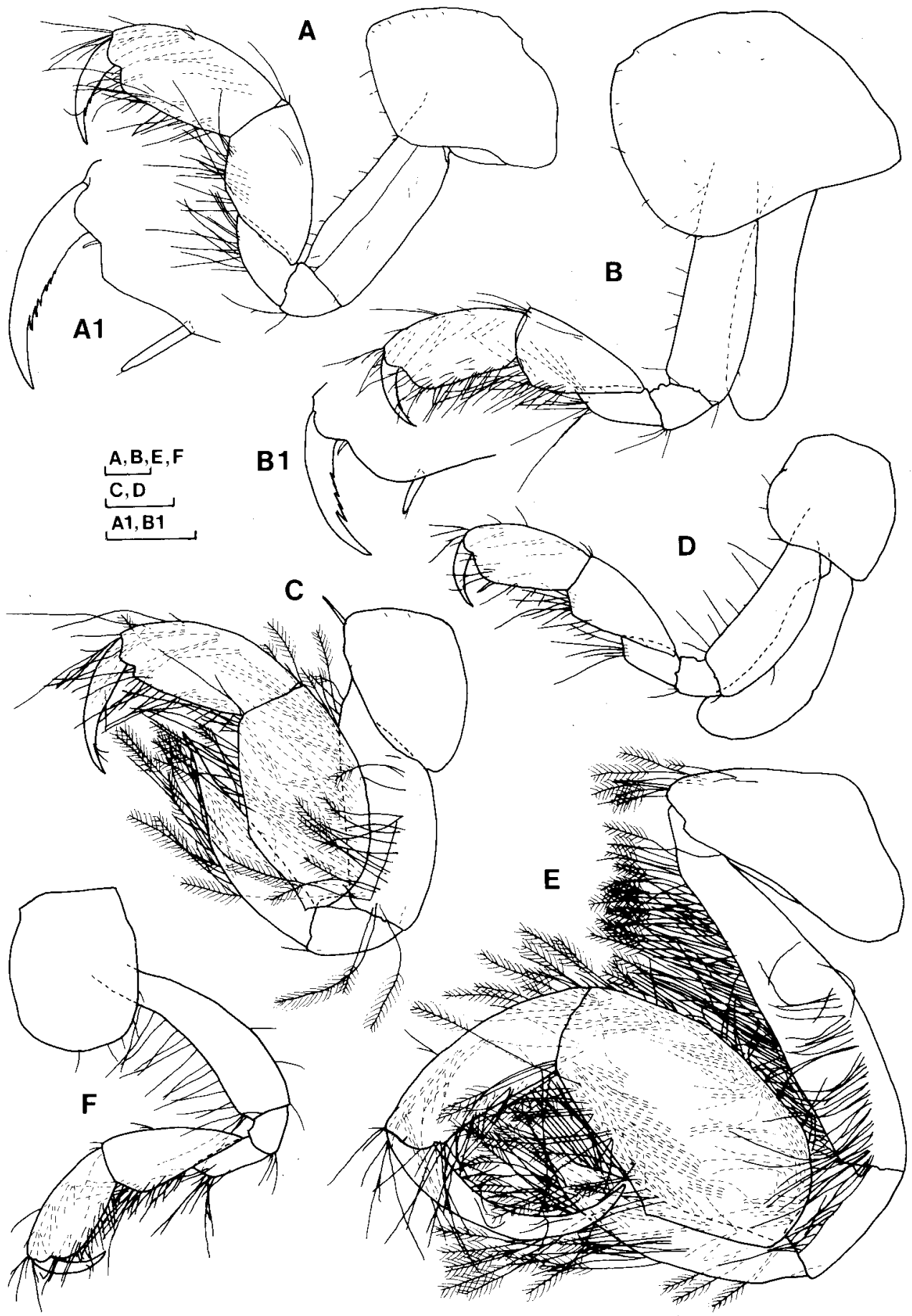

Fig. 19. Aoroides longimerus Ren and Zheng. Female(1), 4.6mm: A, gnathopod 1; A1, palm and article 7 of gnathopod 1; B, gnathopod 2 (oostegite omitted); B1, palm and article 7 of gnathopod 2. Male(4), 2.2mm: C-D, gnathopods 1-2. Male(5), 3.1 mm: E, gnathopod 1; F, gnathopod 2 (gill lost). Scale: $0.1 \mathrm{~mm}$. 
Table 4. Numbers of spines on uropod 3 rami in Aoroides longimerus Ren and Zheng.

\begin{tabular}{ccccccc}
\hline \multirow{2}{*}{ Sex } & Body length & \multicolumn{2}{c}{ Outer ramus } & & \multicolumn{2}{c}{ Inner ramus } \\
\cline { 3 - 4 } \cline { 5 - 6 } & & Left & Right & & Left & Right \\
\hline \multirow{2}{*}{ Male } & 4.2 & $3+1^{*}$ & $2+1$ & & $3+0$ & $3+0$ \\
& 3.7 & $2+1$ & $2+1$ & & $2+0$ & $3+0$ \\
& 3.6 & $1+1$ & $2+1$ & & $2+0$ & $2+0$ \\
& 3.5 & $1+0$ & $1+0$ & & $1+0$ & $1+0$ \\
& 3.1 & $2+1$ & $2+1$ & & $2+0$ & $3+0$ \\
& 2.3 & $1+1$ & $1+1$ & & $1+0$ & $1+0$ \\
& 2.2 & $1+1$ & $1+1$ & & $1+0$ & $1+0$ \\
\hline \multirow{2}{*}{ Female } & 4.6 & $3+1$ & $3+1$ & & $3+1$ & $3+1$ \\
& 4.5 & $3+1$ & $2+1$ & & $3+0$ & $3+1$ \\
& 3.7 & $2+1$ & $2+1$ & & $3+2$ & $3+2$ \\
\hline
\end{tabular}

* " $\mathrm{X}+\mathrm{Y}$ " indicates $\mathrm{X}$ marginal spines and $\mathrm{Y}$ terminal spines.

Gnathopod 1 (Fig. 17I): coxal plate medium length, depressed triangular in shape, with several plumose setae and a spine anteriorly; article 2 relatively long, anterior and lateral margins with dense plumose setae, posterior margin bare; article 3 with many plumose setae on lateral margin; article 4 lanceolate (Fig. 17I1), ventral surface with dense plumose setae; article 5 rectangular, ventral and anteroinner surfaces with dense plumose setae; article 6 elongate, slightly curved posteriorly, posterior margin bearing many simple setae, inner surface with several plumose setae; article 7 long, strongly curved, posterior margin with several simple setae.

Gnathopod 2 (Fig. 17J): coxal plate square; article 2 narrow, anterior margin with several simple and a plumose setae, posterior margin with a few short setae; article 5 longish triangular; article 6 relatively short, palm almost transverse, posterior margin setose, with a spine (Fig. 17J1); article 7 medium length, middle part of inner margin serrate.

Pereopods: pereopod 3 (Fig. 18A), coxal plate almost square, article 2 relatively narrow, anterior margin with several setae and posterior margin with a few short setae, article 5 with 2 spines on posterior margin, article 6 slender, article 7 short; pereopod 4 (Fig. 18B) almost the same as pereopod 3; pereopod 5 (Fig. 18C), article 2 rectangular, anterior margin with several short spines and posterior margin with several short setae, article 5, both middle part and distal end with 2 spines, article 7 short; pereopod 6 (Fig. 18D), article 2 rectangular, article 5 with a lateral and 2 distal spines; pereopod 7 (Figs. 18E, E1), coxal plate oval, article 2 longish oval, anterior and posterior margins with a few short setae, articles 4-6 elongate, article 6 with distal long setae.

Epimeral plates 1-3 (Fig. 18F), lower parts of plates 1-2 with a few short setae.

Pleopods (Figs. 18G-I), pleopod 2 longer than pleopod 1, peduncle of pleopod 2 longest.

Uropods: uropod 1 (Fig. 18J), peduncle shorter than both rami, with a basofacial and several dorsal spines, inter-ramal process $40 \%$ length of inner ramus; uropod 2 (Fig. 18K), distal part of peduncle with 2 spines, inter-ramal process $7 \%$ length of inner ramus; uropod 3 (Figs. 18L-M), peduncle $90 \%$ length of outer ramus, inner proximal surface and outer distal end of peduncle with 3 and 3-4 spines, respectively, inner ramus with 3 dorsal spines, outer ramus with 2-3 dorsal spines and a terminal short spine.

Telson (Fig. 18M) roundish trapezoidal in lateral view.

Female(1), 4.6mm

Gnathopod 1 (Figs. 19A, A1): coxal plate lozenge-shaped, without plumose setae; article 2 relatively stout, anterior margin with several short setae; article 5 broad; article 6 relatively long, palm angular; middle part of inner margin of article 7 denticulate.

Gnathopod 2 (Figs. 19B, B1): coxal plate very large, roundish lozenge-shaped; article 2 straight, 
with several short setae on anterior margin; article 6 relatively elongate, palm slightly oblique; inner margin of article 7 serrate.

Variation

Gnathopods of small male [male(4), 2.2mm]: gnathopod 1 (Fig. 19C), coxal plate roundish triangular, without plumose setae, article 2 wide, anterior and lateral margins with many plumose setae, articles 4-5 almost the same as the holotype, article 6 wider and article 7 shorter than the holotype; gnathopod 2 (Fig. 19D) almost the same as the holotype, except each article shorter.

Gnathopods of medium-sized male [male(5), 3.1mm]: gnathopod 1 (Fig. 19E) the same as the holotype; gnathopod 2 (Fig. 19F) almost similar, except all setae on article 2 simple.

Numbers of spines on uropod 3 rami (Table 4): outer ramus with 1-3 marginal spines and usually with a terminal spine; inner ramus with 1-3 marginal spines, in females with 0-2 terminal spines.

Coloration in life (Plate I, Fig. 5)

Dorsal part of head, anterior and posterior margins of pereonite 1, posterior margins of pereonites 2-5 and 7 (sometimes 6 also) and pleonites 1-2, ventral parts of pleonites 1-3, ventral surface of coxa 1 brown or with brown dots; other parts white. In females, whole pereonites 1-5 with brown dots.

Remarks

Morphological characters of this species well agree with the descriptions and figures of Ren and Zheng (1996). Aoroides longimerus closely resembles A. ellipticus and A. secundus in the heavily setose male gnathopod 1. However, A. longimerus can be clearly distinguished from the latter two species by the setose male coxa 1 .

For the body color of Aoroides secunda, Nagata (1965) wrote "whitish, with a speckling of small black spots, particularly along the articulate line of body segments". This description almost agrees with the color of $A$. longimerus. However, $A$. secunda sensu Nagata is different from my materials in having flagellar articles of the antenna 2 each with a long curving spine (2-4 spines in my materials) and article 3 of the mandibular palp shorter than article 2 (longer in my materials).

Habitat

Aoroides longimerus usually lives on the surface of animals (ascidians, hydroids, bryozoans and sponges) and among algae in the subtidal zone. This species also occurs under stones in the intertidal zone, though it is rare.

Distribution

Seawall of Kansai International Airport in Izumisano, Osaka Prefecture; from the mouth of the Onosato River in Han nan to Tanigawa in Misaki, Osaka Prefecture; Shirahama in Wakayama Prefecture; Dayawan in China (Ren and Zheng, 1996).

\section{Aoroides myojinensis sp. nov.}

(Plate I, Fig. 6; Text-figs. 20-24; Table 5)

(Japanese name: myoujin-burabura-sokoebi, new)

Material examined.

Holotype: male (OMNH-Ar-4199), 3.5mm, lower intertidal zone of Myojin-zaki coast in Misaki, Osaka Pref. ( $\left.34^{\circ} 19^{\prime} \mathrm{N}, 135^{\circ} 06^{\circ} \mathrm{E}\right)$, under stones, 5 May 1997. Allotype: ovigerous female (OMNH-Ar4200 ), $3.9 \mathrm{~mm}$, the same data as the holotype. Paratypes: 3 males, $3.2 \mathrm{~mm}$ (OMNH-Ar-4201), $2.8 \mathrm{~mm}$ (OMNH-Ar-4202) and 3.9mm (OMNH-Ar-4203), and 2 ovigerous females, 3.5mm (OMNH-Ar-4204) and $2.7 \mathrm{~mm}$ (OMNH-Ar-4205), the same data as the holotype. 
Male (holotype, $3.5 \mathrm{~mm}$ )

Body (Fig. 20), eyes relatively large.

Antennae: antenna 1 (Figs. 21 A, A1), ratio of peduncular articles 1-3 1:1.2:0.5, inner surface of article 1 with 6 spines, distal part of primary flagellum lost; antenna 2 (Fig. 21B) stout, setose ventrally, inner surfaces of peduncular articles 3-4 spinous, flagellum with 3 articles, articles 1-3 with 9, 2, 2 spines, respectively (Fig. 21B1).

Mouth parts: upper lip (Fig. 21C) galeate; mandible (Fig. 21D), palp article 2 with a plumose seta, article 3 with 2 simple setae (1 seta lost); maxilla 1 (Fig. 21F), palp article 2 with 7 apical spines; maxilla 2 (Fig. 21G), inner plate relatively narrow; maxilliped (Figs. 21H, H1) covered with many plumose setae, outer plate with 10 marginal spines, palp articles wide.

Gnathopod 1 (Fig. 21I): coxal plate medium length, depressed triangular in shape, without spines; article 2 with middle part broadened, anterior and lower lateral margins with dense plumose setae, posterior margin bare; article 3, lateral part with several plumose setae; article 4 falcate, gradually narrowed distally, ventrodistal margin with many plumose setae; article 5 oval, anteroinner surface with dense plumose setae, ventral and distal margins bearing many plumose setae; article 6 relatively short, posterior margin and inner surface with many plumose setae; article 7 medium in size, posterior margin with several plumose setae.

Gnathopod 2 (Fig. 22A): coxal plate a little longer than wide; gill large; article 2 curved anteriorly, anterior margin with several simple setae, posterior margin with a few short setae; article 6 relatively long, broadened distally, palm slightly oblique, defined by a spine (Fig. 22A1); article 7 long, inner margin with 4 notches.

Pereopods: pereopods 3-4 (Figs. 22B-C), coxal plates a little longer than wide, articles 2 with a few setae on anterior and posterior margins, articles 5 of pereopods $3-4$ with 5 and 7 spines, respectively (Figs. 22B1, C1); pereopod 5 (Fig. 22D), article 2 slender, with several spines on anterior margin and several short setae on posterior margin, articles 4-5, posterior margins with dense plumose setae, distal end of article 5 with 3 spines (Fig. 22D1); pereopod 6 (Fig. 22E) almost similar to

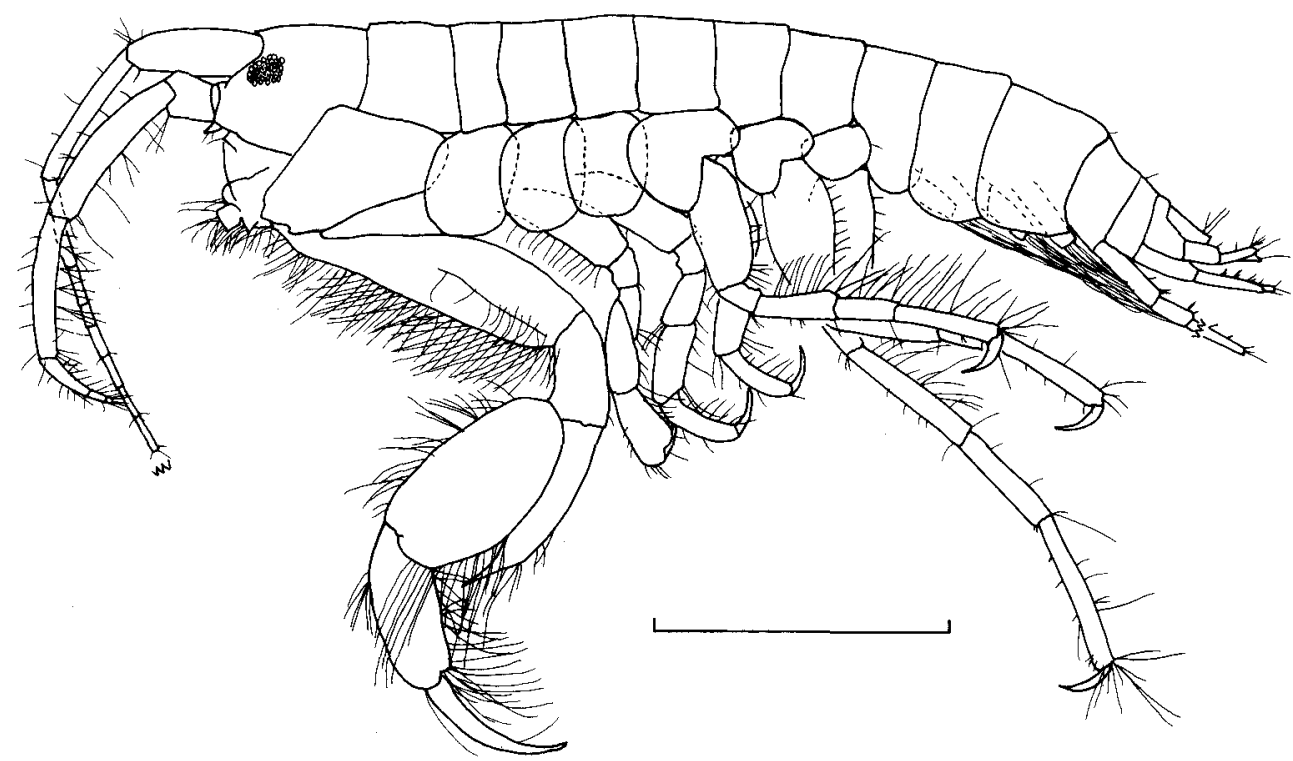

Fig.20. Aoroides myojinensis sp. nov. Male (holotype), $3.5 \mathrm{~mm}$. Scale: $1 \mathrm{~mm}$. 


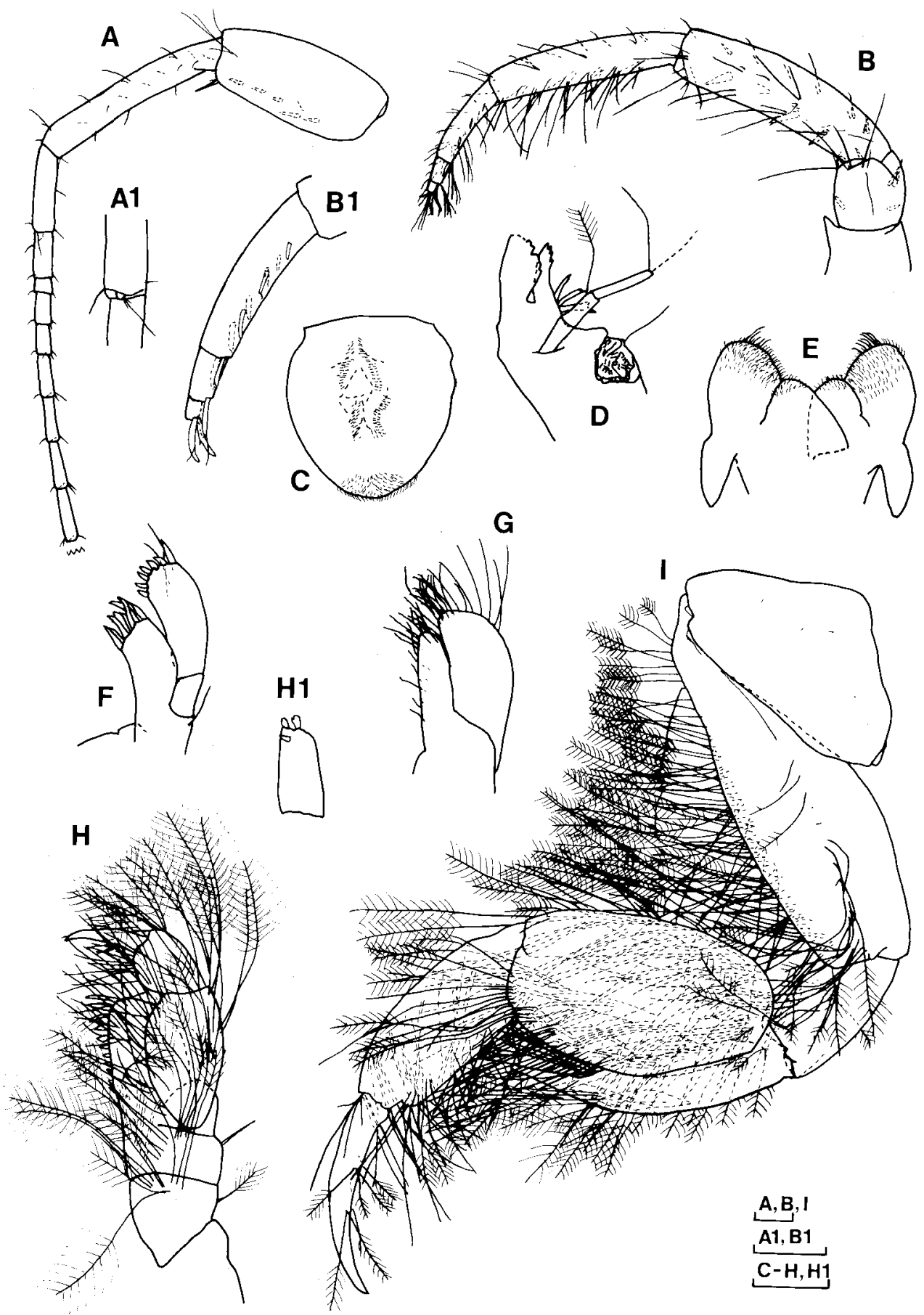

Fig. 21. Aoroides myojinensis sp. nov. Male (holotype), 3.5mm: A, antenna 1; A1, accessory flageilum; B, antenna 2; B1, tip of antenna 2; C, upper lip; D, mandible; E, lower lip; F, maxilla 1; G, maxilla $2 ; \mathrm{H}$, maxilliped; $\mathrm{H} 1$, inner plate of maxilliped; I, gnathopod 1 . Scale: $0.1 \mathrm{~mm}$. 


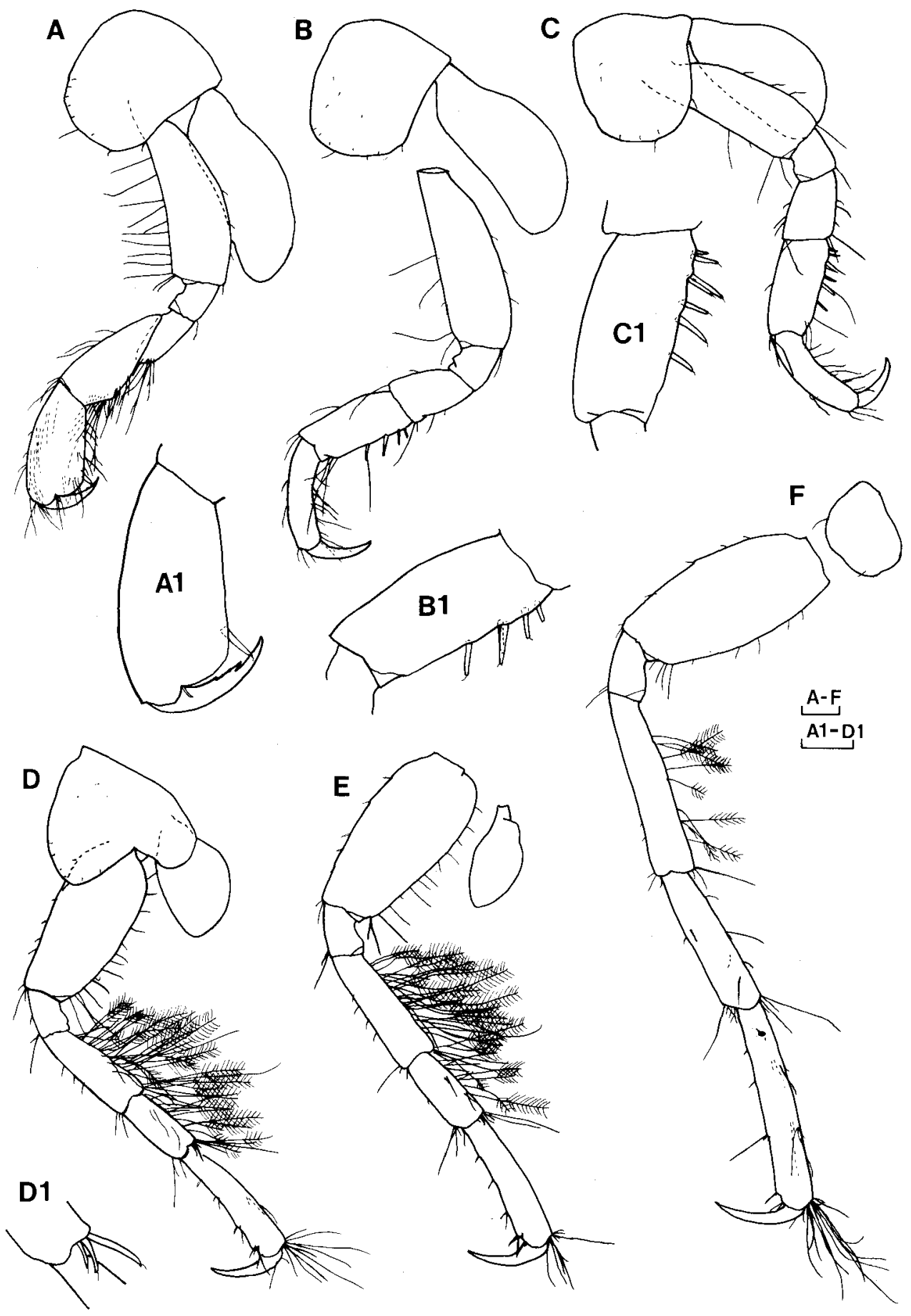

Fig. 22. Aoroides myojinensis sp. nov. Male (holotype), 3.5mm: A, gnathopod 2; A1, articles 6-7 of gnathopod 2; B, pereopod 3; B1, article 5 of pereopod 3; C, pereopod 4; $\mathrm{Cl}$, article 5 of pereopod 4; D, pereopod 5; D1, distal end of pereopod 5 article 5; E, pereopod 6 (coxal plate damaged); F, pereopod 7. Scale: $0.1 \mathrm{~mm}$. 

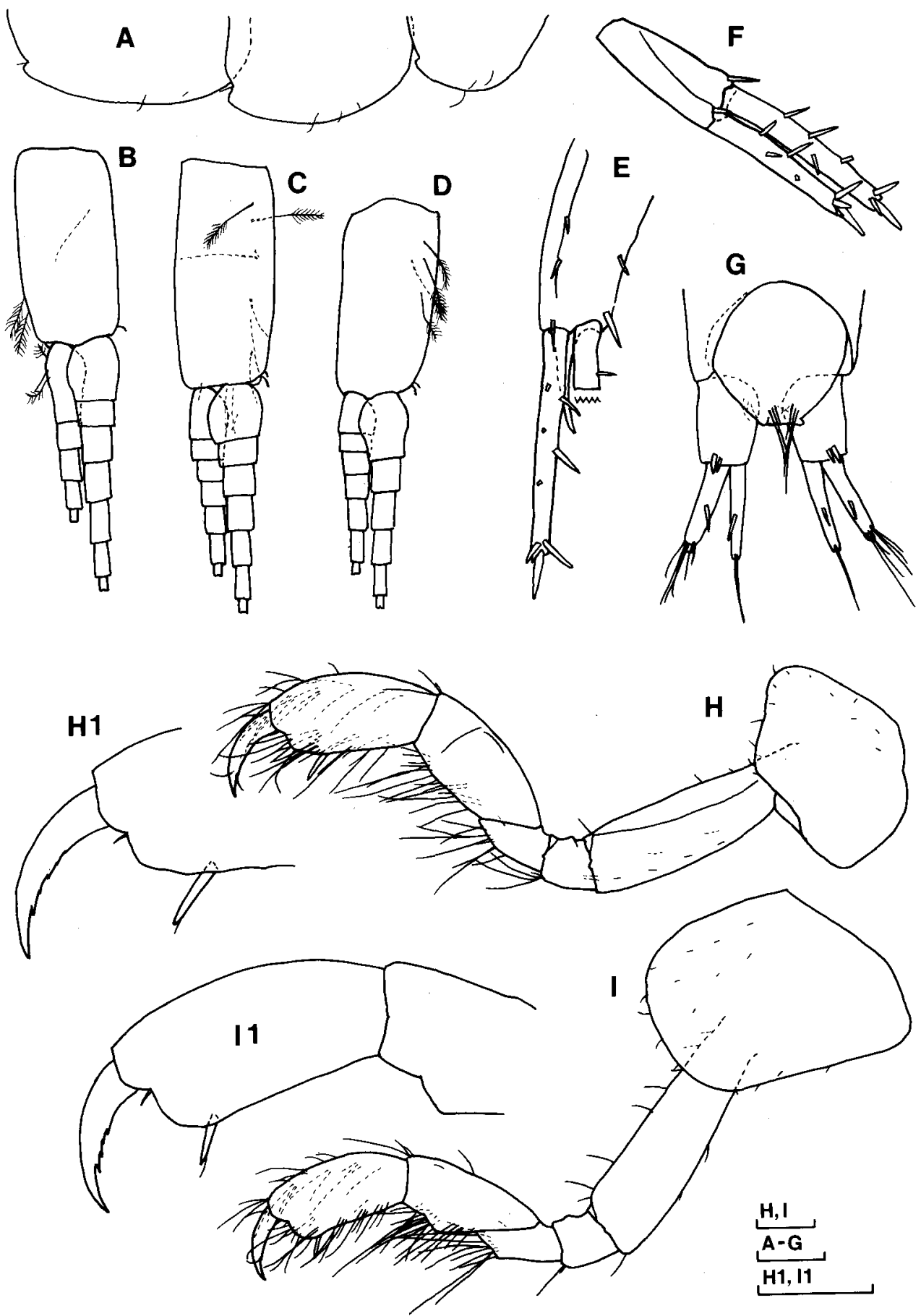

Fig. 23. Aoroides myojinensis sp. nov. Male (holotype), 3.5mm: A, epimeral plates 1-3; B-D, pleopods 1-3; E-F, uropods 1-2; G, telson and uropod 3. Female (allotype), 3.9mm: H, gnathopod 1; H1, palm and article 7 of gnathopod 1; I, gnathopod 2 (gill lost, oostegite omitted); I1, distal part of gnathopod 2. Scale: $0.1 \mathrm{~mm}$. 

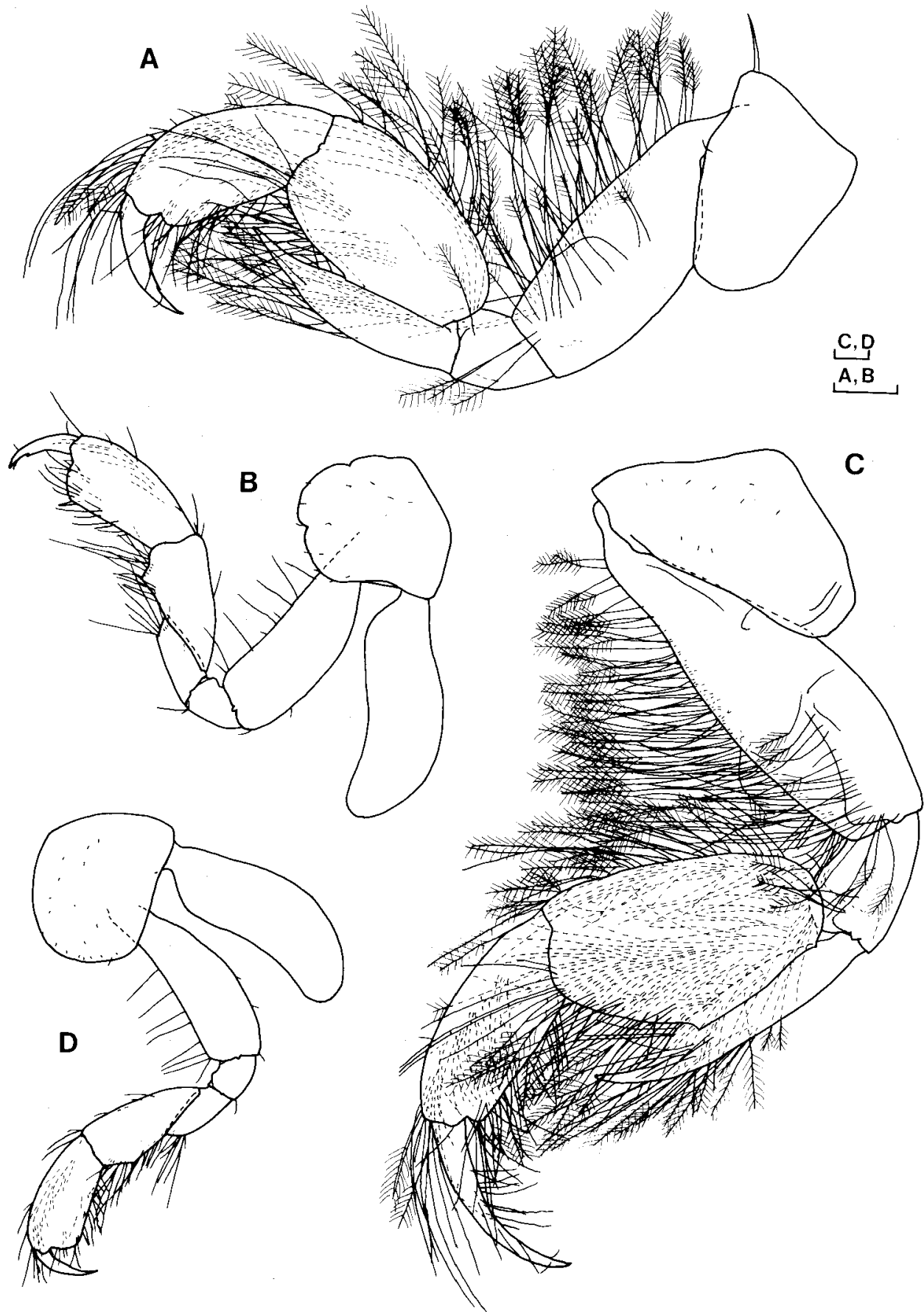

Fig. 24. Aoroides myojinensis sp. nov. Male (paratype 2), 2.8mm: A-B, gnathopods 1-2. Male (paratype 3), 3.9mm: C-D, gnathopods $1-2$. Scale: $0.1 \mathrm{~mm}$. 
Table 5. Numbers of spines on uropod 3 rami in Aoroides myojinensis sp. nov.

\begin{tabular}{ccccccc}
\hline \multirow{2}{*}{ Sex } & Body length & \multicolumn{2}{c}{ Outer ramus } & & \multicolumn{2}{c}{ Inner ramus } \\
\cline { 3 - 4 } \cline { 6 - 7 } & $(\mathrm{mm})$ & Left & Right & & Left & Right \\
\hline \multirow{2}{*}{ Male } & 3.9 & $0+0^{*}$ & $0+0$ & & $2+0$ & $2+0$ \\
& 3.5 & $1+0$ & $1+0$ & & $1+0$ & $1+0$ \\
& 3.2 & $0+0$ & $1+0$ & & $1+0$ & $1+0$ \\
& 2.8 & $0+1$ & $0+1$ & & $1+0$ & $1+0$ \\
\hline \multirow{2}{*}{ Female } & 3.9 & $0+1$ & $1+1$ & & $3+0$ & $2+1$ \\
& 3.5 & $0+1$ & $0+1$ & & $2+0$ & $2+0$ \\
& 2.7 & $0+0$ & $0+0$ & & $1+0$ & $1+0$ \\
\hline
\end{tabular}

* " $\mathrm{X}+\mathrm{Y}$ " indicates $\mathrm{X}$ marginal spines and $\mathrm{Y}$ terminal spines.

pereopod 5; pereopod 7 (Fig. 22F), coxal plate galeate, article 2 slender, posterior margin of article 4 with several plumose setae, article 6 , anterior margin with a few marginal spines, distal end setose.

Epimeral plates 1-3 (Fig. 23A) with a few setae on lower margins.

Pleopods (Figs. 23B-D), peduncles long; pleopod 1 same length as pleopod 2.

Uropods: uropod 1 (Fig. 23E), inter-ramal process about $45 \%$ length of outer ramus, most of inner ramus lost; uropod 2 (Fig. 23F), inter-ramal process $6 \%$ length of inner ramus, distal end of peduncle with 2 spines; uropod 3 (Fig. 23G), peduncle short, 75\% length of outer ramus, distal end with 2 spines, both rami with a marginal spine.

Telson (Fig. 23G) subrounded in dorsal view.

Female (allotype, $3.9 \mathrm{~mm}$ )

Gnathopod 1 (Figs. 23H, H1): coxal plate lozenge-shaped; article 2 slender; article 4 triangular; palm angular; inner margin of article 7 with 5 notches.

Gnathopod 2 (Figs. 23I, I1): coxal plate roundish trapezoidal; article 2 slender; middle part of article 5 broadened; palm slightly oblique; inner margin of article 7 with 4 notches.

\section{Variation}

Gnathopods of small male (paratype 2, 2.8mm): gnathopod 1 (Fig. 24A), coxal plate with an anterior spine, shape of each article almost similar to the holotype, but articles 2 and 6 broader, density of setae higher than the holotype; gnathopod 2 (Fig. 24B) subequal to the holotype.

Gnathopods of large male (paratype 3,3.9mm; Figs. 24C-D) similar to the holotype.

Numbers of spines on uropod 3 rami (Table 5): outer ramus with 0-1 marginal spine and sometimes with a terminal spine; inner ramus with 1-3 marginal spines and almost without a terminal spine.

\section{Coloration in life (Plate I, Fig. 6)}

Pereonites 1-5 and posterior part of pereonite 7 with brown dots; lower parts of pereonite 7 and pleonites 1-2 (sometimes 3 also) brown; coxa 1 also brown; other parts white. In females, coxae 1-5 also with brown dots.

Etymology

Referring to the type locality (Myojin-zaki).

Remarks

The heavily setose maxilliped of Aoroides myojinensis sp. nov. is a unique character in the genus Aoroides. This species has a densely setose male gnathopod 1 and a very short inter-ramal process of uropod 2 as in A. ellipticus, A. longimerus, and A. secundus. Aoroides myojinensis is different from $A$. 
ellipticus and A. longimerus in having the smaller article 5 and shorter article 6 of male gnathopod 1 , and the plumose setae on pereopods 5-7. Aoroides myojinensis can be distinguished from A. secundus by the presence of marginal spines on the uropod 3 inner ramus.

Habitat

Aoroides myojinensis occurs under stones in the lower intertidal zone.

Distribution

Myojin-zaki coast in Misaki, Osaka Prefecture.

Aoroides punctatus sp. nov.

(Plate I, Fig. 7; Text-figs. 25-29; Table 6)

(Japanese name: gomafu-burabura-sokoebi, new)

Aoroides columbiae: Kim and Kim, 1987, pp. 5-6, fig. 4; (not Walker, 1898, p. 285, pl. 16, figs. 7-10)

Aoroides sp. 1 Ishimaru, 1990, pp. 211-212, fig. 2.

Material examined.

Holotype: male (OMNH-Ar-4206), 3.6mm, rearing tank in OPFES in Misaki, Osaka Pref. (34 $\left.{ }^{\circ} 19^{\prime} \mathrm{N}, 135^{\circ} 07^{\prime} \mathrm{E}\right), 11$ Jun. 1996. Allotype: female (OMNH-Ar-4207), 4.3mm, among a brown alga Sargassum muticum (1m depth) at Tanigawa in Misaki, Osaka Pref., 21 Mar. 1996. Paratypes: 3 males, $3.9 \mathrm{~mm}$ (OMNH-Ar-4208), 2.8mm (OMNH-Ar-4209) and 3.3mm (OMNH-Ar-4210), and 1 ovigerous female, $3.2 \mathrm{~mm}(\mathrm{OMNH}-\mathrm{Ar}-4211)$, the same data as the holotype.

Materials from Kyushu (undissected): 2 males, $1.7 \mathrm{~mm}, 4.3 \mathrm{~mm}$, and 7 ovigerous females, 2.0 3.2mm (AMBL-Amph. 146), among a brown alga Sargassum sp. outside of Tomoezaki in Tomioka, Kumamoto Pref., Mar. 1981, collected by K. Imada, identified as Aoroides columbiae.

Male [based on holotype, $3.6 \mathrm{~mm}$, and paratype 1, 3.9mm (mandible and epimeral plates 1-3)]

Body (Fig. 25), eyes medium size.

Antennae: antenna 1 (Figs. 26A, A1), ratio of peduncular articles 1-3 1:1.2:0.4, ventral surface of article 1 setose, primary flagellum with 19 medium and 1 short articles; antenna 2 (Fig. 26B) stout, about half length of antenna 1 , ventral and inner surfaces heavily setose, flagellum short, with 2 articles, tip of flagellum with 3 curved spines (Fig. 26B1).

Mouth parts: upper lip (Fig. 26C) galeate; mandible (Fig. 26D), tip of palp with 2 setae; maxilla 1 (Fig. 26F), palp article 2 with 8 apical spines; maxilla 2 (Fig. 26G), inner plate relatively narrow; maxilliped (Fig. 26H), outer plate wide, with 12 marginal spines, palp articles wide.

Gnathopod 1 (Fig. 26I): coxal plate depressed, with a long spine anteriorly; article 2, lateral margin with dense simple setae, anterior margin with a few tiny setae, posterior margin bare; article 3 setose posterodistally; article 4, proximal two thirds wide and distal third narrow, ventral surface with obtuse process and many simple setae; article 5 rectangular, ventral margin and inner ventral surface setose; article 6 elongate, posterior margin and anterodistal corner bearing many setae; article 7 long, strongly curved.

Gnathopod 2 (Fig. 26J): coxal plate roundish triangular; gill large; article 2 almost straight, anterior margin with a few short setae, posterior margin bare; article 4 trapezoidal; article 5 wide, posterior margin with many serrated setae (Fig. 26J1); article 6 relatively short, palm slightly oblique, defined by a short spine (Fig. 26J2); article 7 long, inner margin with many notches.

Pereopods: pereopods 3-4 (Figs. 27A-B), coxal plates longish, articles 2 wide, anterior margins with a few short setae, articles 3-5 relatively broad, articles 7 short; pereopod 5 (Fig. 27C), article 2 oval, with a few spines on anterior margin, articles 4-5 short, both middle part and distal end of article 


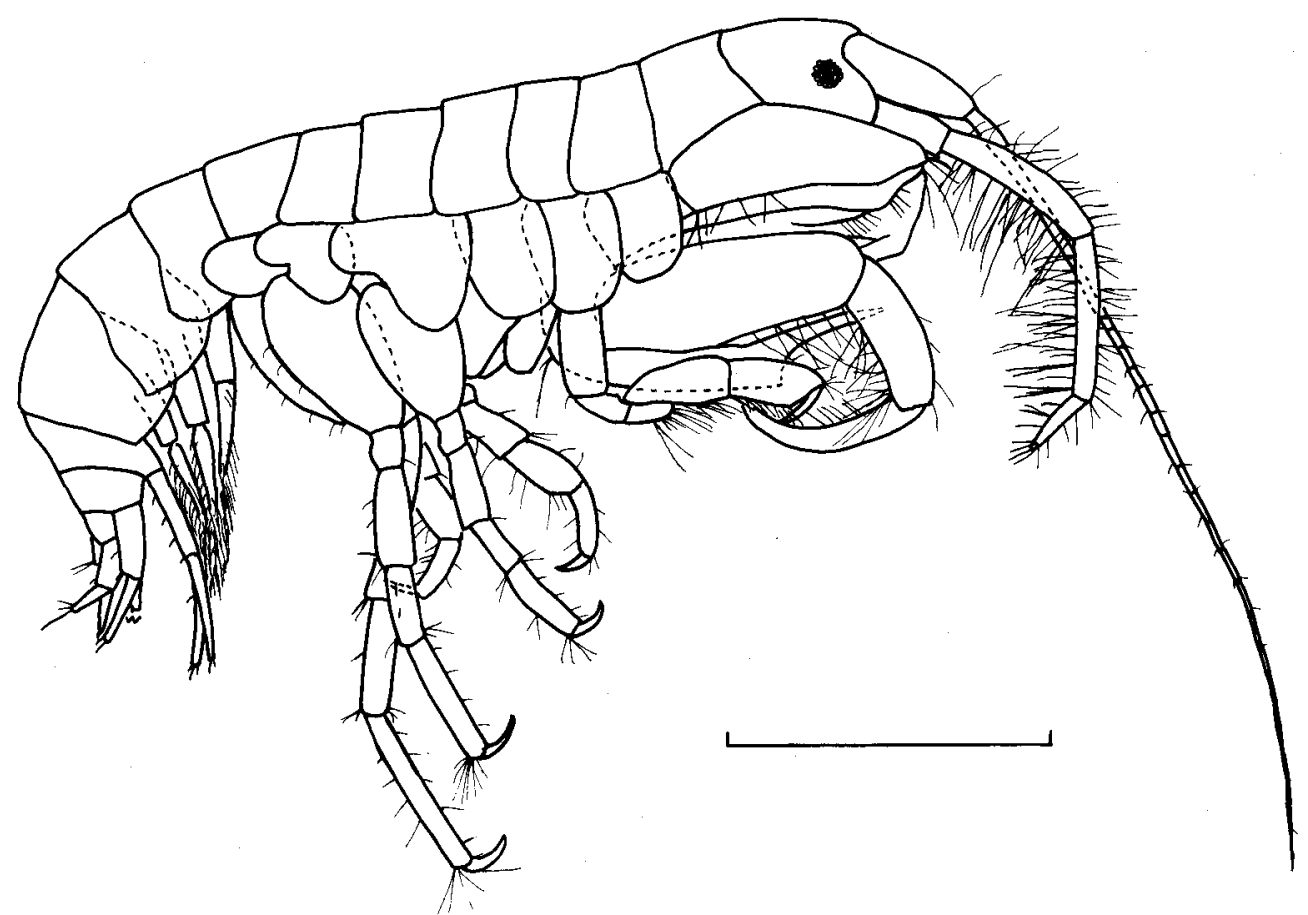

Fig. 25. Aoroides punctatus sp. nov. Male (holotype), 3.6mm. Scale: $1 \mathrm{~mm}$.

5 with 3 spines (Fig. 27C1); pereopod 6 (Fig. 27D), article 2 ovoid, articles 4-6 with 2, 5 and a row of spines, respectively; pereopod 7 (Fig. 27E) elongate, coxal plate oval, article 2 relatively broad, with several short setae, article 4 with 3 spines on posterior margin, articles 5-6 with several marginal spines, distal end of article 6 with long setae.

Pleopods (Figs. 27G-I), pleopod 1 subequal length to pleopod 2, pleopod 3 short.

Uropods: uropod 1 (Fig. 28A), peduncle subequal length to rami, with a basofacial spine and 9 dorsal spines, inter-ramal process $35 \%$ length of inner ramus; uropod 2 (Fig. 28B), inter-ramal process $10 \%$ length of inner ramus, dorsal surface of peduncle with 3 spines; uropod 3 (Fig. 28C), peduncle a little longer than outer ramus, both inner proximal surface and distal end of peduncle with 2 spines, respectively, both rami without spines.

Telson (Fig. 28C) roundish triangular in dorsal view.

Female (allotype, $4.3 \mathrm{~mm}$ )

Gnathopod 1 (Figs. 28D, D1): coxal plate lozenge-shaped; article 2 stout, with a few setae on lateral margin; article 5 relatively short, triangular; palm angular; inner margin of article 7 serrate.

Gnathopod 2 (Figs. 28E, E1) similar to gnathopod 1; coxal plate roundish; article 2 relatively short, with a few short setae anteriorly; article 5 rather short, triangular; palm almost transverse; inner margin of article 7 with 3 notches.

\section{Variation}

Flagellum of antenna 2 (paratype 2, 2.8mm; Fig. 29A) consists of 3 articles, both articles 2-3 with 2 curved spines (other dissected materials except for the holotype also the same). 


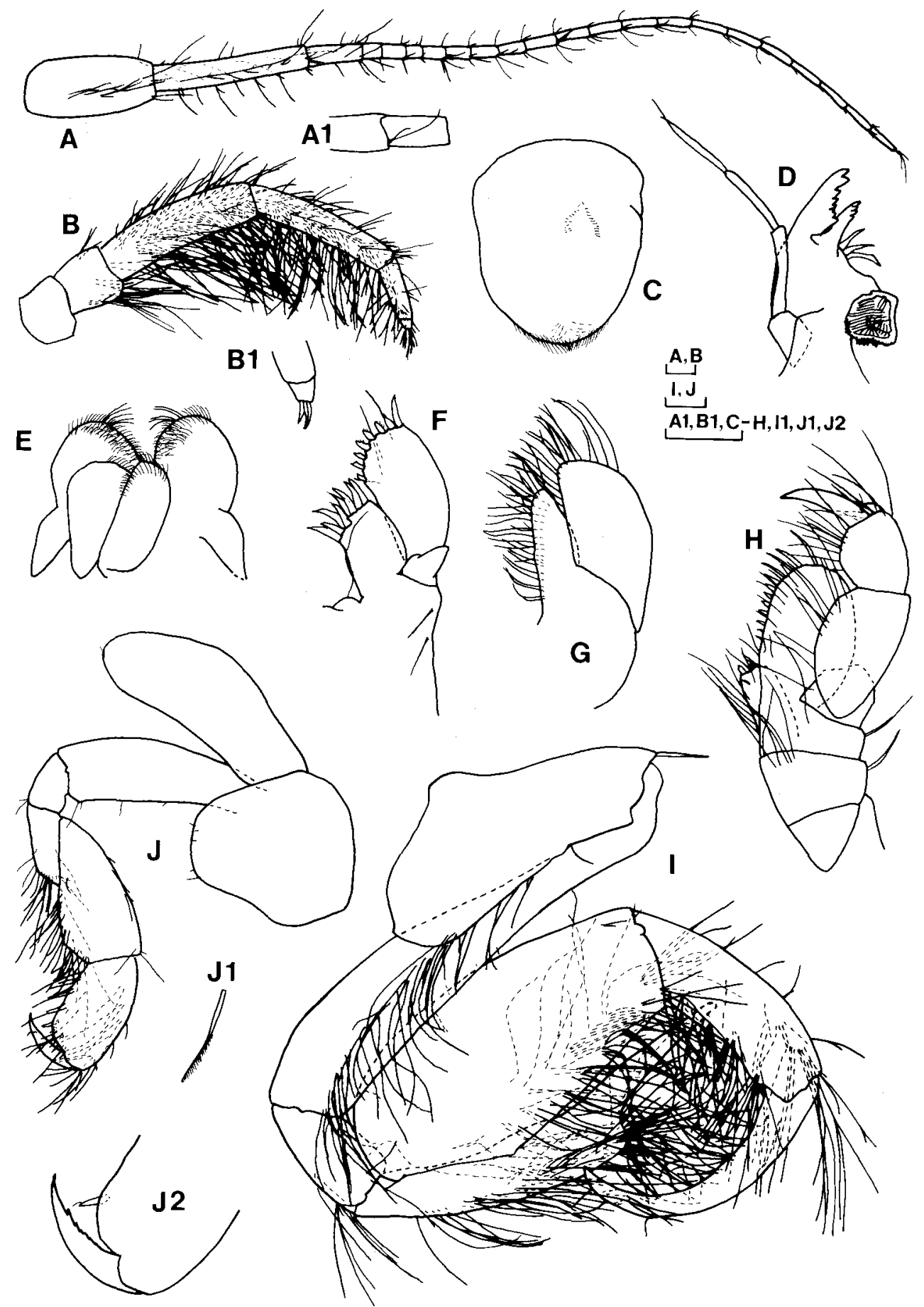

Fig. 26. Aoroides punctatus sp. nov. Male (holotype), 3.6mm: A, antenna 1; A1, accessory flagellum; $\mathrm{B}$, antenna 2; B1, tip of antenna 2; C, upper lip; E, lower lip; F, maxilla 1; G, maxilla 2; H, maxilliped; I, gnathopod 1; J, gnathopod 2; J1, seta of gnathopod 2 article 5; J2, palm and article 7 of gnathopod 2. Male (paratype 1), $3.9 \mathrm{~mm}$ : D, mandible. Scale: $0.1 \mathrm{~mm}$. 


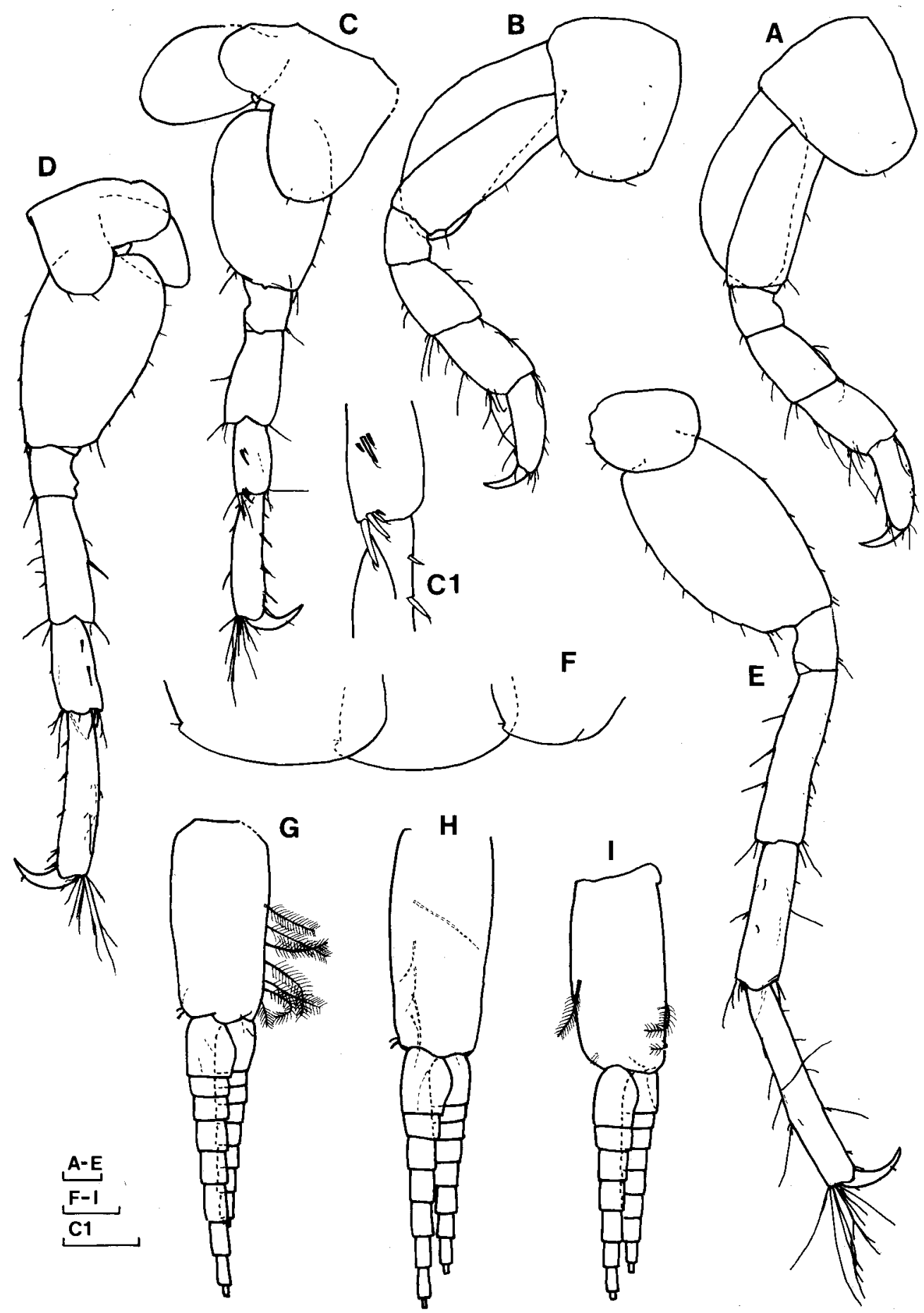

Fig. 27. Aoroides punctatus sp. nov. Male (holotype), 3.6mm: A-C, pereopods 3-5; C1, distal end of pereopod 5 article 5; D-E, pereopods 6-7; G-I, pleopods 1-3. Male (paratype 1), $3.9 \mathrm{~mm}$ : F, epimeral plates $1-3$. Scale: $0.1 \mathrm{~mm}$. 

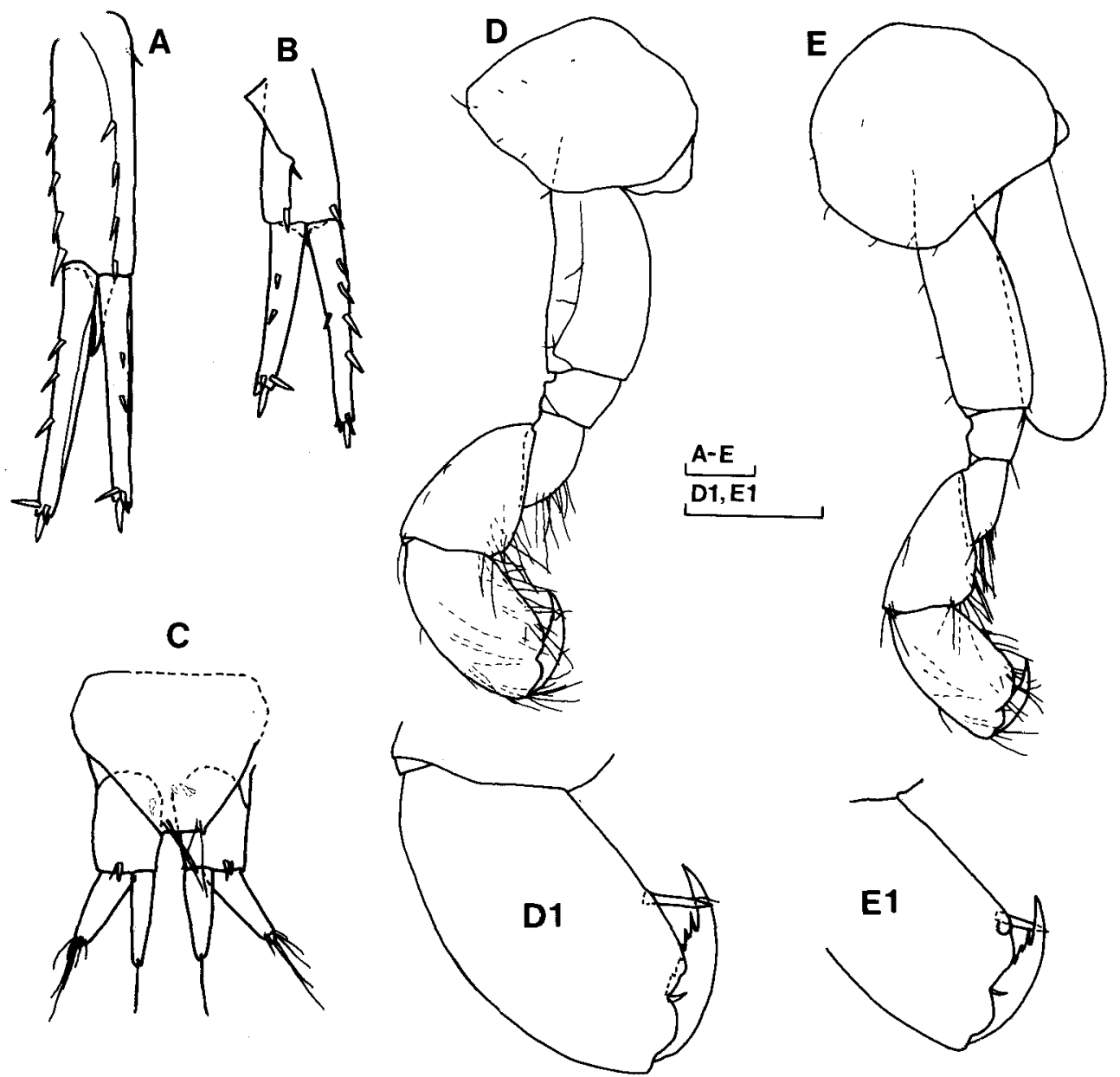

Fig. 28. Aoroides punctatus sp. nov. Male (holotype), 3.6mm: A-B, uropods 1-2; C, telson and uropod 3. Female (allotype), 4.3mm: D, gnathopod 1; D1, articles 6-7 of gnathopod 1; I, gnathopod 2 (oostegite omitted); I1, palm and article 7 of gnathopod 2. Scale: $0.1 \mathrm{~mm}$.

Gnathopods of small male (paratype 2, 2.8mm): gnathopod 1 (Fig. 29B), coxal plate trapezoidal, with a short anterior spine, each article shorter and broader than the holotype, setae fewer; gnathopod 2 (Fig. 29C) subequal to the holotype.

Gnathopods of large male (paratype 1, 3.9mm; Figs. 29D-E) almost the same as the holotype.

Numbers of spines on uropod 3 rami (Table 6): both rami without marginal spines; outer ramus often with a terminal spine in males, always with a terminal spine in females; inner ramus often with a terminal spine in females.

Coloration in life (Plate I, Fig. 7)

Whole the body surfaces (including appendages) are scattered with small black dots. 

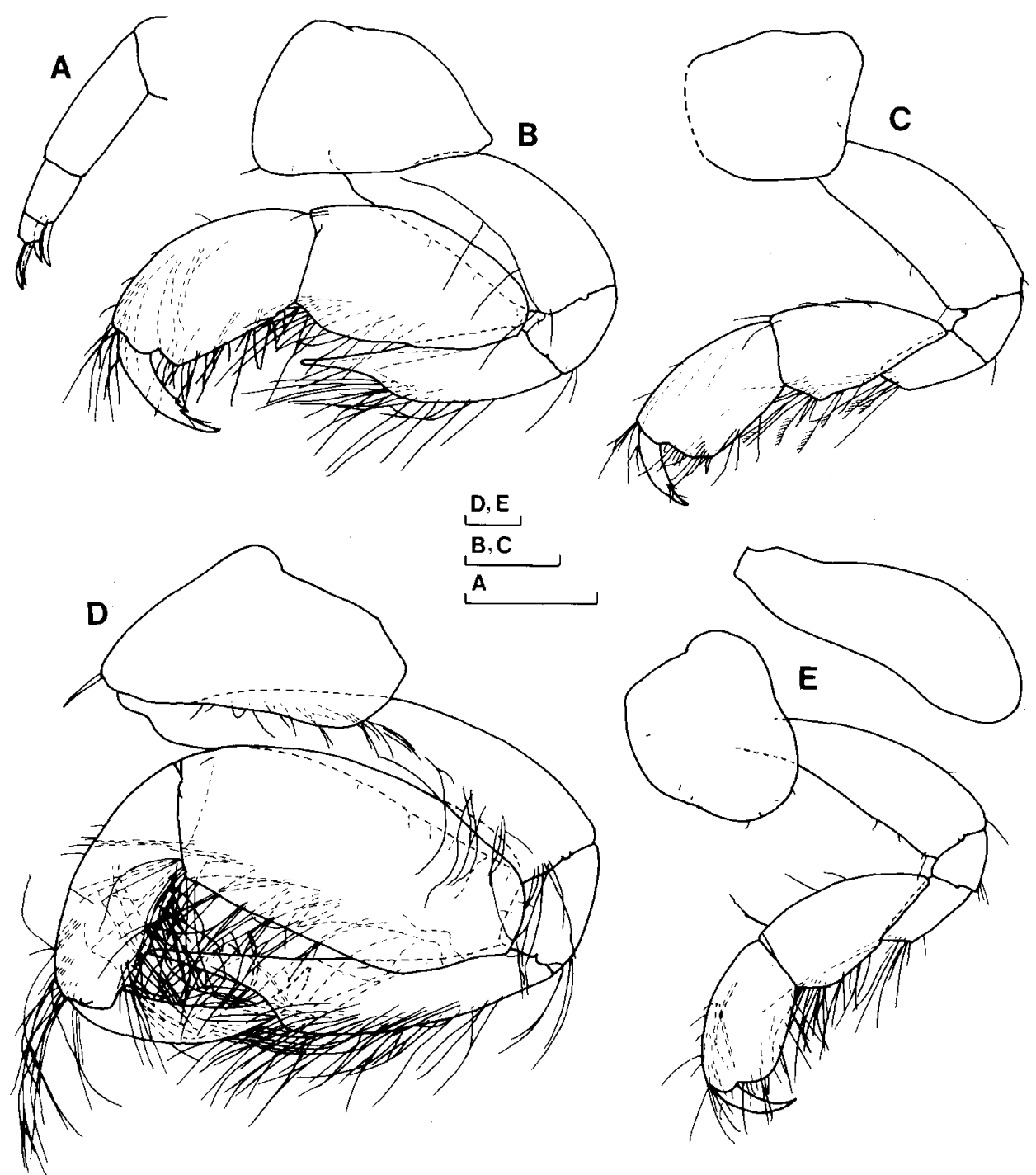

Fig. 29. Aoroides punctatus sp. nov. Male (paratype 2), 2.8mm: A, flagellum of antenna 2; B, gnathopod 1; C, gnathopod 2 (gill lost). Male (paratype 1), 3.9mm: D-E, gnathopods 1-2. Scale: $0.1 \mathrm{~mm}$.

Etymology

From the Latin punctatus (= studded with points), referring to the body coloration.

\section{Remarks}

This new species is characterized by the male gnathopod 1, which has (1) depressed triangular coxa, (2) laterally setose and posterior bared article 2, (3) distally narrowed article 4 with obtuse process ventrally, and (4) posteriorly setose articles 5-7. All other known Aoroides species do not have such a gnathopod 1.

Aoroides columbiae reported from Korea by Kim and Kim (1987) has a similar male gnathopod 1 to the present new species, and other characters of that species are almost the same as A. punctatus sp. 
Table 6. Numbers of spines on uropod 3 rami in Aoroides punctatus sp. nov.

\begin{tabular}{ccccccc}
\hline \multirow{2}{*}{ Sex } & \multirow{2}{*}{$\begin{array}{c}\text { Body length } \\
\end{array}$} & \multicolumn{2}{c}{ Outer ramus } & & \multicolumn{2}{c}{ Inner ramus } \\
\cline { 7 - 7 } \cline { 5 - 6 } & $(\mathrm{mm})$ & Left & Right & & Left & Right \\
\hline \multirow{2}{*}{ Male } & 3.9 & $0+0^{*}$ & $0+0$ & & $0+0$ & $0+0$ \\
& 3.6 & $0+0$ & $0+0$ & & $0+0$ & $0+0$ \\
& 3.3 & $0+0$ & $0+1$ & & $0+0$ & $0+0$ \\
& 2.8 & $0+1$ & $0+1$ & & $0+0$ & $0+0$ \\
\hline \multirow{2}{*}{ Female } & 4.3 & $0+1$ & $0+1$ & & $0+0$ & damaged \\
& 3.2 & $0+1$ & $0+1$ & & $0+1$ & $0+1$ \\
\hline
\end{tabular}

* " $\mathrm{X}+\mathrm{Y}$ " indicates $\mathrm{X}$ marginal spines and $\mathrm{Y}$ terminal spines.

nov. Although they stated that "inner ramus of uropod 3 bears 2 spines", the uropod 3 in their figure looks like uropod 2. It is possible that they mistook uropod 2 for uropod 3. Aoroides sp. 1 from Ishikawa Prefecture by Ishimaru (1990) also seems to be A. punctatus, as the shape of gnathopod 1 and the body coloration are closely alike.

I examined Aoroides punctatus from brown alga in Tomioka, west Kyushu. Hirayama (1984)'s materials of $A$. columbiae were collected from the sediment bottom (Hirayama, 1983), therefore his $A$. columbiae does not include this species because of different habitat.

Habitat

Aoroides punctatus occurs among algae and hydroids in the upper subtidal zone.

Distribution

Seawall of Kansai International Airport in Izumisano, Osaka Prefecture; from Tanigawa in Misaki, Osaka Prefecture to Oura in Hidaka, Wakayama Prefecture; Tomioka in Kumamoto Prefecture; Noto in Ishikawa Prefecture (Ishimaru, 1990); Cheju Island in Korea (Kim and Kim, 1987).

Aoroides rubellus sp. nov.

(Plate I, Fig. 8; Text-figs. 30-34; Table 7)

(Japanese name: akaobi-burabura-sokoebi, new)

Material examined.

Holotype: male (OMNH-Ar-4212), 4.7mm, from the shell surface of an abalone Nordotis madaka (3m depth) off Tanigawa in Misaki, Osaka Pref. ( $\left.34^{\circ} 19^{\prime} \mathrm{N}, 135^{\circ} 07^{\prime} \mathrm{E}\right), 9$ Apr. 1996. Allotype: ovigerous female (OMNH-Ar-4213), 5.0mm, from the surface of an ascidian Halocynthia hispida (5m depth), off Tanigawa in Misaki, Osaka Pref., 18 Mar. 1994. Paratypes: 2 males, 3.1mm (OMNH-Ar4214) and $2.7 \mathrm{~mm}$ (OMNH-Ar-4215), from the surface of an ascidian Halocynthia hispida (5m depth), off Tanigawa in Misaki, Osaka Pref., 29 May 1996; 1 male (OMNH-Ar-4216), 3.6mm, from the shell surface of a sea snail Turbo cornutus ( $2 \mathrm{~m}$ depth), off Tanigawa in Misaki, Osaka Pref., 10 May 1996; 1 female (OMNH-Ar-4217), 4.5mm, rearing tank in OPFES in Misaki, Osaka Pref., 12 May 1996.

Male (holotype, $4.7 \mathrm{~mm}$ )

Body (Fig. 30), eyes medium size.

Antennae: antenna 1 (Figs. 31 A, A1, A2), ratio of peduncular articles 1-3 1:1.4:0.4, inner ventral surface of article 1 spinous, primary flagellum with 24 medium and 1 short articles; antenna 2 (Fig. 31B) slender, setose, about 55\% length of antenna 1, inner surface of peduncular articles 3-4 spinous (Fig. 31B1), flagellum narrow, with 3 articles, articles $1-3$ with 3, 2, 2 curved spines, respectively (Fig. 


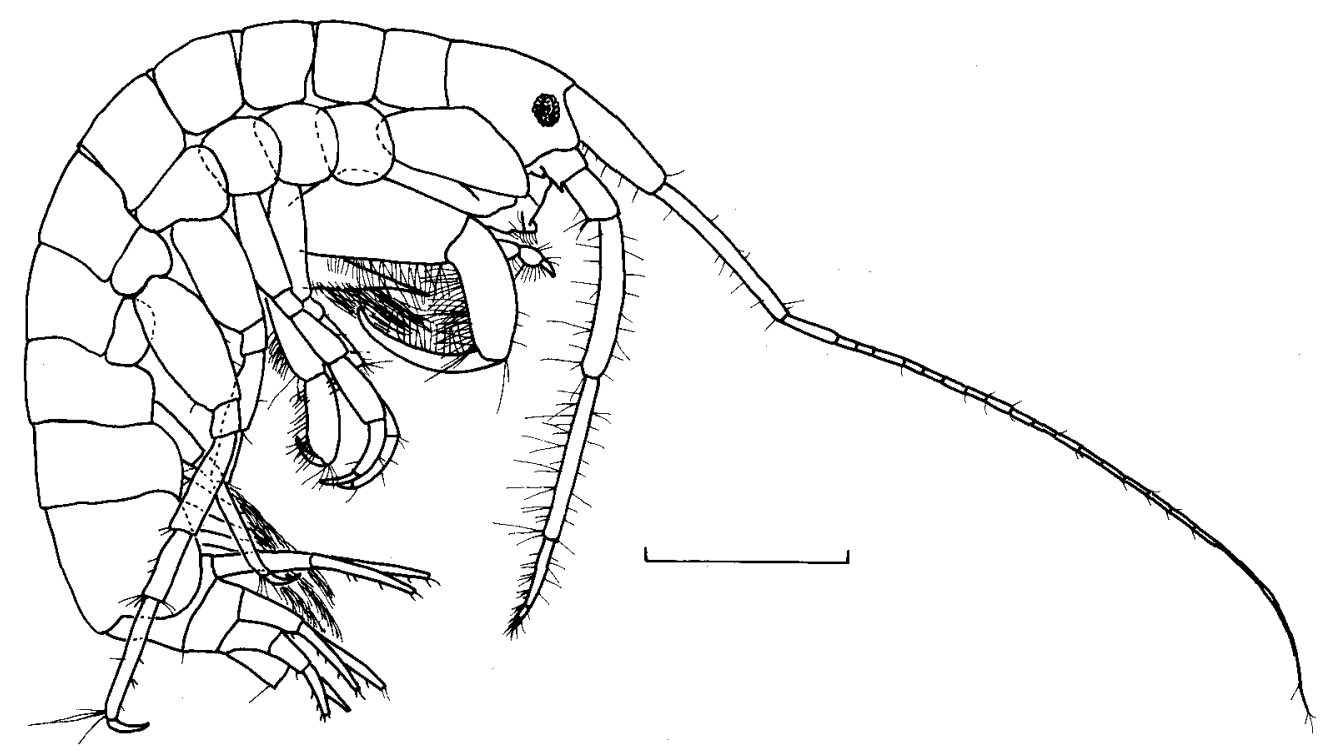

Fig. 30. Aoroides rubellus sp. nov. Male (holotype), $4.7 \mathrm{~mm}$. Scale: $1 \mathrm{~mm}$.

31B2).

Mouth parts: upper lip (Fig. 31C) roundish triangular; mandible (Fig. 31D), palp with 2 terminal setae; lower lip (Fig. 31E), inner lobe large; maxilla 1 (Fig. 31F), palp article 1 with a seta, palp article 2 with 7 apical spines; maxilla 2 (Fig. 31G) with relatively many setae; maxilliped (Figs. 31H, H1), outer plate broad, with 10 marginal spines, palp articles medium width.

Gnathopod 1 (Fig. 31I): coxal plate depressed triangular, with a long spine anteriorly; article 2 broadened distally, anterior and lateral margins with several short setae, posterior margin bare; article 3 with a short seta on posterodistal corner; article 4 (Fig. 31I1) lanceolate, ventral surface with many plumose setae; article 5 longish ovate, ventral surface with many plumose setae; article 6 elongate, posterior surface bearing many simple setae; article 7 long, posterior margin densely setose.

Gnathopod 2 (Fig. 32A): coxal plate roundish square; gill large; article 2 curved anteriorly, anterior and posterior margins with several short setae; article 4 trapezoidal, ventrodistal corner with long setae; article 5 elongate; article 6 long, palm oblique, defined by a spine (Fig. 32A1); article 7 long, inner margin slightly serrate.

Pereopods: pereopods 3-4 (Figs. 32B-C), articles 2 wide, anterior margins with several short setae, posterior margins with a few minute setae, article 5 of pereopod 4 with 3 spines on posterior margin, articles 6 curved posteriorly, articles 7 relatively long; pereopod 5 (Fig. 32D), article 2 roundish rectangular, with several minute setae on anterior and posterior margins, article 5, proximal part, middle part and distal end with 1, 2, 3 spines, respectively; pereopod 6 (Fig. 32E), article 2 roundish rectangular, article 5 with 5 spines; pereopod 7 (Fig. 32F) elongate, coxal plate trapezoidal, article 2 roundish square, with several short setae marginally, articles 4-6 slender, posterodistal end of article 6 with many long setae, article 7 long.

Pleopods (Figs. 33B-D), pleopod 1 same length as pleopod 2, peduncle of pleopod 2 longest.

Uropods: uropod 1 (Fig. 33E), peduncle same length as outer ramus, shorter than inner ramus, with 2 basofacial spines, inter-ramal process $26 \%$ length of inner ramus, dorsal surface of peduncle and both rami heavily spinous; uropod 2 (Fig. 33F), inter-ramal process $3 \%$ length of inner ramus, dorsodistal surface of peduncle with 2 spines, dorsal surface of both rami with many spines; uropod 3 (Figs. 33G-H), peduncle 75\% length of outer ramus, inner proximal surface and outer distal end of 


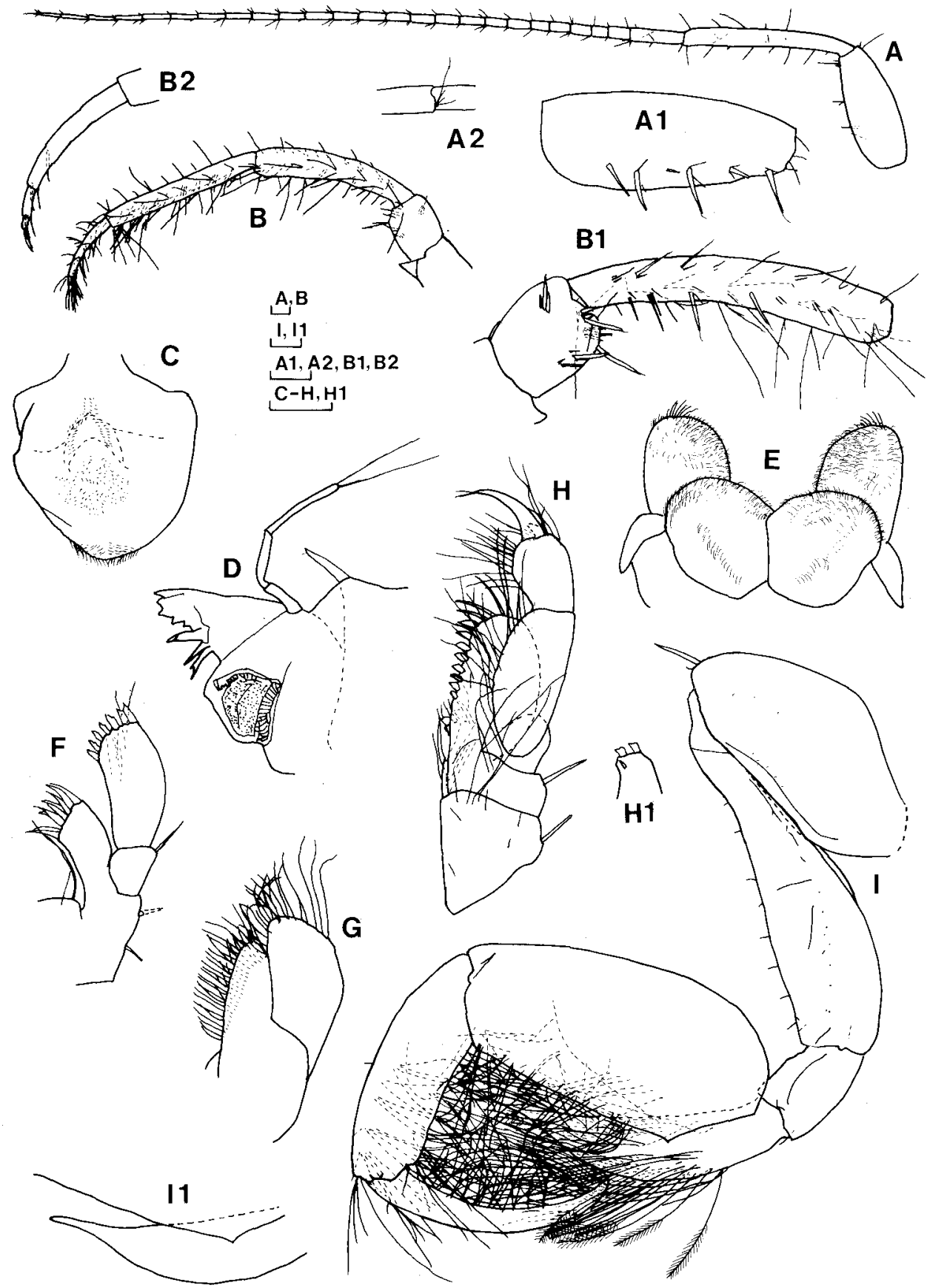

Fig. 31. Aoroides rubellus sp. nov. Male (holotype), 4.7mm: A, antenna 1; A1, peduncular article 1 of antenna 1 (inner view); A2, accessory flagellum; B, antenna 2; B1, peduncular articles 3-4 of antenna 2 (inner view); B2, tip of antenna 2; C, upper lip; D, mandible; E, lower lip; F, maxilla 1; G, maxilla 2; H, maxilliped; H1, inner plate of maxilliped; I, gnathopod 1; I1, distal part of gnathopod 1 article 4 (setae omitted). Scale: $0.1 \mathrm{~mm}$. 


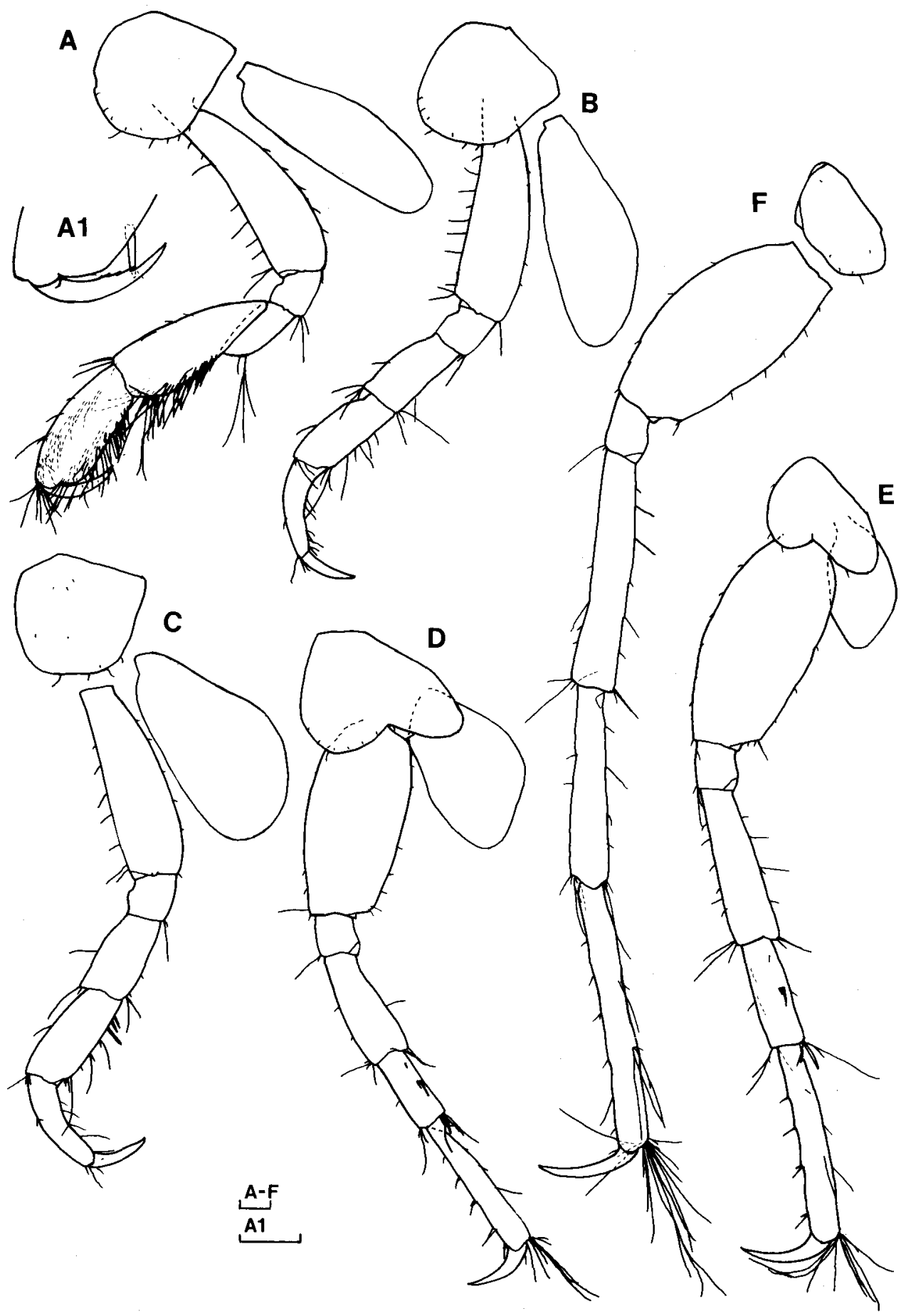

Fig. 32. Aoroides rubellus sp. nov. Male (holotype), 4.7mm: A, gnathopod 2; A1, palm and article 7 of gnathopod 2; B-F, pereopods 3-7. Scale: $0.1 \mathrm{~mm}$. 


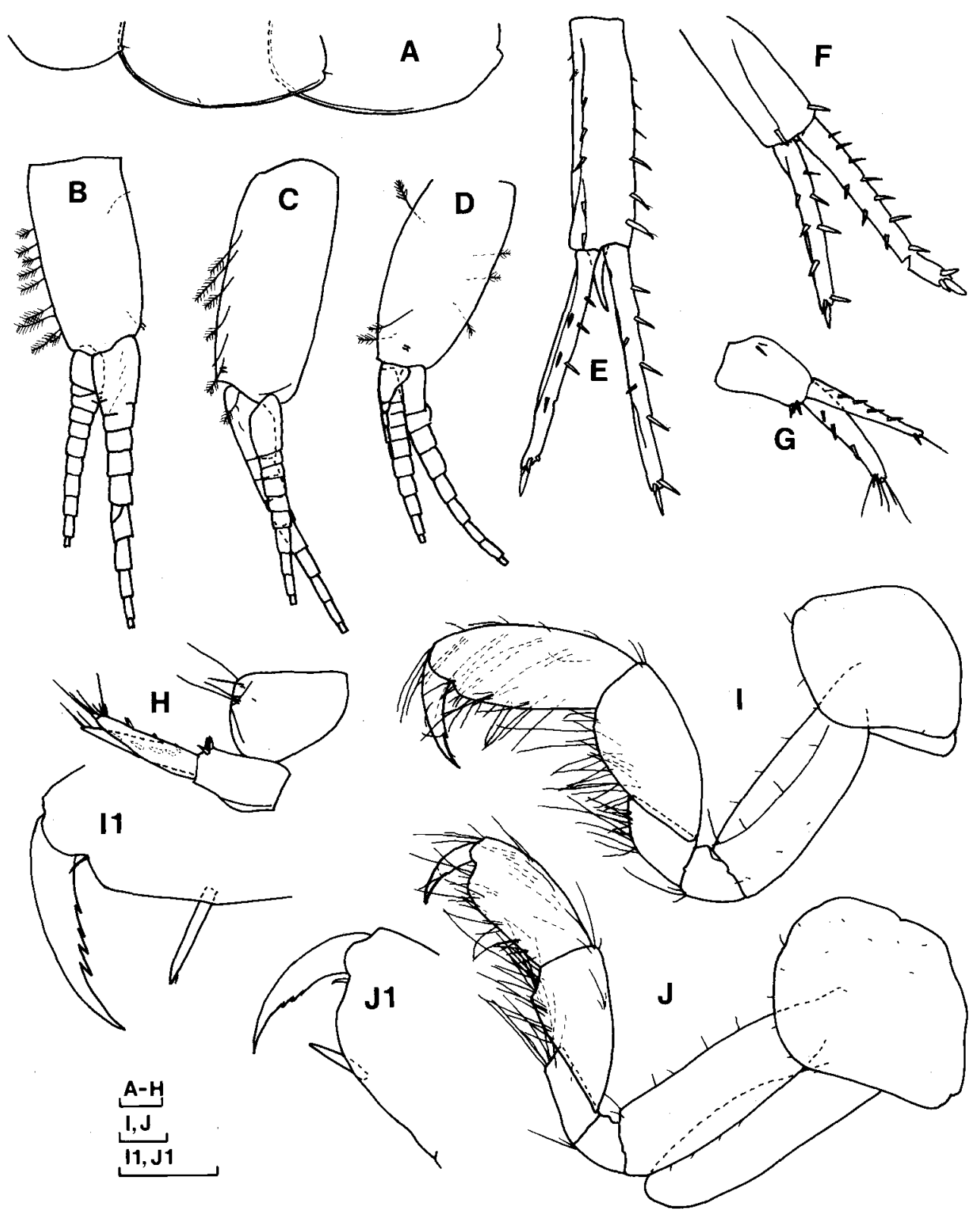

Fig. 33. Aoroides rubellus sp. nov. Male (holotype), 4.7mm: A, epimeral plates 1-3; B-D, pleopods 1-3; E-G, uropods 1-3; H, telson and right uropod 3 (lateral view). Female (allotype), 5.0mm: I, gnathopod 1; I1, palm and article 7 of gnathopod 1; J, gnathopod 2 (oostegite omitted); J1, palm and article 7 of gnathopod 2. Scale: $0.1 \mathrm{~mm}$. 


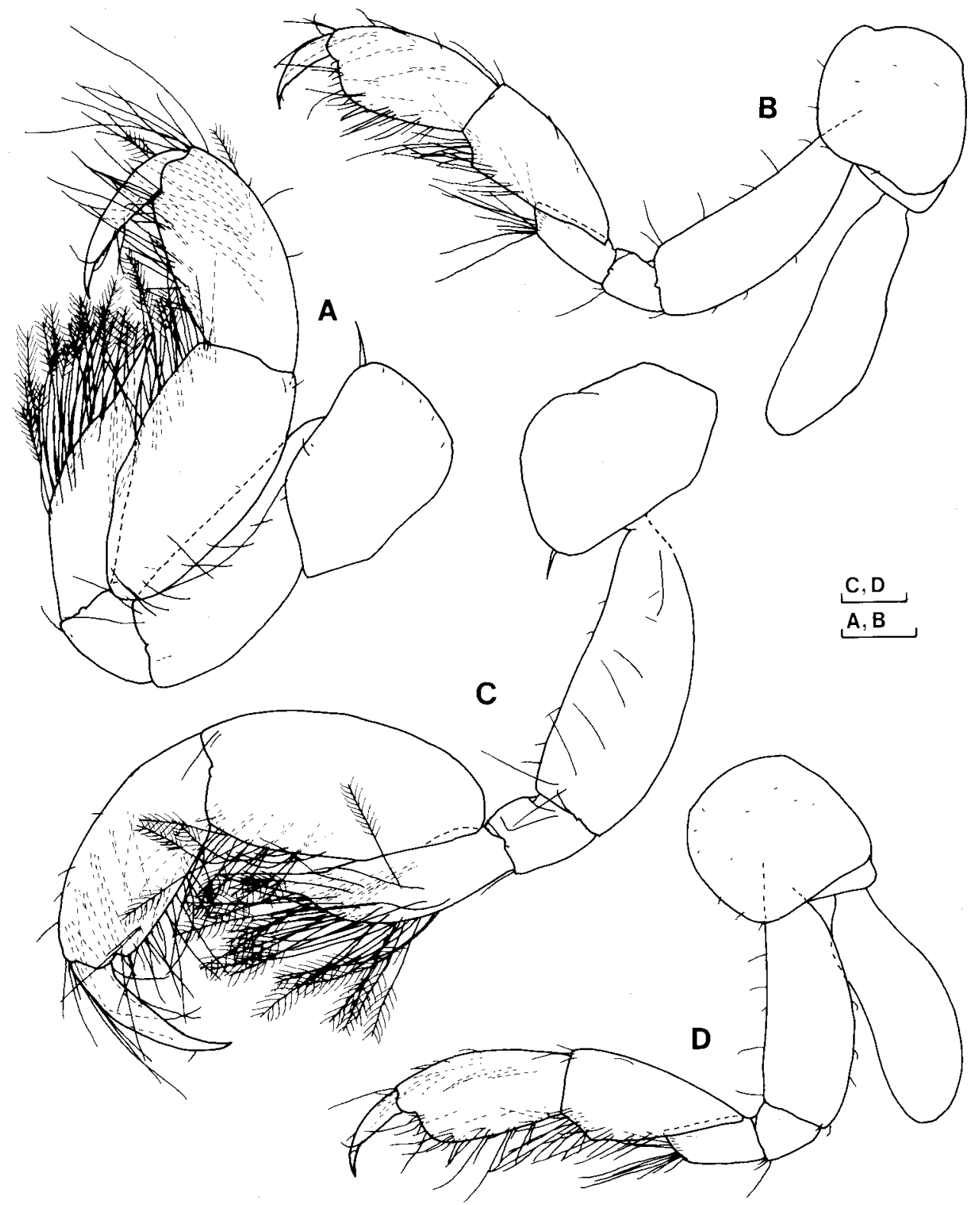

Fig. 34. Aoroides rubellus sp. nov. Male (paratype 2), 2.7mm: A-B, gnathopods 1-2. Male (paratype 3), $3.6 \mathrm{~mm}$ : C-D, gnathopods $1-2$. Scale: $0.1 \mathrm{~mm}$. 
Table 7. Numbers of spines on uropod 3 rami in Aoroides rubellus sp. nov.

\begin{tabular}{ccccccc}
\hline \multirow{2}{*}{ Sex } & Body length & \multicolumn{2}{c}{ Outer ramus } & & \multicolumn{2}{c}{ Inner ramus } \\
\cline { 3 - 4 } \cline { 6 - 7 } & $(\mathrm{mm})$ & Left & Right & & Left & Right \\
\hline \multirow{2}{*}{ Male } & 4.7 & $3+2^{*}$ & $3+1$ & & $5+1$ & $4+0$ \\
& 3.6 & $1+1$ & $1+1$ & & $2+0$ & $2+0$ \\
& 3.1 & $1+1$ & $1+1$ & & $2+0$ & $2+0$ \\
& 2.7 & $1+1$ & $1+2$ & & $2+0$ & $1+0$ \\
\hline \multirow{2}{*}{ Fermale } & 5.0 & $2+2$ & $1+1$ & & $2+2$ & $2+1$ \\
& 4.5 & $2+1$ & $2+1$ & & $2+1$ & $2+1$ \\
\hline
\end{tabular}

* " $\mathrm{X}+\mathrm{Y}$ " indicates $\mathrm{X}$ marginal spines and $\mathrm{Y}$ terminal spines.

peduncle with 2, 3 spines, respectively, inner ramus with 4-5 dorsal spines and 0-1 terminal spine, outer ramus with 3 dorsal and 1-2 terminal spines.

Telson (Fig. 33H) roundish triangular in lateral view.

Female (allotype, $5.0 \mathrm{~mm}$ )

Gnathopod 1 (Figs. 33I, I1): coxal plate lozenge-shaped; article 2 relatively stout, anterior and lateral margins with a few short setae; article 5 broad; article 6 long, palm angular; inner margin of article 7 with 4 notches.

Gnathopod 2 (Figs. 33J, J1): coxal plate lozenge-shaped; article 2 straight, with a few short setae anteriorly; articles 5-6 shorter than the holotype, palm slightly oblique; inner margin of article 7 with 3 notches.

Variation

Gnathopods of small male (paratype 2, 2.7mm): gnathopod 1 (Fig. 34A), coxal plate short, middle part of posterior margin projected, article 2 broad, lateral margin with several short setae, articles 4-5 with dense plumose setae ventrally, article 6 broad, with simple and plumose setae, article 7 short, inner margin minutely serrate, with a few simple setae; gnathopod 2 (Fig. 34B), articles 2, 5 and 6 shorter and broader than the holotype.

Gnathopods of medium-sized male (paratype 3, 3.6mm; Figs. 34C-D) almost the same as the paratype 2.

Numbers of spines on uropod 3 rami (Table 7): outer ramus with 1-3 marginal spines and 1-2 terminal spines; inner ramus with 1-5 (mainly 2) marginal spines, in large materials with 0-2 terminal spines.

Coloration in life (Plate I, Fig. 8)

Dorsal middle and posterior parts of head, posterior parts of pereonites 1-5, dorsal and posterior parts of pereonite 7 and pleonites 1-2 pale red or orange; lower parts of pereonites 1-5, posterior parts of pereonites 5, 7, lower parts of pleonites 1-2 brown; coxae 1, 5 brown; other parts white. In females, most parts of pereonites 1-5 and coxae 2-4 also brown.

Etymology

From the Latin rubellus (= reddish), referring to the body coloration.

Remarks

In this new species, the articles 4-7 of male gnathopod 1 bear dense setae posteriorly, but the article 2 and the anterior part of article 5 are not setose. This is a unique character in Aoroides species. 
Habitat

Aoroides rubellus occurs on the surface of gastropods and ascidians, and among algae in the subtidal zone.

Distribution

Seawall of Kansai International Airport in Izumisano, Osaka Prefecture; Tanigawa in Misaki, Osaka Prefecture; Kii-yura and Shirahama in Wakayama Prefecture; Tateyama in Chiba Prefecture.

\author{
Aoroides secundus Gurjanova, 1938 \\ (Plate I, Fig. 9; Text-figs. 35-39; Table 8) \\ (Japanese name: kebuka-burabura-sokoebi, new)
}

Aoroides secunda Gurjanova, 1938, p. 339, fig. 43; Gurjanova, 1951, pp. 828-830, fig. 579.

Aoroides secundus: Conlan and Bousfield, 1982, p. 79 (key).

Not Aoroides secunda: Nagata, 1965, pp. 309-310.

Material examined.

Male(1) (OMNH-Ar-4218), 3.9mm, intertidal zone of Toyokuni-zaki coast in Misaki, Osaka Pref., among a red alga Lomentaria catenata, 21 Apr. 1996; ovigerous female(1) (OMNH-Ar-4219), $3.6 \mathrm{~mm}$, the same data as male(1); male(2) (OMNH-Ar-4220), 3.3mm, intertidal zone of Nagasaki coast in Misaki, Osaka Pref., among a red alga Pterocladia capillacea, 17 May 1992; males(3-5), $2.7 \mathrm{~mm}$ (OMNH-Ar-4221), 3.2mm (OMNH-Ar-4222), 3.0mm (OMNH-Ar-4223), and ovigerous females(2-3), 2.6mm (OMNH-Ar-4224), 3.9mm (OMNH-Ar-4225), the same data as male(1).

Male [based on male(1), 3.9mm, and male(2), 3.3mm (mandible and epimeral plates 1-3)]

Body (Fig. 35), eyes oval, medium size.

Antennae: antenna 1 (Figs. 36A, A1), ratio of peduncular articles 1-3 1:0.7:0.3, ventroinner

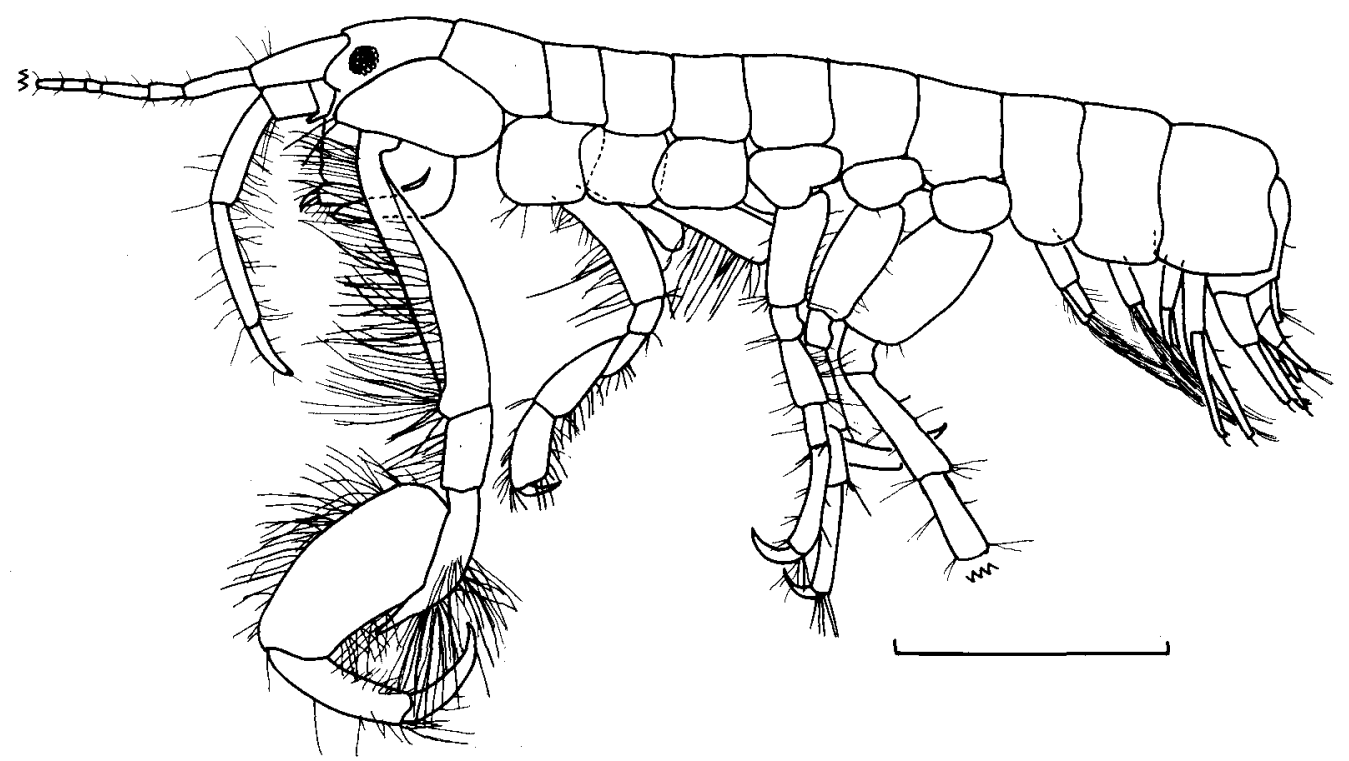

Fig. 35. Aoroides secundus Gurjanova. Male(1), $3.9 \mathrm{~mm}$. Scale: $1 \mathrm{~mm}$. 


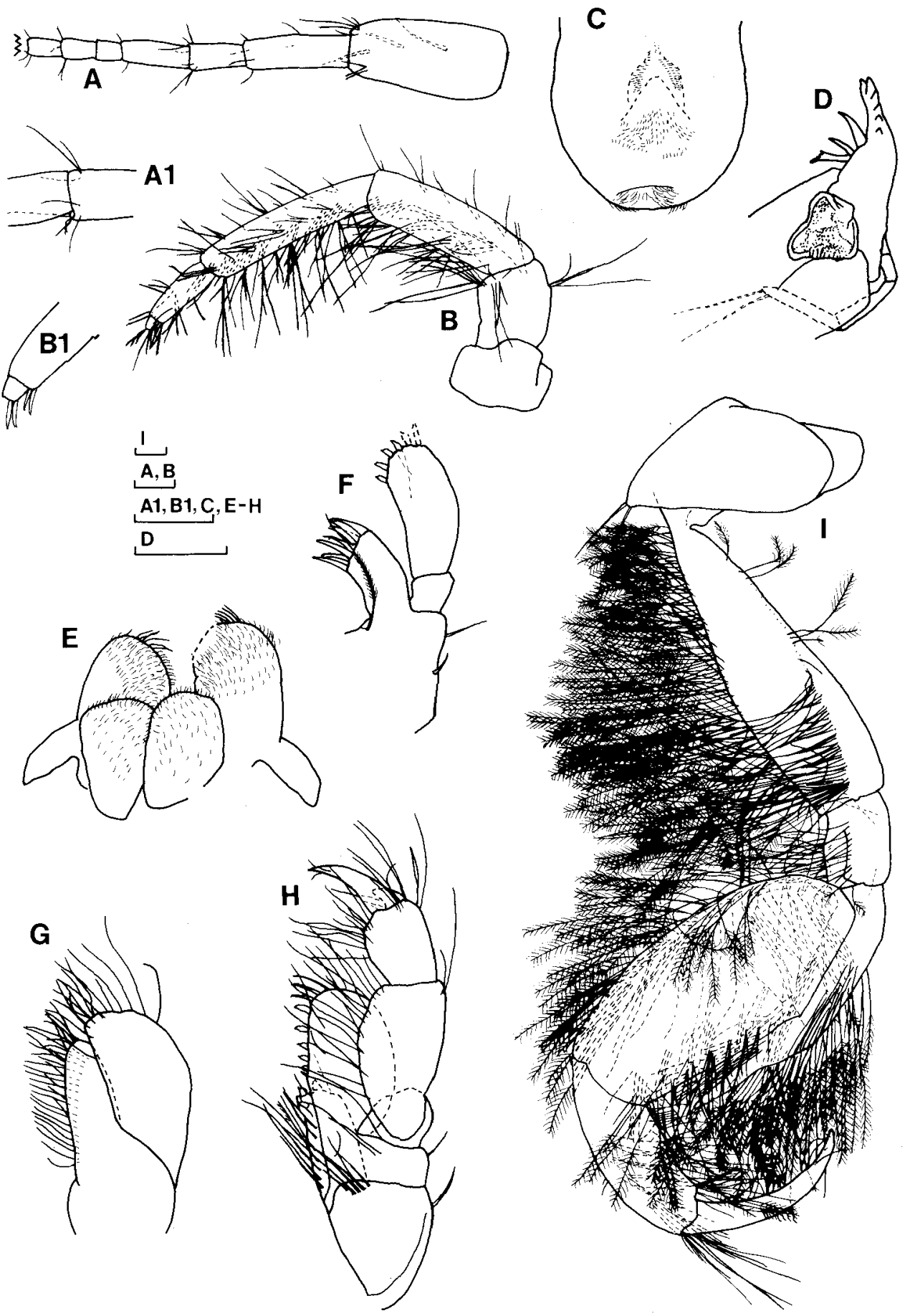

Fig. 36. Aoroides secundus Gurjanova. Male(1), 3.9mm: A, antenna 1; A1, accessory flagellum; B, antenna 2; B1, tip of antenna 2; C, upper lip; E, lower lip; F, maxilla 1; G, maxilla 2; H, maxilliped; I, gnathopod 1. Male(2), $3.3 \mathrm{~mm}: \mathrm{D}$, mandible. Scale: $0.1 \mathrm{~mm}$. 


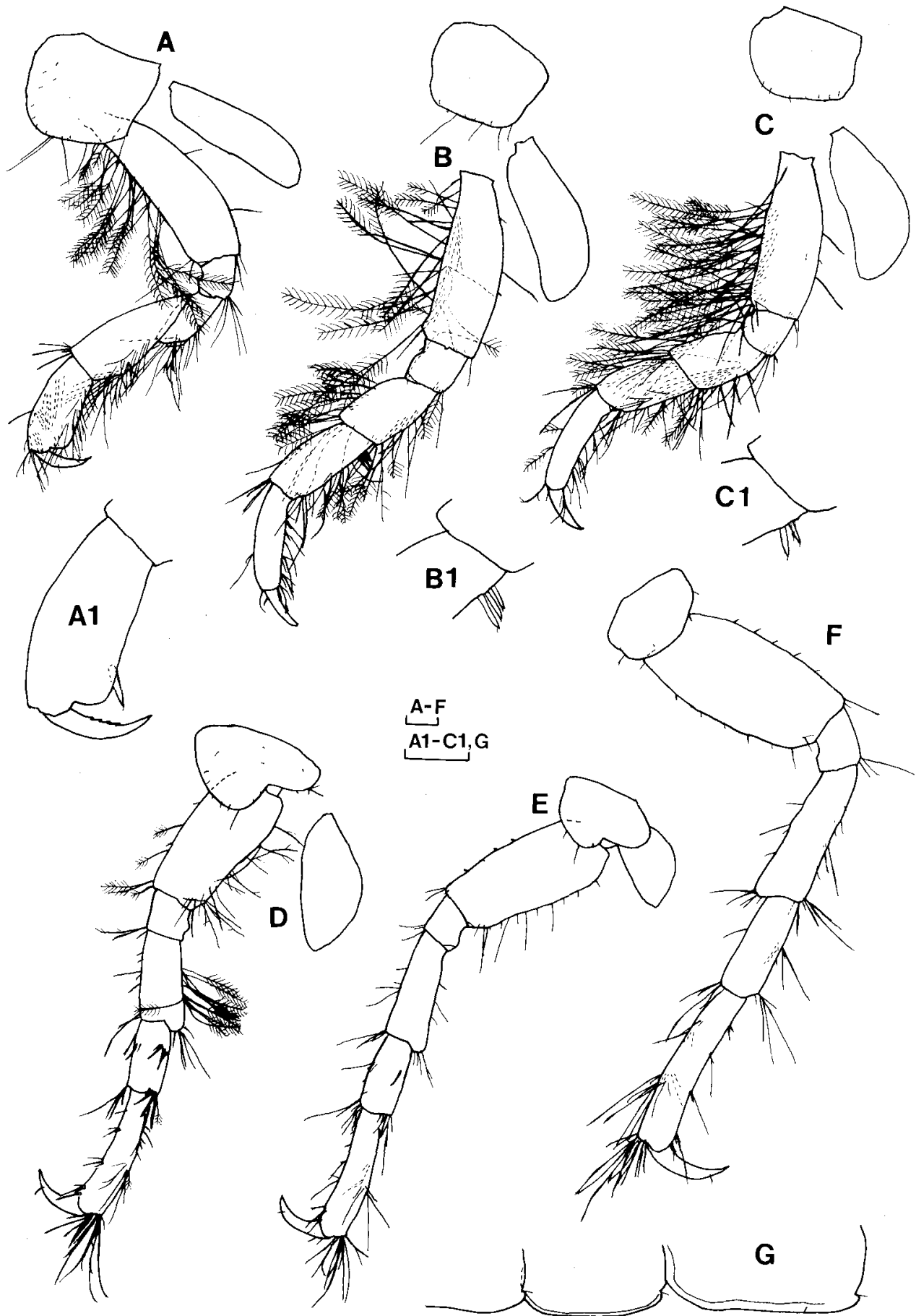

Fig. 37. Aoroides secundus Gurjanova. Male(1), 3.9mm: A, gnathopod 2; A1, articles 6-7 of gnathopod 2; B-D, pereopods 3-5; B1-C1, spines on article 5 of pereopods 3-4; E, pereopod 6; F, right pereopod 7. Male(2), $3.3 \mathrm{~mm}$ : G, epimeral plates 1-3. Scale: $0.1 \mathrm{~mm}$. 


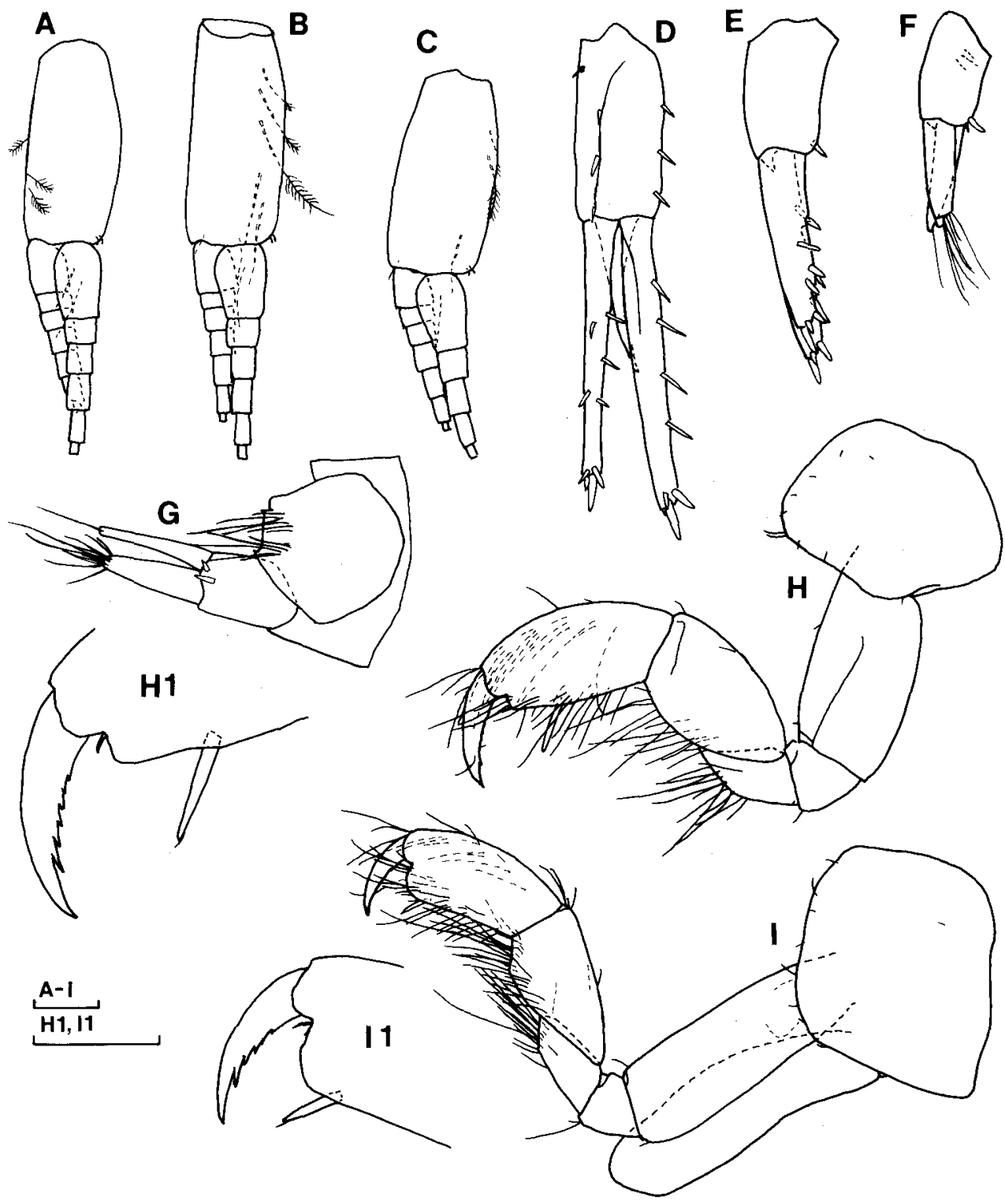

Fig. 38. Aoroides secundus Gurjanova. Male(1), 3.9mm: A-C, pleopods 1-3; D-F, uropods 1-3; G, telson and right uropod 3 (dorsal view). Female(1),3.6mm: $\mathrm{H}$, gnathopod $1 ; \mathrm{H} 1$, palm and article 7 of gnathopod 1; I, gnathopod 2 (oostegite omitted); I1, palm and article 7 of gnathopod 2. Scale: $0.1 \mathrm{~mm}$.

surface of article 1 with a few thick setae, distal part of flagellum lacking; antenna 2 (Fig. 36B) stout, ventral surface with many setae, flagellum with 2 articles, both articles with 2 curved spines (Fig. 36B1).

Mouth parts: upper lip (Fig. 36C) galeate; mandible (Fig. 36D), palp with 2 setae; maxilla 1 (Fig. 

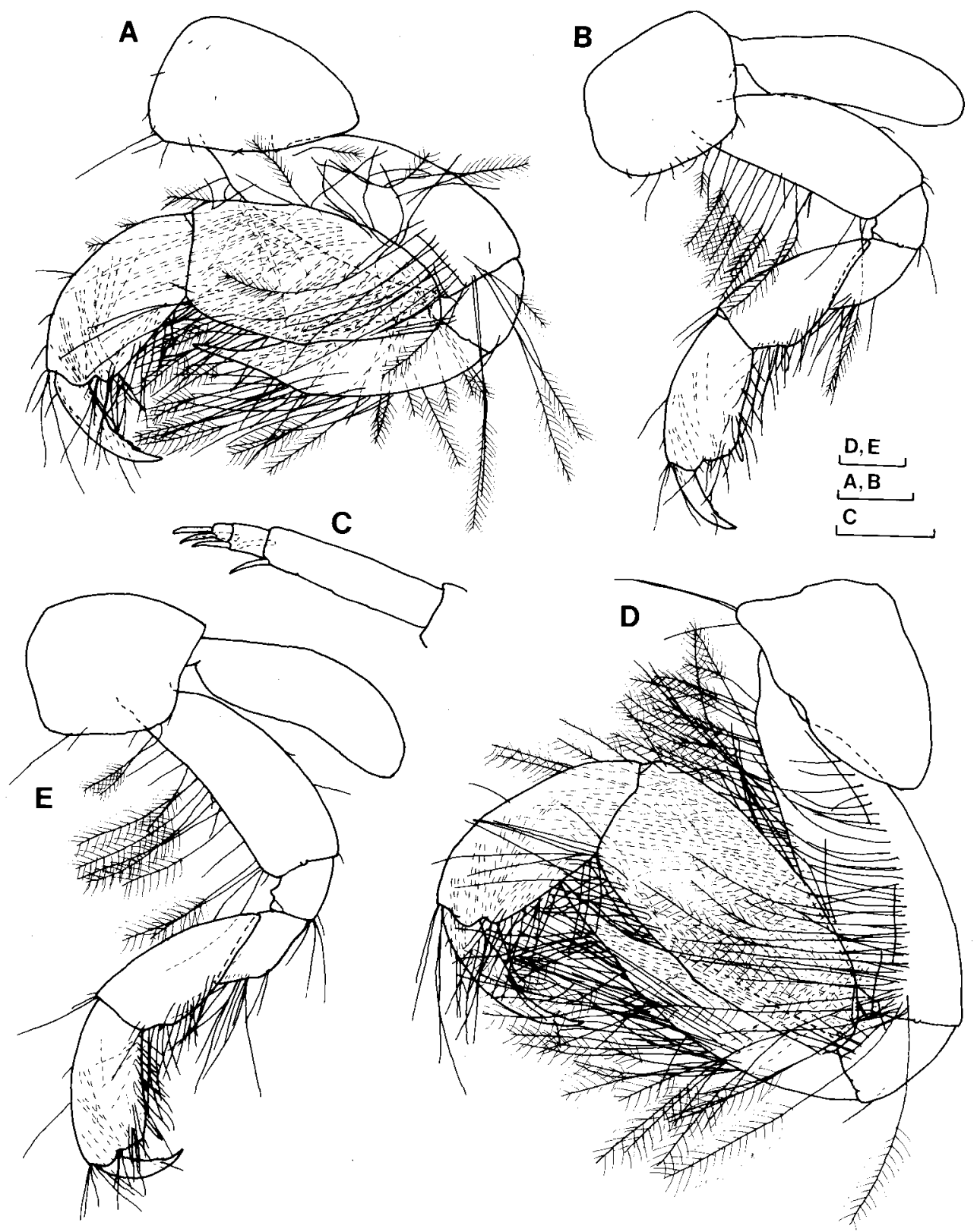

Fig. 39. Aoroides secundus Gurjanova. Male(3), 2.7mm: A-B, gnathopods 1-2. Male(2), 3.3mm: C, flagellum of antenna 2 ; D-E, gnathopods $1-2$. Scale: $0.1 \mathrm{~mm}$.

$36 \mathrm{~F}$ ), inner plate with a plumose seta, palp article 2 with 6 apical spines ( 2 spines lost); maxilliped (Fig. 36H), outer plate broad, with 7 marginal spines, width of palp articles medium.

Gnathopod 1 (Fig. 36I): coxal plate medium length, depressed triangular in shape, roundish posteriorly, with 2 long spines anteriorly; article 2 straight, broadened distally, anterior margin and distal part of lateral margin with dense plumose setae, posterior margin bare; article 3 with many plumose setae on anterior and lateral margins; article 4 lanceolate, ventral surface with dense plumose 
Table 8. Numbers of spines on uropod 3 rami in Aoroides secundus Gurjanova.

\begin{tabular}{ccccccc}
\hline \multirow{2}{*}{ Sex } & Body length & \multicolumn{2}{c}{ Outer ramus } & & \multicolumn{2}{c}{ Inner ramus } \\
\cline { 3 - 4 } & $(\mathrm{mm})$ & Left & Right & & Left & Right \\
\hline \multirow{2}{*}{ Male } & 4.0 & $0+0^{*}$ & $0+1$ & & $0+0$ & $0+0$ \\
& 3.9 & $0+0$ & $0+0$ & & $0+0$ & $0+0$ \\
& 3.3 & $0+0$ & $0+0$ & & $0+0$ & $0+1$ \\
& 3.2 & lost & $0+1$ & & lost & $0+0$ \\
& 2.7 & $0+1$ & $0+2$ & & $0+0$ & $0+0$ \\
\hline \multirow{2}{*}{ Female } & 3.9 & $0+1$ & $0+1$ & & $0+1$ & $0+2$ \\
& 3.6 & $0+2$ & $0+1$ & & $0+1$ & $0+1$ \\
& 2.6 & $0+1$ & $0+1$ & & $0+0$ & $0+0$ \\
\hline
\end{tabular}

* " $\mathrm{X}+\mathrm{Y}$ " indicates $\mathrm{X}$ marginal spines and $\mathrm{Y}$ terminal spines.

setae; article 5 longish ovate, posterior margin and anteroinner surface with dense plumose setae; article 6 slightly curved posteriorly, posterior surface bearing many plumose setae, inner surface with many simple setae; article 7 medium, posterior margin with several simple setae.

Gnathopod 2 (Fig. 37A): coxal plate roundish square; article 2 with several long plumose setae on anterior margin and with a few short setae on posterior margin; article 4 trapezoidal; article 5 relatively long; article 6 long, palm almost transverse, defined by a spine (Fig. 37A1); article 7 relatively short, inner margin denticulate.

Pereopods: pereopods 3-4 (Figs. 37B-C), coxal plates roundish rectangular, articles 2-5 with many plumose setae, posteroproximal margins of article 5 with 3 spines (Figs. 37B1, C1), articles 7 relatively short; pereopod 5 (Fig. 37D), article 2 narrow, anterior margin with a few plumose setae and posterior margin with several simple setae, article 4 bearing several plumose setae posteriorly, article 5 , both middle and distal parts with 4 spines, article 6 with anterior margin spinous, posterodistal corner with many long setae, article 7 strongly curved; pereopod 6 (Fig. 37E), article 2 narrow, middle and distal parts of article 5 with 1, 3 spines, respectively; pereopod 7 (Fig. 37F), coxal plate squarish oval, article 2 rectangular, with several short spines, articles 4-6 with several spines on anterior and posterior margins, posterodistal end of article 6 relatively setose, article 7 short.

Pleopods (Figs. 38A-C), pleopod 2 longest.

Uropods: uropod 1 (Fig. 38D), peduncle shorter than both rami, with a basofacial spine, interramal process about $50 \%$ length of inner ramus, dorsal surface of peduncle and both rami spinous; uropod 2 (Fig. 38E), inter-ramal process $6 \%$ length of inner ramus, dorsodistal corner of peduncle with a spine, dorsal surface of both rami with many spines; uropod 3 (Figs. 38F-G), peduncle same length as outer ramus, inner proximal surface and outer distal end of peduncle with 3,2 spines, respectively, both rami without spines.

Telson (Fig. 38G) roundish in dorsal view.

Female(1), 3.6mm

Gnathopod 1 (Figs. 38H, H1): coxal plate roundish trapezoidal; article 2 stout, anterior margin with a few short setae; articles 5-6 relatively short, palm angular; inner margin of article 7 with 6 notches.

Gnathopod 2 (Figs. 38I, I1): coxal plate rectangular; article 2 straight, with a seta on anterodistal corner; articles 3-7 almost the same as the male(1), but articles 5-6 broader.

Variation

Flagellum of antenna 2 [male(2), 3.3mm; Fig. 39C] consists of 3 articles, both articles 1-3 with 2 curved spines [other materials except for male(1) also the same]. 
Gnathopods of small male [male(3), $2.7 \mathrm{~mm}$ ]: gnathopod 1 (Fig. 39A), coxal plate short, roundish triangular, articles 2 and 6 wider and aricle 5 shorter than male(1), anterior and lateral margins of article 2 with several long plumose setae, posterior margin bare, bearing style of setae almost similar, posterodistal corner of article 6 with a notch; gnathopod 2 (Fig. 39B) almost the same as male(1), but articles 2,5 and 6 broader.

Gnathopods of medium-sized male [male(2), 3.3mm]: gnathopod 1 (Fig. 39D) almost the same as male(1), but density of setae lower; gnathopod 2 (Fig. 39E) almost the same as male(3).

Numbers of spines on uropod 3 rami (Table 8), both rami without marginal spines but often with 1-2 terminal spines.

Coloration in life (Plate I, Fig. 9)

Dorsal and posterior parts of head, whole of pereonites 1-7 and pleonites 1-2, anterior part of pleonite 3, coxae 1-7 brown; other parts white. Females similar to males.

\section{Remarks}

This species has (1) dense plumose setae on male gnathopod 1, (2) uropod 3 without marginal spines on both rami, and (3) shorter peduncular article 2 of antenna 1. These characters well agree with the descriptions and figures of Gurjanova (1951). Conlan and Bousfield (1982) stated that Aoroides secundus had no inter-ramal process on uropod 2. Therefore I conclude that the specimens from Osaka Bay can be identified as $A$. secundus. However, there are some differences between them. In Gurjanova's figures, the eye is elongated longitudinally, the setae on article 2 of male gnathopod 2 are simple, and the article 2 of pereopod 7 is rounder.

Nagata (1965) reported Aoroides secunda from the subtidal zone in Hiroshima Prefecture. Unfortunately he described briefly the morphological characters and the body color and did not provide any figures. Aoroides secundus differs from Nagata's A. secunda in the antenna 2 flagellum and the mandibular palp as well as Aoroides longimerus. Because the body color and the habitat of Nagata's specimens are also different, his specimens probably belong to another species of Aoroides.

\section{Habitat}

Aoroides secundus occurs among algae, rarely under stones, in the lower intertidal zone and upper subtidal zone.

\section{Distribution}

From Nagasaki coast in Misaki, Osaka Prefecture to Kii-yura in Wakayama Prefecture; Kiinagashima and Kami Island in Mie Prefecture; Tateyama in Chiba Prefecture; Primorskii Krai in Russia (Gurjanova, 1951).

\section{Aoroides semicurvatus sp. nov.}

(Plate I, Fig. 10; Text-figs. 40-44; Table 9)

(Japanese name: burabura-sokoebi-modoki, new)

Material examined.

Holotype: male (OMNH-Ar-4226), 3.5mm, intertidal zone of Nagasaki coast in Misaki, Osaka Pref. (34 $\left.20^{\circ} \mathrm{N}, 135^{\circ} 09^{\prime} \mathrm{E}\right)$, under stones, 22 Apr. 1985. Allotype: ovigerous female (OMNH-Ar-4227), $3.0 \mathrm{~mm}$, among a red alga Pterocladia capillacea at Nagasaki coast in Misaki, Osaka Pref., 17 May 1992. Paratypes: 1 male (OMNH-Ar-4228), $4.2 \mathrm{~mm}$, intertidal zone of Tagura-zaki coast in Wakayama Pref., under stones, 29 Mar. 1998; 2 males, 3.1mm (OMNH-Ar-4229) and 2.7mm (OMNH-Ar-4230), and ovigerous female (OMNH-Ar-4231), 3.6mm, intertidal zone of Toyokuni-zaki coast in Misaki, Osaka Pref., under stones, 2 Jun. 1985; 2 males, 3.2mm (OMNH-Ar-4232) and 3.0mm (OMNH-Ar- 


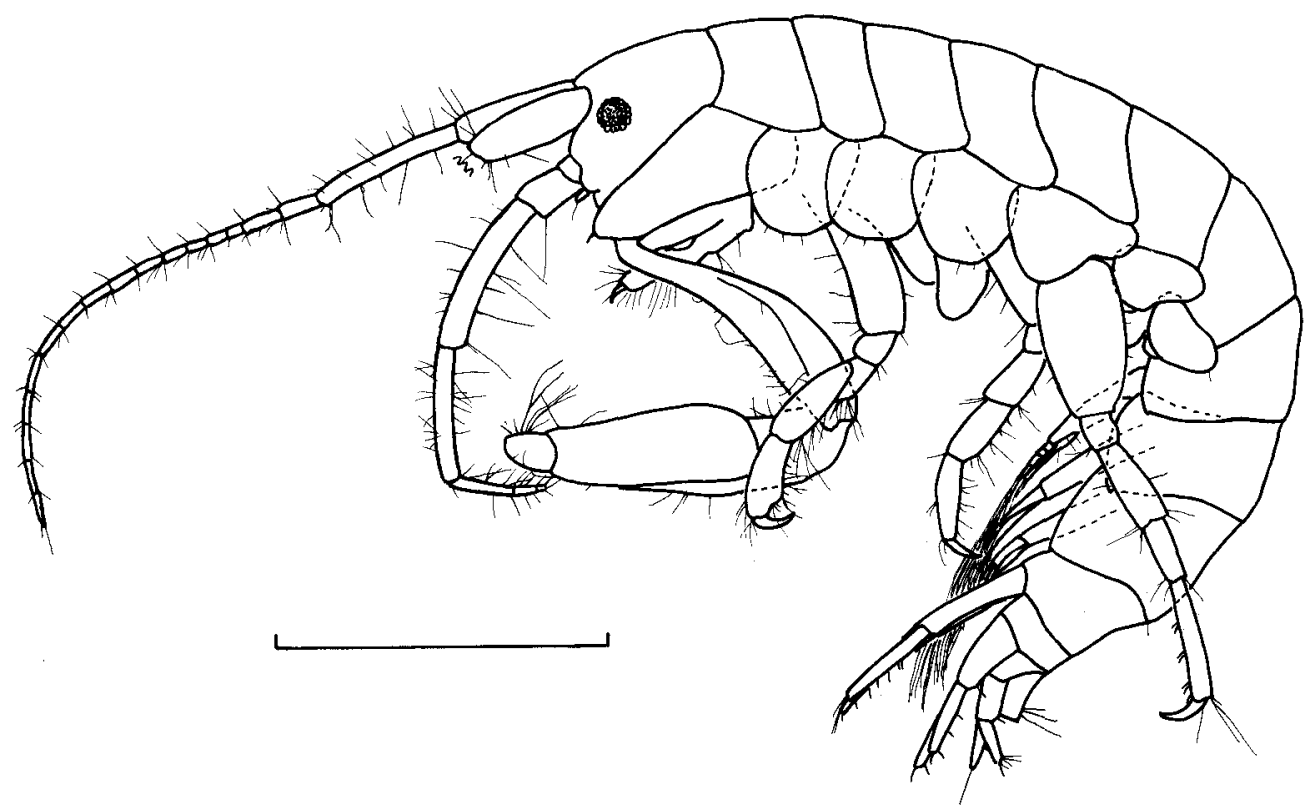

Fig. 40. Aoroides semicurvatus sp. nov. Male (paratype 1), $4.2 \mathrm{~mm}$. Scale: $1 \mathrm{~mm}$.

4233), and 1 ovigerous female (OMNH-Ar-4234), 3.3mm, the same data as the holotype.

Male [based on holotype, $3.5 \mathrm{~mm}$, paratype 1,4.2mm (body), and paratype 2, 3.1 mm (mandible)]

Body (Fig. 40), eyes medium size.

Antennae: antenna 1 (Figs. 41A, A1), ratio of peduncular articles 1-3 1:1.4:0.5, ventral surface of article 1 spinous, primary flagellum with 15 medium and 1 short articles; antenna 2 (Fig. 41B) slender, setose, about 55\% length of antenna 1, peduncular articles without spines, flagellum narrow, with 3 articles, articles 1-3 with 1, 1, 2 curved spines, respectively (Fig. 41B1).

Mouth parts: upper lip (Fig. 41C) roundish; mandible (Fig. 41D), palp article 3 with 6 marginal and a terminal setae; maxilla 1 (Fig. 41F), palp article 2 broad, with 6 apical spines; maxilliped (Fig. $41 \mathrm{H}$ ), outer plate broad, with 8 marginal spines, palp articles relatively slender.

Gnathopod 1 (Fig. 41I): coxal plate elongate, with a spine anteriorly; article 2 long, broadened distally, almost bare; article 3 with a few setae on lateral surface; article 4 short, lanceolate, ventral surface with several setae; article 5 roundish rectangular, ventral surface poorly setose; article 6 elongate, gradually curved posteriorly, posterior margin with many setae; article 7 long.

Gnathopod 2 (Fig. 41J): coxal plate damaged; article 2 broad, anterior and posterior margins with several setae; article 4 trapezoidal; article 5 pyriform; article 6 long, strongly curved posteriorly, palm almost transverse, defined by a long spine (Fig. 41J1); article 7 long, inner margin markedly serrate.

Pereopods: pereopods 3-4 (Figs. 42A-B), articles 2 a little broad, anterior and posterior margins with several short setae, articles 5 with a few spines on posterior margin, articles 6 almost straight, articles 7 short; pereopod 5 (Fig. $42 \mathrm{C}$ ), article 2 roundish rectangular, with several short setae on anterior and posterior margins, article 5, distal end with 2 spines; pereopod 6 (Figs. 42D-E), article 2 rectangular, article 5 with 3 distal spines; pereopod 7 (Fig. 42F) elongate, article 2 roundish trapezoidal, with several short setae, articles 4-6 slender, posterodistal corner of article 6 with many long setae, article 7 long.

Pleopods (Figs. 42H-J), pleopod 2 longer than pleopod 1, peduncle of pleopod 2 particularly long.

Uropods: uropod 1 (Fig. 43A), peduncle shorter than both rami, inter-ramal process $39 \%$ length of 


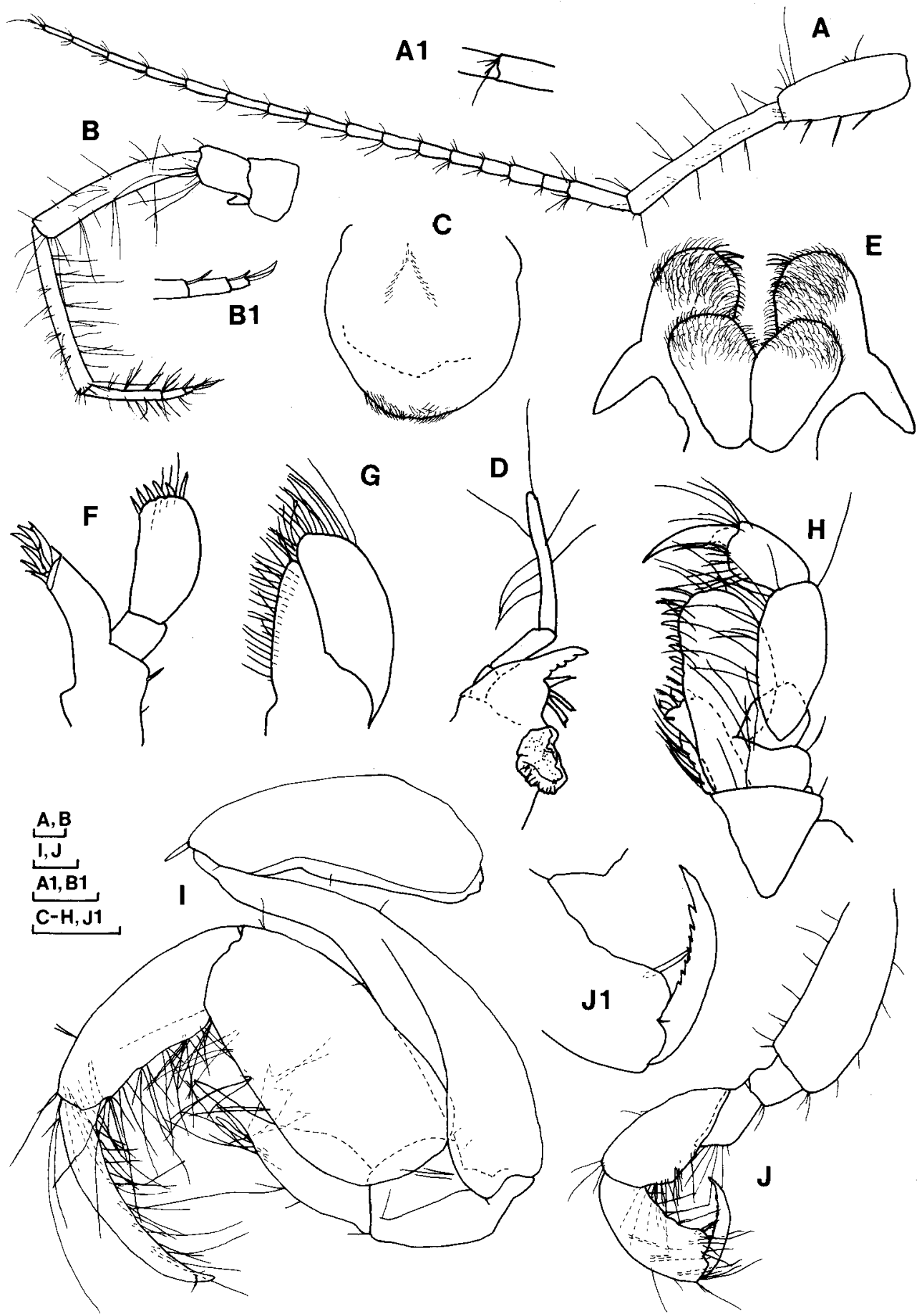

Fig. 41. Aoroides semicurvatus sp. nov. Male (holotype), 3.5mm: A, antenna 1; A1, accessory flagellum; B, antenna 2; B1, tip of antenna 2; C, upper lip; E, lower lip; F, maxilla 1; G, maxilla 2; $\mathrm{H}$, maxilliped; I, gnathopod 1; J, gnathopod 2; J1, palm and article 7 of gnathopod 2. Male (paratype 2), $3.1 \mathrm{~mm}: \mathrm{D}$, mandible. Scale: $0.1 \mathrm{~mm}$. 


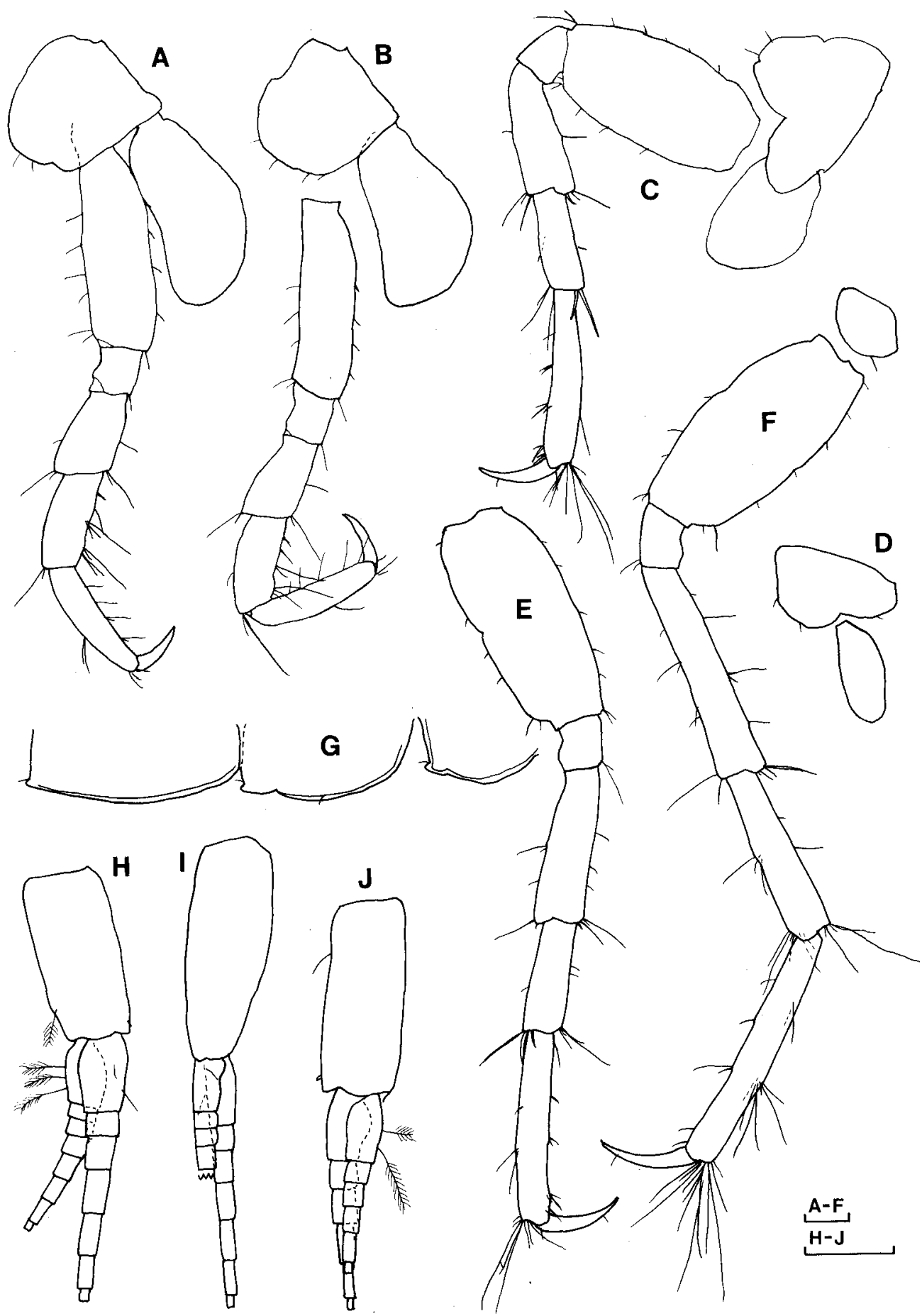

Fig. 42. Aoroides semicurvatus sp. nov. Male (holotype), 3.5mm: A-C, pereopods 3-5; D, left coxa and gill on pereopod 6; E, right pereopod 6; F, pereopod 7; G, epimeral plates 1-3; H-J, pleopods 13. Scale: $0.1 \mathrm{~mm}$. 


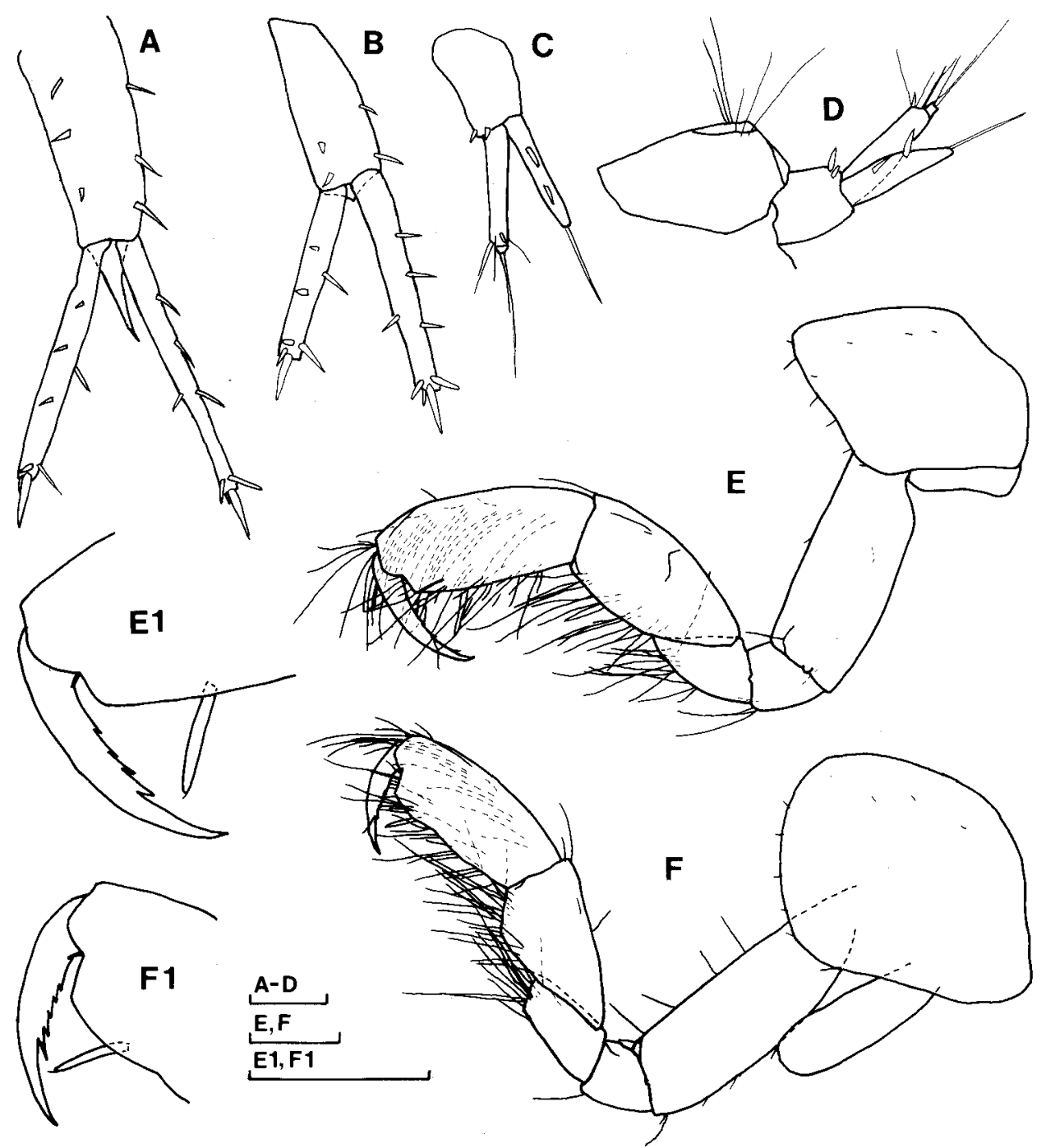

Fig. 43. Aoroides semicurvatus sp. nov. Male (holotype), 3.5mm: A-C, uropods 1-3; D, telson and right uropod 3 (lateral view). Female (allotype), 3.0mm: E, gnathopod 1; E1, palm and article 7 of gnathopod 1; F, gnathopod 2 (oostegite omitted); F1, palm and article 7 of gnathopod 2. Scale: $0.1 \mathrm{~mm}$.

inner ramus, dorsal surface of peduncle and both rami spinous; uropod 2 (Fig. 43B), inter-ramal process $7 \%$ length of inner ramus, dorsal surface of peduncle and both rami spinous; uropod 3 (Figs. $43 \mathrm{C}-\mathrm{D}$ ), peduncle about $80 \%$ length of outer ramus, outer distal end of peduncle with 2 spines, inner ramus with 2 dorsal spines, tip of outer ramus with a dorsal spine.

Telson (Fig. 43D) trapezoidal in lateral view.

Female (allotype, $3.0 \mathrm{~mm})$

Gnathopod 1 (Figs. 43E, E1): coxal plate lozenge-shaped; article 2 relatively stout, margins almost bare; article 5 broad; article 6 long, palm angular; inner margin of article 7 with 4 notches. 


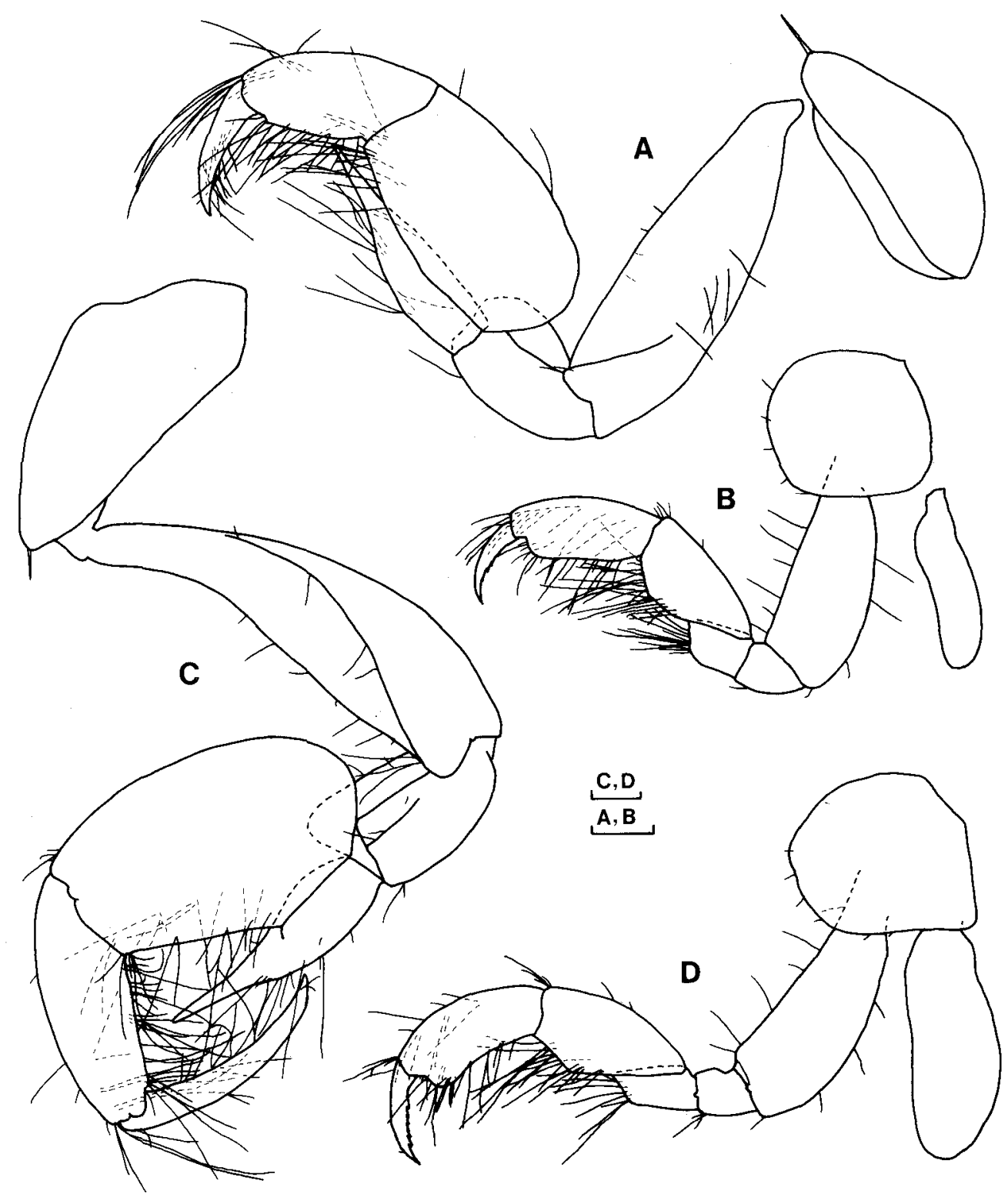

Fig. 44. Aoroides semicurvatus sp. nov. Male (paratype 3), 2.7mm: A-B, gnathopods 1-2. Male (paratype 1), $4.2 \mathrm{~mm}$ : C-D, gnathopods $1-2$. Scale: $0.1 \mathrm{~mm}$. 
Table 9. Numbers of spines on uropod 3 rami in Aoroides semicurvatus sp. nov.

\begin{tabular}{|c|c|c|c|c|c|}
\hline \multirow[t]{2}{*}{ Sex } & \multirow{2}{*}{$\begin{array}{c}\text { Body length } \\
(\mathrm{mm})\end{array}$} & \multicolumn{2}{|c|}{ Outer ramus } & \multicolumn{2}{|c|}{ Inner ramus } \\
\hline & & Left & Right & Left & Right \\
\hline \multirow[t]{6}{*}{ Male } & 4.2 & $0+0^{*}$ & $0+1$ & $2+0$ & $2+0$ \\
\hline & 3.5 & $0+1$ & $0+1$ & $2+0$ & $2+0$ \\
\hline & 3.2 & $0+0$ & $0+0$ & $2+0$ & $2+0$ \\
\hline & 3.1 & $0+0$ & $0+0$ & $2+0$ & $1+0$ \\
\hline & 3.0 & $0+0$ & $0+0$ & $1+0$ & $1+0$ \\
\hline & 2.7 & $0+0$ & $0+0$ & $1+0$ & $1+0$ \\
\hline \multirow[t]{3}{*}{ Female } & 3.6 & $0+0$ & $0+0$ & $2+0$ & $2+0$ \\
\hline & 3.3 & damaged & $0+2$ & $3+0$ & $3+1$ \\
\hline & 3.0 & $0+0$ & $0+0$ & $1+0$ & $1+0$ \\
\hline
\end{tabular}

* " $\mathrm{X}+\mathrm{Y}$ " indicates $\mathrm{X}$ marginal spines and $\mathrm{Y}$ terminal spines.

Gnathopod 2 (Figs. 43F, F1): coxal plate roundish lozenge-shaped; article 2 straight, with a few short setae on anterior and posterior margins; article 6 longish, straight, palm angular; inner margin of article 7 with 5 notches.

Variation

Gnathopods of small male (paratype 3,2.7mm): gnathopod 1 (Fig. 44A), coxal plate and articles 2, 5, 6, 7 shorter than the holotype; gnathopod 2 (Fig. 44B) almost the same as the holotype, except article 6 nearly straight and with a ventral spine.

Gnathopods of large male (paratype 1, 4.2mm): gnathopod 1 (Fig. 44C), coxal plate depressed triangular, article 2 elongate, anterior and lateral margins with several short setae, posterior margin bare, article 3 with distal inner part lobed, articles 4-7 almost the same as the holotype; gnathopod 2 (Fig. 44D), coxal plate roundish square, articles 2-7 almost the same as the holotype.

Numbers of spines on uropod 3 rami (Table 9): outer ramus without marginal spines but rarely with 1-2 terminal spines; inner ramus with 1-3 marginal spines and almost without terminal spines.

Coloration in life (Plate I, Fig. 10)

Posterior part of head, ventral surface of coxa 1, posterior and lower parts of pereonites 1-5, posterior part of pereonite 7, ventral parts of pleonites 1-2 brown; antennae slightly reddish; other parts white. In females, coxae 1-5 also brown, gnathopods light brown.

Etymology

From the Latin semicurvatus (= somewhat curved), referring to the shape of article 6 of the male gnathopod 2.

\section{Remarks}

This new species closely resembles Aoroides curvipes in the poorly setose male gnathopod 1 and the curved article 6 of male gnathopod 2. However, A. semicurvatus sp. nov. can be distinguished from $A$. curvipes by the lack of marginal spines on the outer ramus of uropod 3.

Habitat

Aoroides semicurvatus occurs under stones, rarely among algae, in the lower intertidal zone.

Distribution

From Nagasaki coast in Misaki, Osaka Prefecture to Oura in Hidaka, Wakayama Prefecture; Kami Island in Mie Prefecture. 
Key to adult males of Aoroides species from Osaka Bay

In what follows, spines of uropod 3 rami refer to marginal ones.

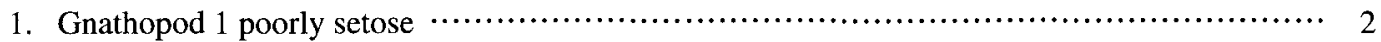

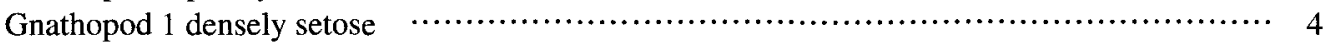

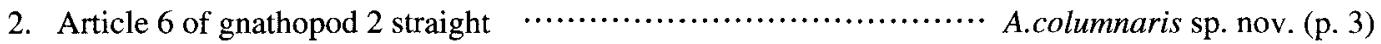

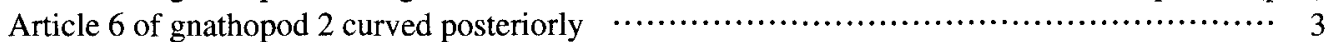

3. Uropod 3, outer ramus with 1-2 spines, inner ramus with 2-3 spines

Uropod 3, outer ramus marginally bare, inner ramus with 1-2 spines

A. curvipes sp. nov. (p. 9)

A. semicurvatus sp. nov. (p. 54)

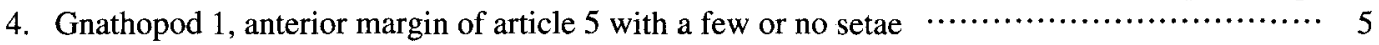

Gnathopod 1, anterior margin of article 5 bearing dense plumose setae …..................... 7

5. Gnathopod 1, anterior margin of article 2 bearing many plumose setae; article 2 of pereopod 7

elliptical …........................................................... A. ellipticus sp. nov. (p. 16)

Gnathopod 1, anterior margin of article 2 with a few simple setae; article 2 of pereopod 7

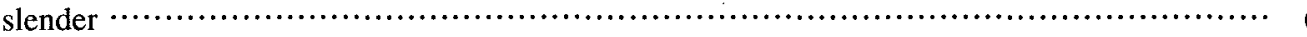

6. Uropod 3, outer and inner rami without spines; body with many small black dots in life

A. punctatus sp. nov. (p. 35)

Uropod 3, outer ramus with 1-3 spines, inner ramus with 1-5 spines; body with red or orange bands in life ….................................................... A. rubellus sp. nov. (p. 41)

7. Coxa 1, anterior margin with several plumose setae

A. longimerus Ren and Zheng, 1996 (p. 23)

Coxa 1 without setae

8. Pereopods 3-4 bearing a few setae; uropod 3, outer ramus with $0-1$ spine, inner ramus with

1-2 spines

A. myojinensis sp. nov. (p. 28)

Pereopods 3-4 bearing dense plumose setae; uropod 3, outer and inner rami without spines

A. secundus Gurjanova, 1938 (p. 48)

\section{Discussion}

Since Nagata (1965) recorded Aoroides columbiae and A. secunda, Japanese Aoroides species have been identified as A. columbiae and A. secunda only based on either poorly setose or densely setose male gnathopod 1 , respectively. However, in the present paper, nine species including seven new species were described, and some of them were distributed also in China, Korea and Primorskii Krai in Russia. Most of Aoroides species hitherto recorded from Japan and the adjacent waters possibly belong to these nine species.

These Aoroides species can be distinguished from one another mainly by the setation of male gnathopod 1, and the setal patterns change a little with growth. Male gnathopods 1 of $A$. columnaris, $A$. curvipes and $A$. semicurvatus are poorly setose, while the other species have a densely setose male gnathopod 1. The setation of each densely setose species is very various: for example, coxa 1 is setose in only A. longimerus, anterior margin of article 2 bears dense plumose setae in A. ellipticus, $A$. longimerus, A. myojinensis and $A$. secundus, and anterior margin of article 5 has many plumose setae in A. longimerus, $A$. myojinensis and A. secundus. The shapes of articles 4, 5 and 7 of male gnathopod 1 are also diverse in each species: articles 4-5 are cylindrical in $A$. columnaris, article 4 with ventral obtuse process in A. punctatus, and article 7 is strongly curved in A. longimerus and A. punctatus.

There are some distinguishing characters besides male gnathopod 1 . Setation is various as well in the other male appendages: antenna 2 is heavily setose in $A$. punctatus, maxilliped has many plumose setae in A. myojinensis, article 2 of gnathopod 2 is setose anteriorly in A. ellipticus and A. secundus, pereopods 3-4 are setose in $A$. secundus, and articles 4-5 of pereopods 5-6 bear many plumose setae in A. myojinensis. The shapes of article 6 of male gnathopod 2 and article 2 of pereopod 7 , and the 
Table 10. Main habitats of Aoroides species from Osaka Bay.

\begin{tabular}{|c|c|c|c|c|c|}
\hline \multirow{2}{*}{ Species } & \multicolumn{2}{|c|}{ Intertidal } & \multicolumn{3}{|c|}{ Subtidal } \\
\hline & $\begin{array}{l}\text { under } \\
\text { stones }\end{array}$ & $\begin{array}{l}\text { among } \\
\text { algae }\end{array}$ & $\begin{array}{l}\text { among } \\
\text { algae }\end{array}$ & $\begin{array}{l}\text { surface of } \\
\text { animals }\end{array}$ & $\begin{array}{l}\text { on sandy } \\
\text { mud bottom }\end{array}$ \\
\hline Aoroides myojinensis & (2) & & & & \\
\hline Aoroides semicurvatus & () & O & & & \\
\hline Aoroides secundus & $\bigcirc$ & (0) & O & & \\
\hline Aoroides punctatus & & & (0) & $\bigcirc$ & \\
\hline Aoroides columnaris & & & (0) & (0) & \\
\hline Aoroides longimerus & & & (0) & (2) & \\
\hline Aoroides rubellus & & & 0 & (2) & \\
\hline Aoroides curvipes & & & 0 & 0 & (0) \\
\hline Aoroides ellipticus & & & & & (2) \\
\hline
\end{tabular}

numbers of spines on uropod 3 rami are also useful taxonomic characters. Article 6 of male gnathopod 2 is curved posteriorly in A. curvipes and A. semicurvatus, although this characteristic is not revealed conspicuously in young males. Only A. ellipticus has an elliptical article 2 of pereopod 7 . Both rami of uropod 3 are bare in A. punctatus and A. secundus, and outer ramus has no spine in A. columnaris and $A$. semicurvatus. In addition, the body coloration in life varies considerably among species (Plate I), even in females without obvious morphological differences.

Nine Aoroides species were found to occur in the small sea area from Tanigawa to the Myojinzaki coast in Osaka Bay (distance: $2.5 \mathrm{~km}$; Fig. 1). This fact indicates a high biodiversity of this genus in the sea area. Table 10 summarizes the main habitats of these species. Aoroides species from Osaka Bay can live in both the intertidal zone and subtidal zone (to a depth of $10 \mathrm{~m}$ ), and attach on various substrata. Aoroides may have speciated by advancing into varied habitats. However, the morphological characters of the species are not related to their habitats. For example, although $A$. columnaris, A. curvipes and A. semicurvatus have poorly setose gnathopod 1 in males, the habitats of these species are quite different. The cause of the non-relation is unknown for the lack of functional information of the appendages.

The western Pacific Aoroides species have a short (or rudimentary) inter-ramal process of uropod 2 (the present study) or lack the process (Ledoyer, 1979; Myers, 1995), while the northeastern Pacific species have a well-developed process (Conlan and Bousfield, 1982). Conlan and Bousfield (1982) divided Aoroides species into two groups: (1) stouter bodied, more setose group, (2) more slender bodied, less setose group. Considering the distribution of Aoroides species, the length of the uropod 2 inter-ramal process is more important to divide groups.

Myers (1988) analyzed cladistically the subfamily Aorinae using the characters of uropod 3, palp and molar of mandible, and maxilliped. He divided the subfamily into three clades (Aora clade, Bemlos clade and Lembos clade), and the Aora clade includes 4 genera, i.e. Aora, Aorella, Aoroides and Columbaora. Figure 45 shows the distribution of the genera included in the Aora clade in the Indo-Pacific region (based on the present study; Alderman, 1936; Barnard, 1970; Barnard and Karaman, 1991; Conlan and Bousfield, 1982; Griffiths, 1976a, 1976b; Hirayama, 1984; Ledoyer, 1979, 1982; Myers, 1985, 1995, 1998; Myers and Moore, 1983). Aora, the ancestor of Aoroides (Barnard, 1973), occurs on the southern hemisphere except for Aora pseudotypica Hirayama, 1984 in Japan. Nevertheless Aoroides is distributed in the Pacific Ocean north of the latitude $10^{\circ} \mathrm{S}$. In the western Pacific only group A (having a short or no inter-ramal process of uropod 2) occurs northward to Primorskii Krai, and in the eastern Pacific only group B (having a well-developed inter-ramal process of uropod 2) occurs from the Aleutian Islands to California. Moreover, in Hawaii two Aoroides species were recorded (Barnard, 1970): A. nahili belongs to group A and A. ?columbiae to 


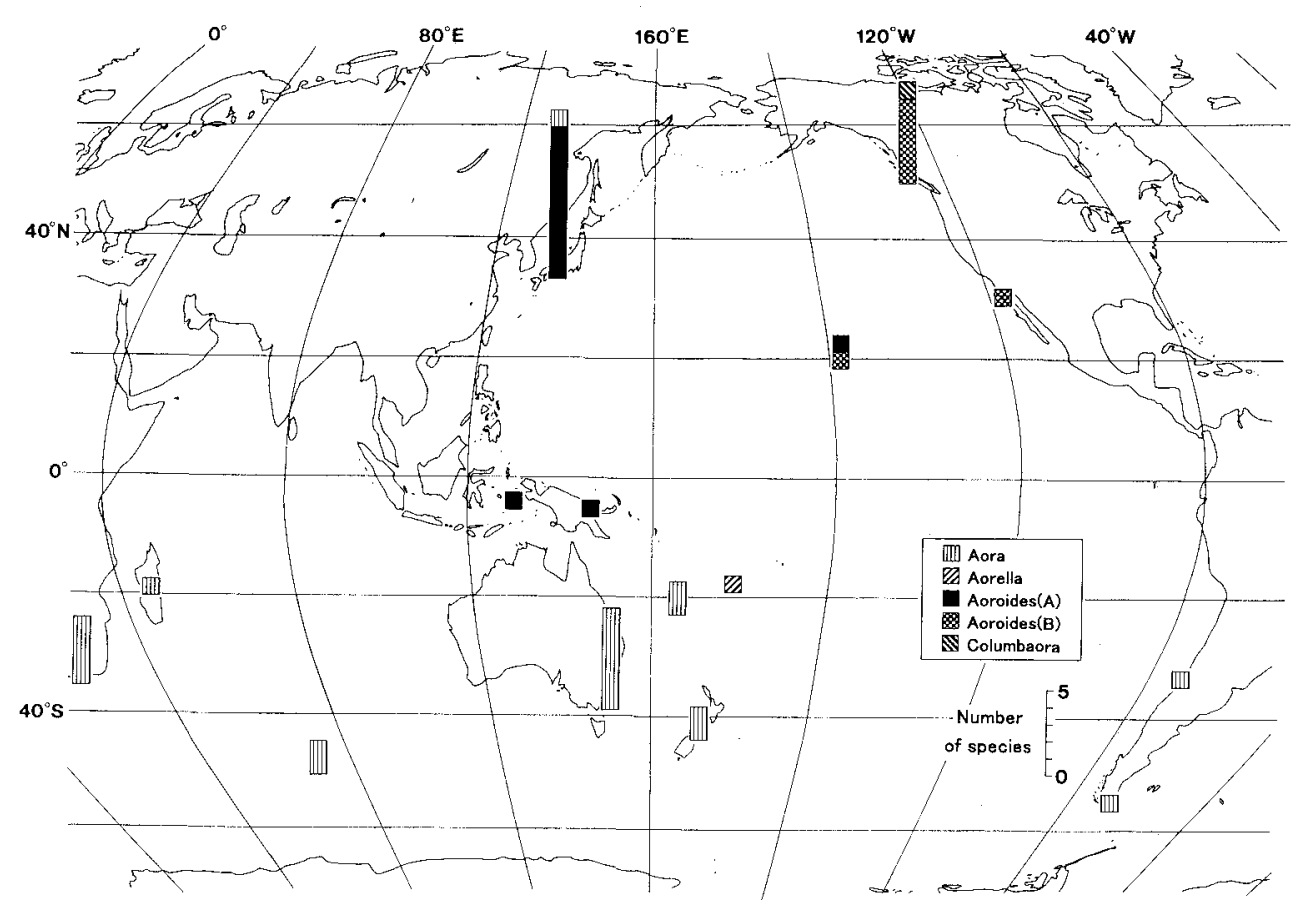

Fig. 45. Distribution of the genera included in the Aora clade (Myers, 1988) in the Indo-Pacific region. Aoroides (A): Aoroides having a short or no inter-ramal process of uropod 2, Aoroides (B): Aoroides having a well-developed inter-ramal process of uropod 2.

group B.

Dispersal of the North Pacific amphipods has been discussed in several groups (e.g. Bousfield and Hendrycks, 1994). In the case of Aoroides, Conlan and Bousfield (1982) considered that $A$. columbiae was the most primitive and most widely didtributed, and that $A$. secundus and $A$. nahili had been derived from $A$. columbiae. However, their hypothesis was based on the assumption that identification of $A$. columbiae from Japan and Hawaii was accurate, and the assumption is turned out to be false in the present study.

Nishimura (1981) analyzed extensive biogeographical data in the sea, and inferred that the eastern coast of Asia had been an adequate area for speciation from the warm-temperate fauna to the coldwater one, and that the species groups distributed both on the western and eastern North Pacific coasts today had been dispersed from either of the habitats along the North Pacific rim. Accepting his opinion, I can propose the following hypothesis from the distribution of the Aora clade: (1) Aoroides group A derived from Aora in the southwestern Pacific; (2) Aoroides group A had been dispersed northward and diversified; (3) Aoroides group B derived from Aoroides group A in the North Pacific; (4) Aoroides group B penetrated into the eastern Pacific and had speciated.

With respect to the Hawaiian Aoroides species, Barnard (1970) stated that those two species had been immigrated from America. However, Myers (1993) indicated that the endemic species in Hawaii had been dispersed from the central-east Pacific and the non-endemic species from the Indo-West Pacific. Because Aoroides nahili was distributed also in Indonesia (Ledoyer, 1979) and A. nahili and A. ?columbiae belong to group A and B, respectively, I think the former had been dispersed from the Indo-West Pacific and the latter possibly derived from the North American population. 


\section{Acknowledgements}

I would like to thank especially Dr. Hiroshi Morino of Ibaraki University for critical reading of the manuscript. I am grateful to Drs. Yoshihisa Shirayama and Shigeyuki Yamato of the Seto Marine Biological Laboratory for their kind advice, Dr. Ryohei Yamanishi of the Osaka Museum of Natural History who provided facility for preservation of the specimens, Dr. Hisashi Yokoyama of National Research Institute of Aquaculture who donated some materials, and Dr. Goro Yoshida of National Research Institute of Fisheries and Environment of Inland Sea who helped with collecting samples in Hiroshima Prefecture. I am greatly indebted to Dr. Hiroyuki Sudo of Japan Sea National Fisheries Research Institute, Dr. Keisuke Mori of Amakusa Marine Biological Laboratory, Kyushu University and Dr. Akira Hirayama of Kaihatsu Koeisha Co. Ltd. for the loan of the specimens from Kyushu, and Dr. Ren Xianqui of Institute of Oceanology, the Chinese Academy of Sciences for sending Chinese literature. I also thank two anonymous reviewers for improving the manuscript.

\section{References}

Alderman, A. L. 1936. Some new and little known amphipods of California. University of California Publications in Zoology, 41, 53-74.

Barnard, J. L. 1970. Sublittoral Gammaridea (Amphipoda). of the Hawaiian Islands. Smithsonian Contributions to Zoology, 34, 1-286.

Barnard, J. L. 1973. Revision of Corophiidae and related families (Amphipoda). Smithsonian Contributions to Zoology, 151, 1-27.

Barnard, J. L. and Karaman, G. S. 1991. The families and genera of marine gammaridean Amphipoda (except marine gammaroids). Records of the Australian Museum, Supplement, 13 (Parts 1 and 2), 1-866.

Bousfield, E. L. and Hendrycks, E. A. 1994. A revision of family Pleustidae (Amphipoda: Gammaridea). Part I. Systematics and biogeography of component subfamilies. Amphipacifica, 1(1), 17-57.

Conlan, K. E. and Bousfield, E. L. 1982. The superfamily Corophioidea in the North Pacific region Family Aoridae: systematics and distributional ecology. Publications in Biological Oceanography, National Museums of Canada, 10, 77-101.

Griffiths, C. L. 1976a. Guide to the Benthic Marine Amphipods of Southern Africa. South African Museum, Cape Town, $106 \mathrm{pp}$.

Griffiths, C. L. 1976b. Some new and notable Amphipoda from southern Africa. Annals of the South African Museum, 72, 11-35.

Gurjanova, E. F. 1938. Amphipoda, Gammaroidea of Siaukhu Bay and Sudzukhe Bay (Japan Sea). Reports of the Japan Sea Hydrobiological Expedition of the Zoological Institute of the Academy of Sciences USSR in 1934, 1, 241-404. [in Russian, not seen]

Gurjanova, E. F. 1951. Bokoplavy morej SSSR i sopredel'nykh vod (Amphipoda-Gammaridea). Akademiia Nauk SSSR, Opredeliteli po Faune SSSR, 41, 1-1031. [in Russian]

Hirayama, A. 1983. Taxonomic studies on the shallow water gammaridean Amphipoda of west Kyushu, Japan. I. Acanthonotozomatidae, Ampeliscidae, Ampithoidae, Amphilochidae, Anamixidae, Argissidae, Atylidae and Colomastigidae. Publications of the Seto Marine Biological Laboratory, 28 (1/4), 75-150.

Hirayama, A. 1984. Taxonomic studies on the shallow water gammaridean Amphipoda of west Kyushu, Japan. II. Corophiidae. Publications of the Seto Marine Biological Laboratory, 29 (1/3), 1-92.

Hirayama, A. 1995. Gammaridea. In, Nishimura, S. (ed.) Guide to Seashore Animals of Japan with Color Pictures and Keys. Vol. II., Hoikusha, Osaka, pp. 172-193. [in Japanese]

Ishimaru, S. 1990. Gammaridean amphipods of Ishikawa Prefecture. In, "Ishikawa no Seibutsu", The Society of High School Biological Education in Ishikawa Prefecture, Kanazawa, pp. 210-215. [in Japanese]

Kim, H. S. and Kim, C. B. 1987. Marine gammaridean Amphipoda (Crustacea) of Cheju Island and its adjacent waters, Korea. Korean Journal of Systematic Zoology, 3 (1), 1-23.

Ledoyer, M. 1979. Expédition Rumphius II (1975) Crustacés parasites, commensaux, etc. (Th. Monod et R. Serène, éd.) VI. Crustacés amphipodes gammariens. Bulletin du Museum National d'Histoire Naturelle, Paris, $4^{\mathrm{e}}$ sér., 1 , section $\mathrm{A}, \mathrm{n}^{\circ}$ 1, 137-181.

Ledoyer, M. 1982. Crustaces amphipodes gammariens familles des Acanthonotozomatidae a Gammaridae. Faune de Madagascar, 59 (1), 1-598.

Myers, A. A. 1985. Shallow-water, coral reef and mangrove Amphipoda (Gammaridea) of Fiji. Records of the 
Australian Museum, Supplement, 5, 1-144.

Myers, A. A. 1988. A cladistic and biogeographic analysis of the Aorinae subfamily nov. Crustaceana, Supplement, 13, 167-192.

Myers, A. A. 1993. Dispersal and endemicity in gammaridean Amphipoda. Journal of Natural History. 27, 901908.

Myers, A. A. 1995. The Amphipoda (Crustacea) of Madang Lagoon: Aoridae, Isaeidae, Ischyroceridae and Neomegamphopidae. Records of the Australian Museum, Supplement, 22, 25-95.

Myers, A. A. 1998. The Amphipoda (Crustacea) of New Caledonia: Aoridae. Records of the Australian Museum, $50,187-210$.

Myers, A. A. and Moore, P. G. 1983. The New Zealand and south-east Australian species of Aora Krøyer (Amphipoda, Gammaridea). Records of the Australian Museum, 35, 167-180.

Nagata, K. 1960. Preliminary notes on benthic gammaridean Amphipoda from the Zostera region of Mihara Bay, Seto Inland Sea, Japan. Publications of the Seto Marine Biological Laboratory, 8 (1), 163-182.

Nagata, K. 1965. Studies on marine gammaridean Amphipoda of the Seto Inland Sea III. Publications of the Seto Marine Biological Laboratory, 13 (4), 291-326.

Nishimura, S. 1981. The Sea and Life of the Earth: An Introduction to Marine Biogeography. Kaimeisha, Tokyo, 284 pp. [in Japanese]

Ren, X. and Zheng, C. 1996. Fouling Amphipoda (Crustacea) from Dayawan, Guangdong Province, China (South China Sea). Annual Research Reports, Marine Biology Research Station at Dayawan, South China Sea Institute of Oceanology, the Chinese Academy of Sciences, 1, 58-78. [in Chinese with English abstract]

Walker, A. O. 1898. Crustacea collected by W. A. Herdman, F. R. S., in Puget Sound, Pacific coast of North America, September, 1897. Proceedings and Transactions of the Liverpool Biological Society, 12, 268-287. [not seen] 


\section{Explanation of Plate I}

Fig. 1. Aoroides columnaris sp. nov. Male from Tanigawa in Misaki, Osaka Prefecture.

Fig. 2. Aoroides columnaris sp. nov. Male from Oura in Hidaka, Wakayama Prefecture.

Fig. 3. Aoroides curvipes sp. nov. Male from Tanigawa in Misaki, Osaka Prefecture.

Fig. 4. Aoroides ellipticus sp. nov. Male from Tanigawa in Misaki, Osaka Prefecture.

Fig. 5. Aoroides longimerus Ren and Zheng. Male from Shirahama, Wakayama Prefecture.

Fig. 6. Aoroides myojinensis sp. nov. Male from Myojin-zaki coast in Misaki, Osaka Prefecture.

Fig. 7. Aoroides punctatus sp. nov. Male from a rearing tank of Osaka Prefectural Fisheries Experimental Station in Misaki, Osaka Prefecture. Black spot on coxa 4 is a scar.

Fig. 8. Aoroides rubellus sp. nov. Male from Shirahama, Wakayama Prefecture.

Fig. 9. Aoroides secundus Gurjanova. Male from Toyokuni-zaki coast in Misaki, Osaka Prefecture.

Fig. 10. Aoroides semicurvatus sp. nov. Male from Nagasaki coast in Misaki, Osaka Prefecture. 

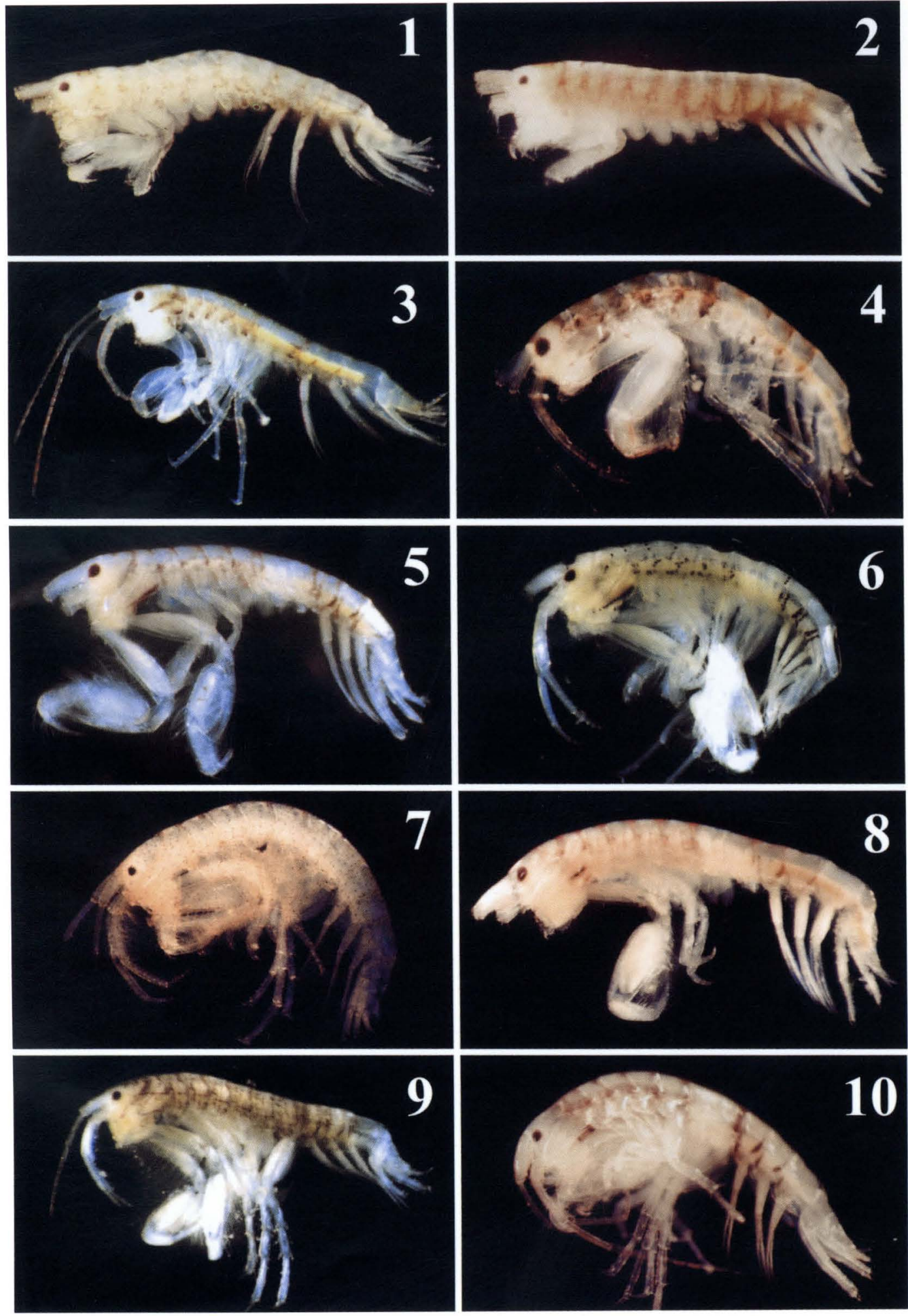